\title{
ANÁLISE DA INTERAÇÃO ESTACA-SOLO VIA COMBINAÇÃO DO MÉTODO DOS ELEMENTOS FINITOS COM O MÉTODO DOS ELEMENTOS DE CONTORNO
}

RUBENS FERNANDES DE MATOS FILHO

Dissertação apresentada à Escola de Engenharia de São Carlos, da Universidade de São Paulo, como parte dos requisitos para obtenção do Título de Mestre em Engenharia de Estruturas.

ORIENTADOR: Prof. Dr. João Batista Paiva

São Carlos

Março/1999 
\begin{tabular}{l} 
Class. TESE-E SC \\
Gutt. -3475 \\
Tombo $0109 / 99$ \\
\hline
\end{tabular}

Ficha catalográfica preparada pela Seção de Tratamento da Informação do Serviço de Biblioteca - EESC/USP

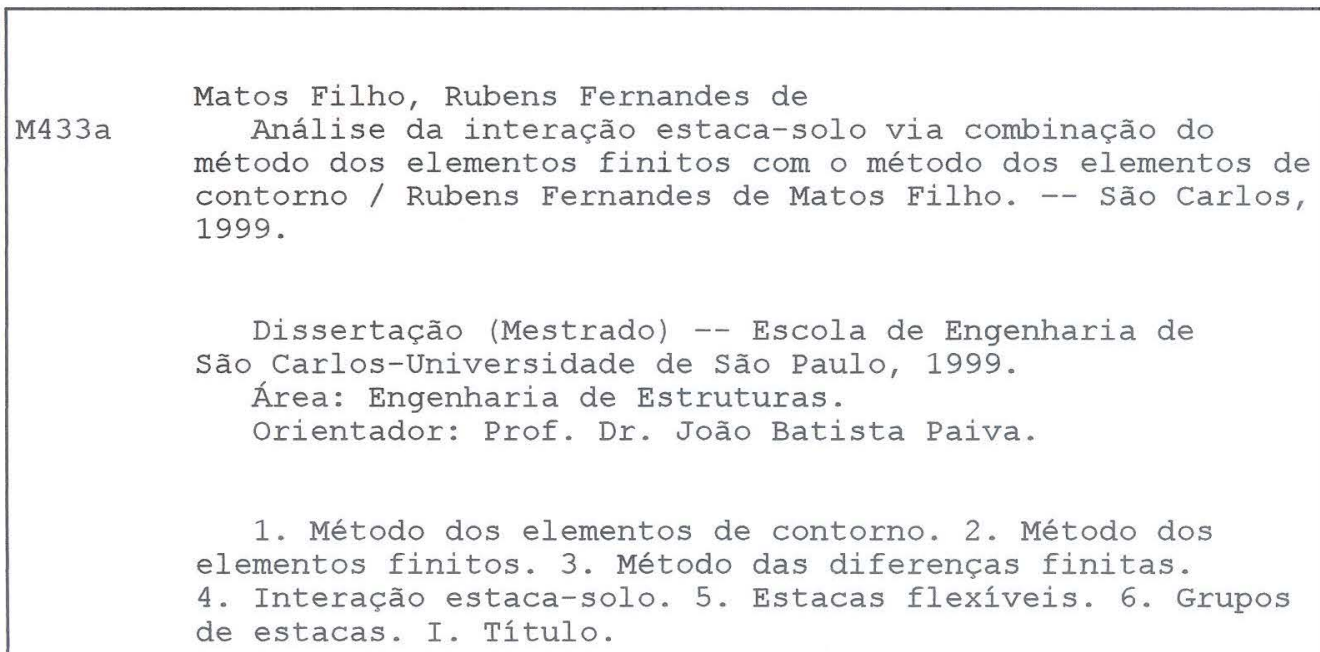




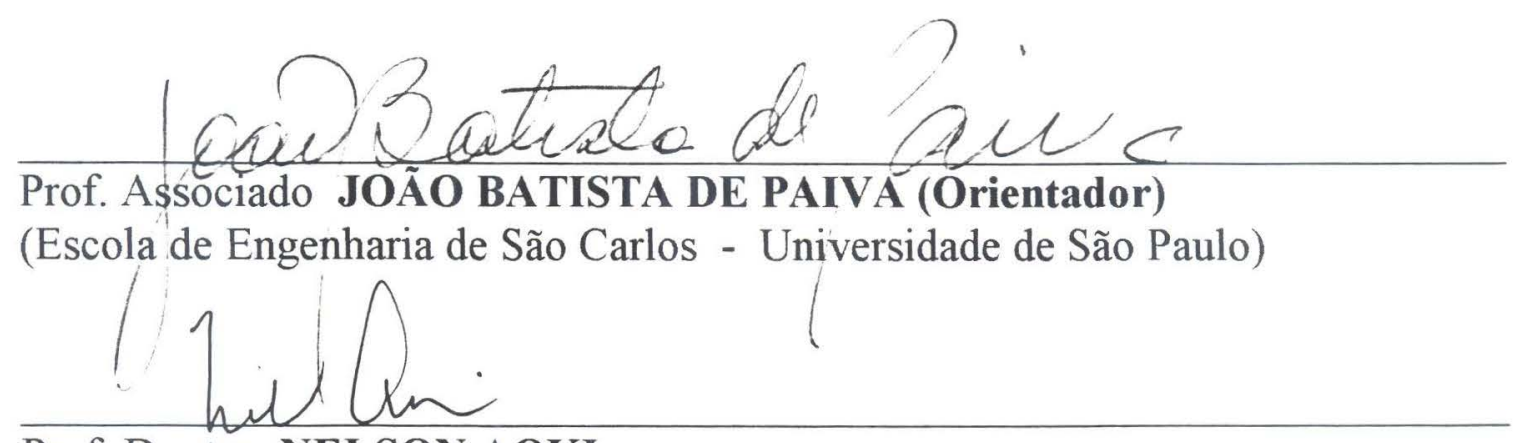

Prof. Doutor NELSON AOKI

(Escola de Engenharia de São Carlos - Universidade de São Paulo)

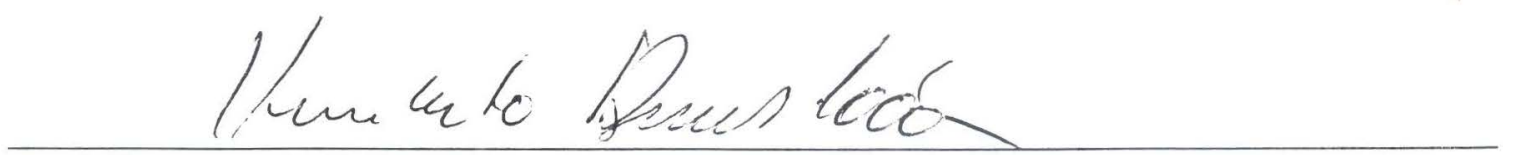

Prof. Doutor HUMBERTO BREVES CODA

(Escola de Engenharia de São Carlos - Universidade de São Paulo)

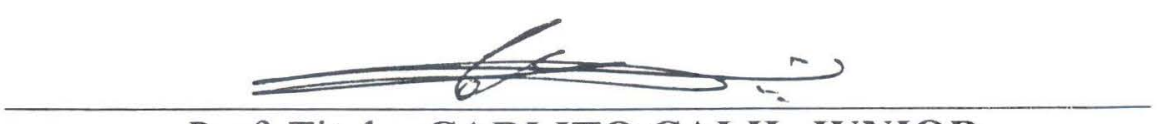

Prof. Titular CARLITO CALIL JUNIOR

Coordenador da Área de Engenharia de Estruturas

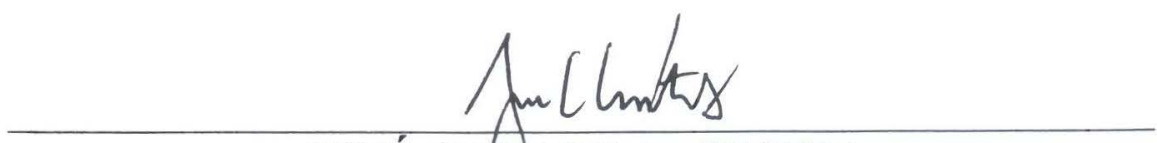

JOSÉ CARLOS A. CINTRA

Presidente da Comissão de Pós-Graduação da EESC 
A minha tia, Eliza Rodrigues.

Aos meus pais. 


\section{AGRADECIMENTOS}

Ao Prof. Dr. João Batista Paiva, pela amizade, orientação e incentivo na elaboração do presente trabalho.

Ao Prof. Dr. Nelson Aoki, pelo incentivo e valiosa colaboração durante o desenvolvimento deste trabalho.

Aos amigos e professores da Escola de Engenharia de Piracicaba.

Aos amigos, professores e funcionários deste departamento.

Ao CNPq pelo apoio financeiro.

Enfim, a todas as pessoas que contribuíram direta ou indiretamente na realização desta obra. 


\section{SUMÁRIO}

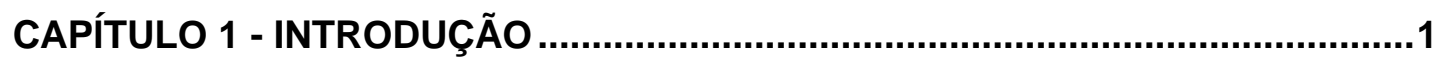

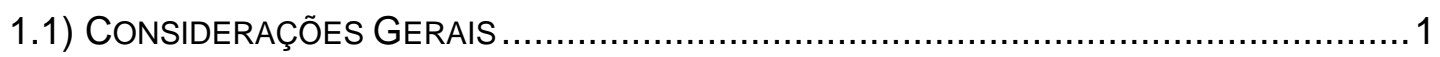

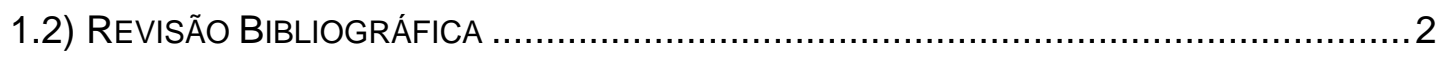

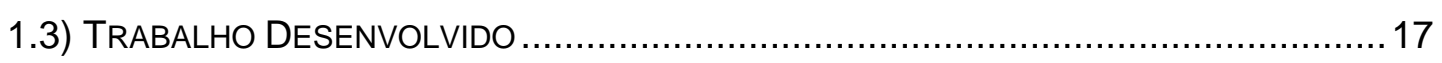

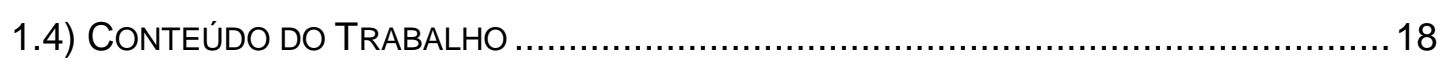

CAPÍTULO 2 - MÉTODO DOS ELEMENTOS DE CONTORNO .............................20

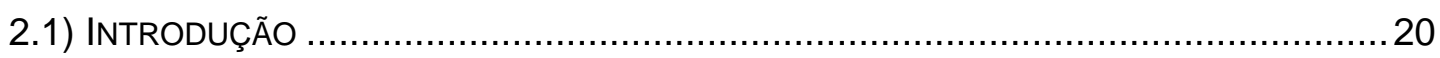

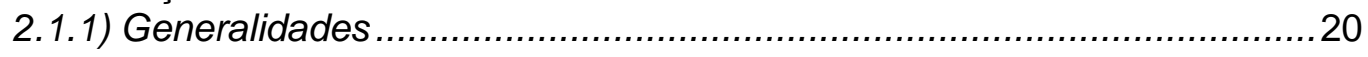

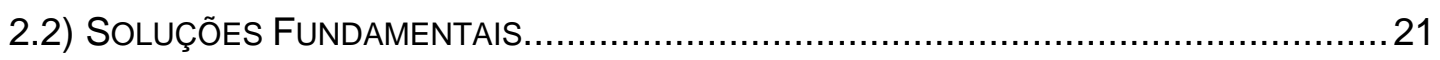

2.2.1) Solução Fundamental de Kelvin .....................................................21

2.2.2) Solução Fundamental de Mindlin.......................................................22

2.2.3) Solução Fundamental de Boussinesq-Cerruti.....................................2 25

2.3) RepresentaÇÃo INTEGRAL PARA o CAMPo dE DESLOCAMENTOS ......................26

\section{CAPÍTULO 3 - ESTACAS VERTICAIS ISOLADAS SUBMETIDAS À}

CARREGAMENTOS LATERAIS EM UMA DIREÇÃO ........................................30

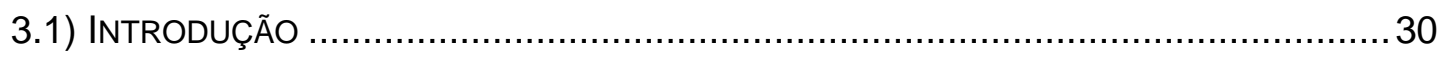

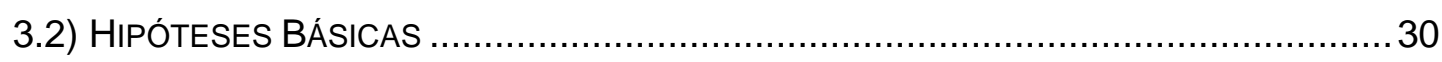

3.3) INTERAÇÃO DE UM MEIO TRIDIMENSIONAL COM ESTRUTURAS DE BARRAS .............31

3.3.1) Discretização da Representação Integral ........................................ 32

3.3.2) Sub-Elementação da Integração .................................................. 33

3.4) ANÁLISE ELÁSTICA EM ESTACAS ISOLADAS .................................................. 33

3.4.1) Método Adaptado de POULOS (1971a) ........................................... 33

3.4.2) Abordagem via MEC/MEF ...................................................... 40

\section{CAPÍTULO 4 - GRUPOS DE ESTACAS VERTICAIS SUBMETIDOS À}

CARREGAMENTOS LATERAIS EM DUAS DIREÇÕES.....................................58

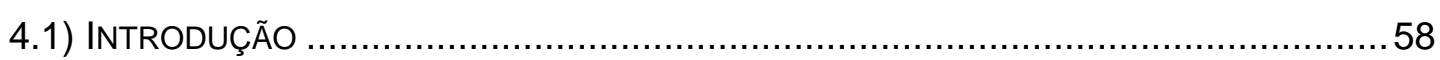

4.2) ESTACAS CARREGAdAS EM DUAS DIREÇÕES ............................................ 58

4.3) Grupos de EstacAs Sujeitas a CARREgamentos HoRIZONTAIS NAS DuAS

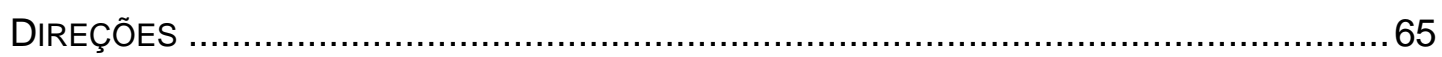

4.3.1) Avaliação do Modelo .................................................................6 67

4.4) Blocos de CAPEAMENTO RíGIDO EM GRupos de Estacas SuJEITAS À CARGAS

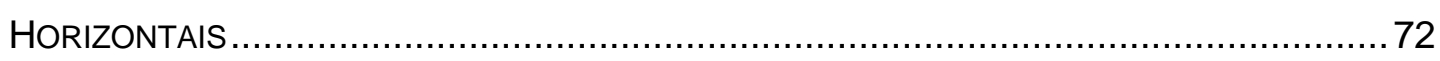

4.4.1) Avaliação do Método .................................................................. 73 
CAPÍTULO 5 - ESTACAS VERTICAIS ISOLADAS SUBMETIDAS À

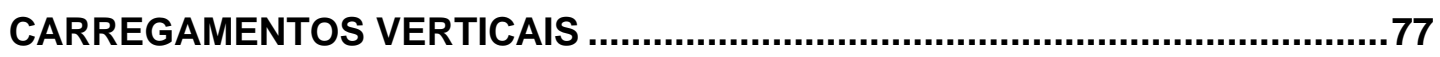

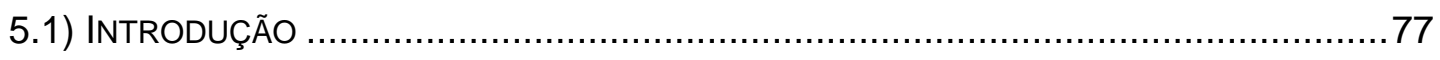

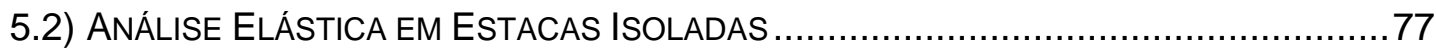

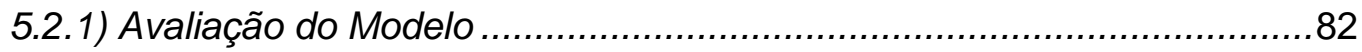

CAPÍTULO 6 - ESTACAS ISOLADAS E GRUPOS DE ESTACAS VERTICAIS E INCLINADAS SOLICITADAS POR CARREGAMENTOS VERTICAIS E HORIZONTAIS.

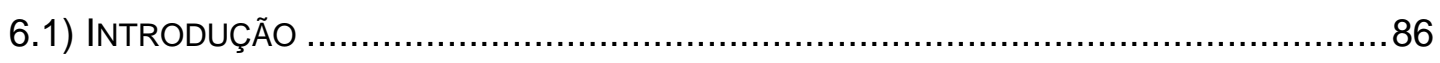

6.2) EstaCAS ISOLADAS SUJEITAS A CARGAS VERTICAIS E HORIZONTAIS ....................86

6.2.1) Avaliação do Modelo ....................................................................

6.3) GRUPOS DE ESTACAS SUJeItAS A CARREGamentos HoRIZONTAIS E VERTICAIS.. 92

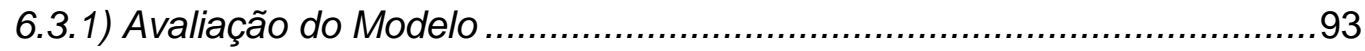

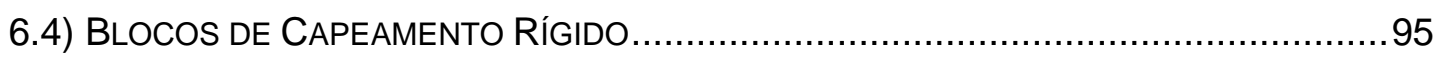

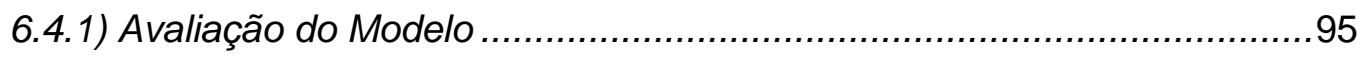

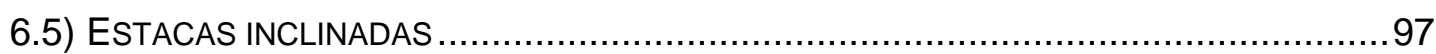

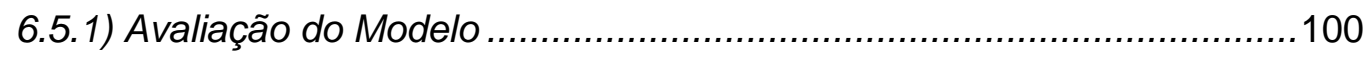

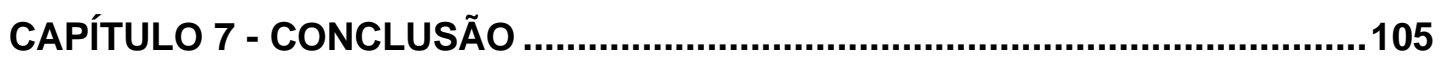

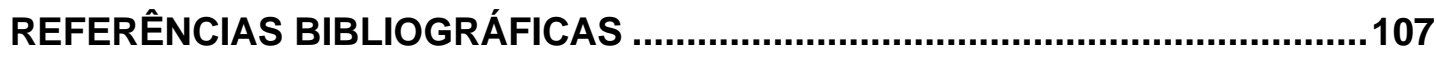




\section{LISTA DE FIGURAS}

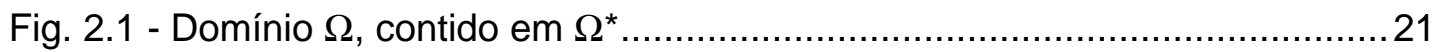

Fig. 2.2 - Figura adaptada de NAKAGUMA (1979) - Problema de Kelvin ...............22

Fig. 2.3 - Figura Adaptada de NAKAGUMA (1979) - Problema de Mindlin ............23

Fig. 2.4 - Figura adaptada de NAKAGUMA (1979) - Problema de Boussinesq -

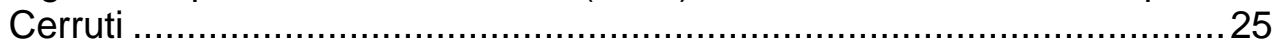

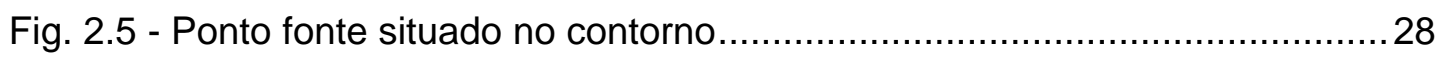

Fig. 3.1 - Domínio tridimensional com linhas de cargas....................................... 31

Fig. 3.2 - Figura adaptada de POULOS (1980) - Estaca Flutuante; a) Tensões e cargas externas agindo sobre a estaca; b) Solo adjacente à estaca e suas tensões

Fig. 3.3 - Discretização do Problema; a) Forças no topo da estaca; b) Pontos de colocação na estaca; c) Parâmetros nodais na estaca;

d) Parâmetros nodais no solo.

Fig. 3.4 - Forças de interação variando cubicamente ao longo da estaca.

Fig. 3.5 - Elemento contínuo e suas respectivas funções de interpolação $\left(\phi_{1}, \phi_{2}, \phi_{3}\right.$, e $\left.\phi_{4}\right)$.

Fig. 3.6 - Figura adaptada de FERRO (1993) - Estaca em meio semi-infinito sujeita a uma carga horizontal e a um momento.

Fig. 3.7a) - Deslocamento horizontal devido a carga de 181,60 kN. 48

Fig. 3.7b) - Deslocamento horizontal devido ao momento de $-95,826$ kN.m...........48

Fig. 3.8 - Deslocamento horizontal na direção $X_{1}$ ao longo da estaca................... 49

Fig. 3.9a) - Deslocamento Horizontal devido a carga de 181,60 kN. ....................50

Fig. 3.9b) - Deslocamento horizontal devido ao momento de $-95,826$ kN.m...........50

Fig. 3.10 - Deslocamento horizontal na direção $X_{1}$ ao longo da estaca. ..................51

Fig. 3.11 - Influência do comprimento da estaca e do módulo do solo no deslocamento da estaca. 52

Fig. 3.12 - Deslocamento horizontal devido a carga de 181,60 kN. 53

Fig. 3.13 - Deslocamento horizontal devido a carga de 181,60 kN. 53

Fig. 3.14a) - Deslocamento Horizontal devido a carga de 181,60 kN. 54 
Fig. 3.14b) - Deslocamento horizontal devido ao momento de $-95,826$ kN.m. 55

Fig. 3.15 - Deslocamento horizontal devido a uma carga lateral $(60 \mathrm{kN}) \mathrm{na}$ direção $X_{1}$ e um momento $(-69 \mathrm{kN} . \mathrm{m})$ em torno de $\mathrm{X}_{2}$

Fig. 3.16 - Deslocamento horizontal devido a carga de 181,60 kN. 56

Fig. 3.17 - Deslocamento horizontal devido a carga de 181,60 kN. 57

Fig. 4.1 - Discretização do Problema; a) Cargas externas aplicadas no topo da estaca; b) Pontos de colocação da estaca; c) Parâmetros nodais do elemento nas duas direções; d) Forças da interface agindo no elemento; e) Forças da interface agindo no solo.

Fig. 4.2 - Forças e tensões interagindo no Problema; a) Forças e tensões agindo nas estacas; (b) Tensões agindo no solo.

Fig. 4.3 - Situação em planta de duas estacas idênticas e com carregamento iguais em intensidade e sentido

Fig. 4.4a) - Deslocamento Lateral de uma estaca isolada e de duas estacas idênticas na direção $X_{1}$.

Fig. 4.4b) - Deslocamento Lateral de uma estaca isolada e de duas estacas idênticas na direção $X_{2}$.

Fig. 4.5 - Grupo de 4 estacas sujeitas à cargas horizontais nas duas direções......70

Fig. 4.6 - Divisão das Estacas em quatro subgrupos.

Fig. 4.7 - Deslocamentos laterais ao longo das estacas e seus respectivos subgrupos

Fig. 4.8 - Figura adaptada de POULOS (1980). ............................................ 74

Fig. 4.9 - Distribuição das forças sobre a cabeça das estacas ............................. 75

Fig. 4.10 - Divisão das Estacas em quatro subgrupos e espaçamento "s" variando.

Fig. 4.11 - Comportamento dos subgrupos de estacas para diversos espaçamentos.

Fig. 5.1 - Discretização do Problema; a) Força vertical no topo da estaca;

b) Pontos de colocação na estaca; c) Parâmetros nodais no elemento.77

Fig. 5.2 - Representação das funções interpoladoras na estaca. .78

Fig. 5.3 - Figura adaptada de FERRO (1993) - Estaca em meio semi-infinito sujeita a uma carga vertical. 
Fig. 5.4 - Comparação entre os modelos - deslocamentos verticais ao longo da estaca.

Fig. 5.5 - Comparação entre os modelos - deslocamentos verticais ao longo da estaca.

Fig. 5.6 - Estaca isolada em um semi-espaço e sob um bloco rígido.

Fig. 5.7 - Comparações de modelos - curvas carga-deslocamento para uma estaca isolada sujeita a uma carga unitária horizontal.

Fig. 6.1 - Discretização do problema; a) Forças no topo da estaca; b) Pontos de colocação na estaca; c) Parâmetros nodais de deslocamentos;

d) Forças de interação variando cubicamente nas direções $X_{1}$ e $X_{2}$;

e) Forças de interação variando quadricamente na direção $X_{3}$

Fig. 6.2 - Grupo com 4 estacas igualmente solicitadas por uma carga vertical. .....93

Fig. 6.3 - Comparações de modelos - curvas carga-deslocamento para uma estaca isolada sujeita a uma carga unitária horizontal.

Fig. 6.4 - Grupo de estacas submetidas à cargas horizontais e verticais simultaneamente.

Fig. 6.5 - Figura adaptada de POULOS (1980).

Fig. 6.6 - Sistema de coordenadas locais para uma seção da estaca. 98

Fig. 6.7 - Estaca inclinada solicitada por cargas verticais e horizontais. 100

Fig. 6.8 - Estacas inclinadas solicitadas por cargas horizontais. 101

Fig. 6.9 - Grupos com 4 estacas inclinadas solicitadas por cargas horizontais e verticais. 


\section{LISTA DE TABELAS}

Tab. 3.1a) - Típicos Valores de $K_{R}$ para Solos Argilosos..................................... 38

Tab. 3.1b) - Típicos Valores de $K_{R}$ para Solos Arenosos.......................................38

Tab. 4.1 - Deslocamentos laterais e rotações em uma e em duas direções..........64

Tab. 4.2 - Deslocamentos laterais e rotações em uma e em duas direções...........64

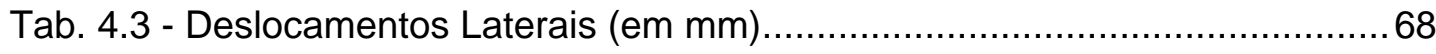

Tab. 4.4 - Deslocamentos laterais e rotações no topo do grupo de estacas............70

Tab. 4.5 - Deslocamentos Laterais para os quatro subgrupos de estacas. ............71

Tab. 4.6 - Forças causadas pelos deslocamentos horizontais unitários nos respectivos subgrupos.

Tab. 6.1 - Deslocamentos laterais, verticais e rotações em uma estaca solicitada por cargas verticais e horizontais separadamente.

Tab. 6.2 - Deslocamentos laterais, verticais e rotações em uma estaca solicitada por cargas verticais e horizontais simultaneamente.

Tab. 6.3 - Deslocamentos laterais, verticais e rotações no topo do grupo de estacas.

Tab. 6.4 - Forças causadas pelos deslocamentos verticais unitários nos respectivos subgrupos.

Tab. 6.5 - Deslocamentos laterais, verticais e rotações em uma estaca inclinada sujeita a cargas horizontais e verticais.

Tab. 6.6 - Deslocamentos laterais, verticais e rotações em duas estacas inclinadas solicitadas por cargas horizontais.

Tab. 6.7 - Deslocamentos laterais, verticais e rotações no topo do grupo de estacas inclinadas. 


\title{
LISTA DE SÍMBOLOS
}

\author{
$A_{p}$ : área da seção transversal da estaca. \\ $b_{i}$ : componentes das forças volumétricas. \\ c: cota do ponto fonte. \\ $\mathrm{C}_{\mathrm{ij}}(\mathrm{s})$ : coeficiente de ponderação utilizado na formulação do MEC. \\ CX: cosseno diretor do eixo $\mathrm{X}_{1}$. \\ $\mathrm{CY}$ : cosseno diretor do eixo $\mathrm{X}_{2}$. \\ $\mathrm{CZ}$ : cosseno diretor do eixo $\mathrm{X}_{3}$. \\ E: módulo longitudinal de elasticidade. \\ $E_{p}$ : módulo longitudinal de elasticidade da estaca. \\ $E_{s}$ : módulo longitudinal de elasticidade do solo. \\ $F_{1}$ : força lateral externa aplicada na direção $X_{1}$. \\ $\mathrm{F}_{2}$ : força lateral externa aplicada na direção $\mathrm{X}_{2}$. \\ G: módulo transversal de elasticidade. \\ $\mathrm{G}_{\mathrm{s}}$ : módulo transversa de elasticidade do solo. \\ $g_{i j}$ : coeficientes oriundos da integração da solução fundamental. \\ $I_{p}$ : momento de inércia da seção transversal da estaca. \\ $\mathrm{H}$ : força horizontal que age no topo da estaca. \\ $\mathrm{K}_{\mathrm{ij}}$ : coeficiente de rigidez da matriz $\left[\mathrm{K}_{\mathrm{c}}\right]$.
}

$\mathrm{Kd}$ : constante elástica utilizada nas soluções fundamentais de Mindlin.

$\mathrm{K}_{\mathrm{R}}$ : coeficiente de flexibilidade do sistema estaca-solo.

L: comprimento da estaca.

M: momento fletor que age no topo da estaca.

$M_{1}$ : momento externo aplicado em torno do eixo $X_{2}$.

$\mathrm{M}_{2}$ : momento externo aplicado em torno do eixo $\mathrm{X}_{1}$.

$m_{\mathrm{ij}}$ : coeficientes das matrizes $[\mathrm{M}]$ e $[\overline{\mathrm{M}}]$.

n: número de elementos, menos um, que constituem uma estaca.

Ne: número de estacas do sistema.

$\mathrm{Ng}$ : número de pontos de Gauss.

$\mathrm{p}_{\mathrm{i}}$ : componentes das forças da interface.

$\mathrm{p}_{\mathrm{ij}}^{*}$ : tensor de forças de superfícies fundamentais.

$P x_{i}$ : equação polinomial das forças da interface.

$\mathrm{q}_{\mathrm{ij}}$ : coeficiente da matriz de transformação [Q]. 
$\mathrm{q}_{\mathrm{i}}^{\mathrm{e}}$ : carga distribuída ao longo das estacas.

$\mathrm{r}_{\mathrm{f}}$ : raio da estaca.

$r_{i}$ : distância entre o ponto fonte e o ponto campo.

$R_{i}$ : distância entre o ponto fonte fictício e o ponto campo.

$\mathrm{U}$ : funcional de energia potencial de deformação do elemento.

$u_{\text {ap }}$ : equação polinomial dos deslocamentos nodais na direção $X_{1}$.

$\mathrm{u}_{\mathrm{i}}$ : representa as componentes de deslocamentos.

$\mathrm{u}_{\mathrm{ij}}^{*}$ : tensor de deslocamentos fundamentais.

V: força vertical externa aplicada no topo da estaca.

$V_{a p}$ : equação polinomial dos deslocamentos nodais na direção $X_{2}$.

$W_{\mathrm{ap}}$ : equação polinomial dos deslocamentos nodais na direção $X_{3}$.

$\mathrm{w}_{\mathrm{m}}$ : peso de ponderação da integração de Gauss.

$\mathrm{x}_{\mathrm{i}}(\mathrm{p})$ : coordenadas do ponto campo.

$\mathrm{x}_{\mathrm{i}}(\mathrm{s})$ : coordenadas do ponto fonte.

$\mathrm{x}_{\mathrm{i}}\left(\mathrm{s}^{\prime}\right)$ : coordenadas do ponto fonte fictício.

$\overline{\mathrm{X}}_{\mathrm{i}}^{\mathrm{p}}$ : coordenadas locais dos pontos campo.

$\overline{\mathrm{x}}_{\mathrm{i}}^{\mathrm{s}}$ : coordenadas locais dos pontos fonte.

$\mathrm{z}$ : cota do ponto campo.

$\alpha$ : ângulo que a estaca faz com o eixo $X_{1}$.

$\beta$ : ângulo que a estaca faz com o eixo $X_{2}$.

$\gamma$ : ângulo que a estaca faz com o eixo $X_{3}$.

$\delta(s, p)$ : distribuição Delta de Dirac.

$\delta_{i j}$ : delta de Kronecker.

$\varepsilon_{\mathrm{ij}}^{*}:$ tensor de deformações fundamentais.

$\varepsilon_{\mathrm{ij}}$ : representa as componentes de deformação no sistema global.

$\lambda$ : ângulo que a projeção da estaca em planta faz com o eixo $X_{1}$.

$v$ : coeficiente de Poisson

$v_{\mathrm{s}}$ : coeficiente de Poisson do solo.

$\sigma_{\mathrm{b}}$ : tensão normal que age na base do elemento.

$\sigma_{\mathrm{ij}}$ : representa as componentes de tensão no sistema global.

$\sigma_{\mathrm{ij}}^{*}$ : tensor de tensões fundamentais.

$\xi$ : cota adimensional do elemento. 
$\tau_{\mathrm{pi}}$ : tensões cisalhantes que agem no fuste do elemento.

$\Gamma_{\mathrm{e}}$ : contorno onde são aplicadas as forças de interação.

$\bar{\Gamma}$ : contorno superficial fictício.

$\Gamma_{\varepsilon}:$ contorno volumétrico fictício.

$\Gamma^{*}$ : contorno de um meio infinito.

$\Gamma$ : contorno finito de um corpo genérico.

$\Gamma_{1}$ : região do contorno de um corpo que contém as forças de superfícies prescritas.

$\Gamma_{2}$ : região do contorno de um corpo que contém os deslocamentos prescritos.

$\Omega_{\varepsilon}$ : domínio volumétrico fictício.

$\Omega^{*}$ : domínio infinito associado ao problema fundamental.

$\Omega$ : domínio finito dos corpos.

$\Omega$ ': funcional de energia potencial do carregamento externo.

$\Pi$ : funcional de energia potencial total do elemento.

$\{A\}$ : vetor auxiliar de carregamento externos.

$\{B\}$ : vetor auxiliar de carregamentos externos.

$[C]$ : matriz auxiliar dos termos da equação $u_{\mathrm{ap}}$.

$\{C\}$ : vetor auxiliar de coeficientes dos momentos externos.

[D]: matriz de coeficientes das diferenças finitas para estacas com topo livre.

$\left[D_{1}\right]$ : matriz de coeficientes das diferenças finitas para estacas com topo fixo.

$\{E\}$ : vetor auxiliar de coeficientes de forças horizontais externas.

$\{F\}$ : vetor de cargas externas.

[G]: matriz de coeficientes de influência do maciço de solos.

[I] : matriz identidade.

$\left[\mathrm{K}_{\mathrm{c}}\right]$ : matriz de rigidez do elemento.

$\left[\mathrm{K}_{\mathrm{c}}^{\mathrm{g}}\right]$ : matriz de rigidez global do elemento.

$[\overline{\mathrm{K}}]$ : matriz de rigidez final do sistema de interação MEC/MEF.

[M]: matriz auxiliar da interação MEC/MEF.

$[\overline{\mathrm{M}}]$ : matriz oriunda da expansão da matriz [M].

[MEC $\left.C_{i j}\right]$ : sub-matriz de coeficientes da matriz [G] referente a grupos de estacas.

$\left[M E F_{i j}\right]$ : sub-matriz de coeficientes da matriz $\left[K_{c}\right]$ referente a grupos de estacas.

$\{\mathrm{M}\}$ : vetor auxiliar de rotação.

$\{N\}$ : vetor final de rotação.

$\{P\}$ : vetor de forças da interface. 
$\left\{P_{p}\right\}$ : vetor de forças da interface que agem sobre a estaca.

$\left\{\mathrm{P}_{\mathrm{s}}\right\}$ : vetor de forças da interface que agem sobre o solo.

[Q]: matriz de transformação das cargas distribuídas na interface em cargas nodais.

$\left[Q_{i j}\right]$ : sub-matriz de coeficientes da matriz [Q] referentes a grupos de estacas.

$[R]$ : matriz de rotação.

[T]: matriz auxiliar do sistema fundação.

$\left[U^{\star}\right]$ : matriz das soluções fundamentais.

$\{\overline{\mathrm{U}}\}$ : vetor final de deslocamentos nodais.

$\{u\}$ : vetor de deslocamentos dos pontos nodais.

$\left\{u_{p}\right\}$ : vetor de deslocamentos nodais da estaca.

$\left\{u_{s}\right\}$ : vetor de deslocamentos nodais do solo.

$\left\{\mathrm{x}^{\mathrm{p}}\right\}$ : vetor de coordenadas globais dos pontos campo.

$\left\{\mathrm{x}^{\mathrm{s}}\right\}$ : vetor de coordenadas globais dos pontos fonte.

$\left\{\overline{\mathrm{X}}^{\mathrm{p}}\right\}$ : vetor de coordenadas locais dos pontos campo.

$\left\{\overline{\mathrm{X}}^{\mathrm{s}}\right\}$ : vetor de coordenadas locais dos pontos fonte.

$\{\alpha\}$ : vetor auxiliar dos termos da equação $u_{a p}$.

$\left\{\delta_{e}\right\}$ : vetor de parâmetros nodais.

$\{\phi\}$ : vetor auxiliar dos termos da equação $u_{\text {ap. }}$.

$\{\bar{\phi}\}$ : vetor de funções interpoladoras das forças da interface para as direções $X_{1}$ e $X_{2}$.

$\{\bar{\varphi}\}$ : vetor de funções interpoladoras das forças da interface na direção $X_{3}$. 


\section{LISTA DE ABREVIATURAS E SIGLAS}

DKT - Discrete Kirchoff Theory.

HSM - Hybrid Stress Model.

MEF - Método dos Elementos Finitos.

MEC - Método dos Elementos de Contorno.

MDF - Método das Diferenças Finitas.

MEF_4PAR_FÇ_CTE - Elemento com 4 parâmetros nodais e função aproximadora das forças de interação constante.

MEF_5PAR_FÇ_CTE - Elemento com 5 parâmetros nodais e função aproximadora das forças de interação constante.

MEF_4PAR_FÇ3ํ - Elemento com 4 parâmetros nodais e função aproximadora das forças de interação cúbica.

MEF_5PAR_FÇ3ํ - Elemento com 5 parâmetros nodais e função aproximadora das forças de interação cúbica.

MEF_5PAR_FÇ4ํำ - Elemento com 5 parâmetros nodais e função aproximadora das forças de interação do $4^{\circ}$ grau.

MEF_6PAR_FÇ5ํ- Elemento com 6 parâmetros nodais e função aproximadora das forças de interação do $5^{\circ}$ grau.

MEF_4PAR_FÇ2º - Elemento com 4 parâmetros nodais e função aproximadora das tensões de cisalhamento no fuste do $2^{\circ}$ grau.

MODELO_14PAR - Elemento com 14 parâmetros nodais. 


\section{RESUMO}

MATOS FILHO, R. F.. Análise da interação estaca-solo via combinação do método dos elementos finitos com o método dos elementos de contorno. São Carlos, 1999. 116p. Dissertação (mestrado) - Escola de Engenharia de São Carlos, Universidade de São Paulo.

Neste trabalho apresenta-se uma combinação de formulações numéricas para a análise da interação estaca-solo com ou sem blocos de capeamento rígido, sujeita à carga horizontal e vertical. Nestas formulações as estacas são representadas pelo método das diferenças finitas (MDF) ou pelo método dos elementos finitos (MEF) e o solo é representado pelo método dos elementos de contorno (MEC). Na utilização do $\mathrm{MEF}$, para a análise das estacas, os deslocamentos e as forças de interação foram representados por várias funções polinomiais chegando-se a um elemento finito final considerado eficiente e constituído por quatro pontos nodais, 14 parâmetros nodais, sendo quatro para deslocamentos lineares em cada uma das direções $\left(X_{1}, X_{2}\right.$ e $\left.X_{3}\right)$ e mais dois parâmetros referentes as rotações do topo da estaca em torno dos eixos $X_{1}$ e $X_{2}$. Os deslocamentos transversais ao longo da estaca foram representados por uma função polinomial do $4^{\circ}$ grau e os deslocamentos axiais foram representados por uma função cúbica. Para as forças da interface nas direções $X_{1}$ e $X_{2}$ são utilizados funções polinomiais cúbicas. As forças de superfície cisalhantes que ocorrem ao longo do fuste da estaca são representadas por um polinômio quadrático e a tensão normal à seção da extremidade inferior da estaca é suposta constante. O maciço de solos é modelado pelo MEC como um meio contínuo, elástico-linear, semi-infinito, isótropo e homogêneo. Combinando-se estes métodos de análise, obtém-se um sistema de equações lineares representando o problema de interação estaca-solo. Após a resolução deste sistema, são obtidos os deslocamentos e rotações nos nós do elemento e as tensões de contato estaca-solo. Vários exemplos envolvendo as formulações propostas são analisados e os resultados obtidos são concordantes com os de outros autores.

Palavras-chave: Método dos Elementos de Contorno; Método dos Elementos Finitos; Método das Diferenças Finitas; Interação Estaca-Solo; Estacas Flexíveis; Grupos de Estacas. 


\begin{abstract}
MATOS FILHO, R. F.. Pile-soil interaction analysis by combination of the finite and boundary element method. São Carlos, 1999. 116p. Dissertação (mestrado) Escola de Engenharia de São Carlos, Universidade de São Paulo.
\end{abstract}

This work presents a mixed numerical formulation of analysis of the pile-soil interaction, with or without rigid caps, under horizontal and vertical loads. In these formulations the piles are modeled by finite difference method (FDM) or finite element method (FEM) and the soil is represented by the boundary element method (BEM). In the finite element method for the pile analysis the displacements and interactions forces with the soil were represented by several polynomials functions leading to an efficient element with four nodal points, 14 nodal parameters, where four parameters are the linear displacements for each directions $\left(X_{1}, X_{2}\right.$ e $\left.X_{3}\right)$ and two parameters for the rotations at the top of the pile. The transversal displacements along the pile were represented by a fourth degree polynomial and the axial displacements were represented by cubic functions. The interface forces in the $X_{1}$ and $X_{2}$ directions are represented by cubic functions. The shear contact forces along of the pile surface are approximated by a second degree polynomial and the normal tractions in the pile tip is assumed to be constant over its crosssection. The soil is modeled by BEM as an isotropic, homogeneous, semi-infinite and linear-elastic continuum. Combining these analysis methods a complete system representing a pile-soil interaction problem can be obtained and from it the displacements and the pile-soil contact tractions can be achieved. Various examples are presented and the results closely agree with others authors.

Keywords: Boundary Element Method; Finite Element Method; Finite Different Method; Pile-Soil Interaction; Flexible Piles; Pile Group. 


\section{CAPÍTULO 1}

\section{INTRODUÇÃO}

\section{1 ) Considerações Gerais}

A interação solo-estrutura é atualmente um dos problemas que tem recebido especial atenção de pesquisadores nos mais diversos centros de pesquisa, principalmente por suas aplicações de caráter prático. Neste sentido, já foi desenvolvido no SET (Departamento de Engenharia de Estruturas da Escola de Engenharia de São Carlos - USP) o programa PILE (MENDONÇA, 1997), voltado para a análise da interação placa-estaca-solo, através da combinação entre o Método dos Elementos Finitos (MEF) e o Método dos Elementos de Contorno (MEC), sendo que apenas o carregamento vertical foi previsto, limitando suas aplicações. Além disso, o maciço de solos é suposto um meio contínuo isótropo, homogêneo elástico-linear e semi infinito.

Em um sistema de fundação composto por estacas, o critério para projeto na maioria dos casos determina a capacidade de carga última da estaca, mas também e muitas vezes a máxima deflexão da mesma. O projeto exige a verificação do estado limite último, mas o critério determinante do dimensionamento é a verificação do estado limite de utilização.

As estacas de um sistema de fundação são freqüentemente submetidas a altas forças horizontais, como por exemplo, em estacas-pranchas, de fundações de pontes, de edifícios altos, de estruturas "off-shore", de torres de transmissão de energia, de muros de arrimo entre outras.

Forças essas, que podem ser causadas pelo vento, ondas marítimas, empuxo de terra e em alguns casos, atuam simultaneamente, como nos pilares de 
pontes que são solicitados, pela ação do vento, pelo fluxo da água e pela frenagem dos veículos sobre o tabuleiro (CINTRA, 1983).

Em regiões sujeitas a sismos, segundo Broms (1964a), as estacas devem ter a capacidade de resistir a uma força lateral equivalente a $10 \%$ da carga axial aplicada.

A estaca suporta carregamento transversal agindo como:

- Elemento ativo quando as cargas, provenientes de ações que agem sobre a estrutura chegam à fundação através da ligação superestruturafundação (esforços solicitantes na seção de ligação);

- Elemento passivo quando as cargas aplicadas sobre o maciço de solos, são a ela transmitidas através do maciço de solos: sobrecargas verticais, sismo ou estacas de reforço de taludes.

Portanto são muitos os problemas que necessitam do cálculo de estacas submetidas a esforços horizontais e a presente dissertação trata apenas do caso da estaca agindo como elemento ativo.

\section{2) Revisão Bibliográfica}

Segundo MENDONÇA (1997), o maciço de solos tem sido alvo de inúmeras pesquisas, devido ao seu papel importante em projetos de engenharia civil e áreas afins. Dentre os vários modelos existentes idealizados para o maciço de solos podem-se citar três principais. O primeiro desenvolvido por WINKLER (1867), prevê que um deslocamento na superfície do maciço de solos, num ponto "k", será diretamente proporcional à força aplicada neste ponto, e independente das demais forças, ou seja, o deslocamento só ocorre no ponto de aplicação da carga, não levando em consideração o efeito da continuidade do meio. O segundo modelo é o 
do meio contínuo, onde considera-se o efeito da continuidade do meio e conseqüentemente ocorrem deslocamentos em pontos distintos aos de aplicação da carga. Flamant analisou o caso de linhas de cargas normais à superfície contidas num semi-espaço que foram descritas posteriormente em TIMOSHENKO \& GOODIER (1970). SELVADURAI (1979) analisou o problema através das integrais de Fourier, para a representação de cargas normais uniformes de larguras finitas. Selvadurai também utilizou o método da superposição, usado anteriormente por SNEDDON (1958). CERRUTI (1882), BOUSSINESQ (1885) e MINDLIN (1936) também apresentaram análises sobre o maciço de solos desenvolvidas através da utilização deste segundo modelo. Estas análises serão descritas no capítulo 2.

O terceiro modelo, é chamado de modelo de dois parâmetros, porque é definido por duas constantes elásticas independentes, reduzindo a descontinuidade apresentada no modelo de Winkler. SELVADURAI (1979) cita alguns dos modelos apresentados por diferentes autores com base neste modelo de dois parâmetros. Dentre eles estão o Modelo de Filonenko-Borodich, que promove a continuidade entre as molas através de uma membrana delgada tencionada entre elas, de tal maneira que a equação diferencial incorpora a contribuição da tensão na membrana e o coeficiente de base elástica de Winkler. O Modelo de Pasternack tem o princípio análogo ao anterior, mas a continuidade entre as molas é simulada por uma camada flexível apenas ao cisalhamento, fazendo com que agora a equação diferencial seja afetada pelo módulo de elasticidade transversal da camada e pelo coeficiente de base elástica. Também foi citado em SELVADURAI (1979) o Modelo de Hetényi, onde a continuidade do meio é simulada através da introdução de uma viga elástica na interação entre as molas, visto que a equação integral tem uma parcela da equação da placa e outra referente a base de Winkler. Por fim pode-se citar o Modelo de Vlasov, sendo este um modelo híbrido, obtido através de restrições sobre as possíveis distribuições de deslocamentos. As 
equações diferenciais para o maciço de solos são obtidas a partir do método variacional. As respostas obtidas são semelhantes às encontradas pelo método de dois parâmetros.

Vários trabalhos foram apresentados utilizando-se o modelo de Winkler, dentre eles podem-se citar MATLOCK \& REESE (1961) que apresentaram um método de cálculo de uma estaca solicitada, na superfície do terreno, por uma força horizontal e por um momento, onde o módulo de reação horizontal do maciço de solos foi analisado por duas formas gerais adequadas para expressar variação contínua com a profundidade, sendo uma delas exponencial e a outra polinomial. NAVDOCKS (1962) apresentou soluções para o problema de uma estaca solicitada por uma carga lateral e um momento fletor, com base nos diagramas de variação do módulo de reação horizontal do solo com a profundidade propostos por REESE \& MATLOCK (1956), onde o módulo de reação horizontal do maciço de solos foi admitido com sendo linearmente crescente com a profundidade (solos arenosos e argilas normalmente adensadas). Estes diagramas também podem ser aplicados para o caso de argilas pré-adensadas, através de uma conversão do módulo de reação. BROMS (1965) obteve soluções analíticas para estacas rígidas e flexíveis, trabalhando no estado limite de ruptura e sob carregamentos laterais no topo. Admitiu-se o módulo de reação horizontal tanto constante, quanto linearmente crescente com a profundidade. DAVISSON \& ROBINSON (1965) trataram do problema de flexão e flambagem em estacas parcialmente enterradas. Os efeitos do momento, carga lateral e axial foram considerados separadamente. Neste estudo, o módulo de reação do solo foi admitido como sendo constante ou linearmente crescente com a profundidade. WERNER (1970) apresentou soluções para momentos fletores em estacas solicitadas para momento e força horizontal na cabeça à superfície, referentes a cinco diagramas distintos do módulo de reação do 
solo, sendo que estas variações foram escolhidas de modo a conter nos seus limites valores práticos deste módulo.

BOLTON (1972) que estudou os grandes deslocamentos e tensões induzidas numa placa circular sujeita a um carregamento uniforme, onde os coeficientes de rigidez da base elástica foram computados através do método matricial na matriz de rigidez da placa. CHILTON \& WEKEVER (1990), apresentaram um modelo de estudo de placas utilizando elementos finitos quadrilaterais não-conforme. CALDERÓN (1991), estudou o problema de uma placa sobre fundação elástica de Winkler pelo MEC, sendo que a integral de domínio, oriunda dos carregamentos externos e da reação de base foi transformada em uma integral de contorno. Ainda em 1991, YUNG \& WANG, discutiram o caso de uma placa sobre fundação elástica utilizando o multiplicador de Lagrange com a finalidade de estabelecer um princípio variacional generalizado com uma função para deslocamento e outra para a reação do maciço de solos. Em 1992, MANZOLI, apresentou uma formulação para análise de placas delgadas através do MEC, cuja solução fundamental levou em conta a presença da base elástica de Winkler.

BADIE \& SALMON (1996) apresentaram um estudo em que o maciço de solos foi representado pelo modelo de dois parâmetros, assim como foi levado em conta a fricção entre a base da estrutura e o solo. A superestrutura foi modelada com elementos finitos quadrilaterais isoparamétricos representando o estado plano de tensão ou de deformação, que foram capazes de computar a distorção da superestrutura. Os deslocamentos foram aproximados quadraticamente e a tensão linearmente.

Com relação ao estudo da interação solo-estrutura, em que o maciço de solos é representado por um meio contínuo tridimensional, vários trabalhos podem ser citados. 
Em 1968, CHEUNG \& NAG estudaram placas e vigas apoiadas sobre o maciço de solos pelo método dos elementos finitos (MEF), levando-se em consideração tanto 0 atrito quanto o deslocamento entre a placa e o maciço de solos, sendo o maciço de solos modelado pela equação de Flamant.

CHAKRAVORTY \& GHOSH (1975), analisaram a interação entre a superfície do maciço de solos e uma placa circular pelo método das diferenças finitas (MDF).

MESSAFER \& COATES (1990), desenvolveram uma formulação através da interação MEC/MEF para análise do problema de interface solo-estrutura, onde o maciço de solos foi suposto um meio contínuo e a placa foi discretizada em elementos finitos. Obtiveram através das análises um número menor de dados de entrada que o das formulações anteriores, mas houve um aumento no número de incógnitas devido a discretização da placa. Em 1992, YANG \& LU, analisaram através de uma interação MEC/MEF semi-analítica, uma torre de resfriamento hiperbólica, onde os deslocamento e forças da interface com maciço de solos foram aproximadas por séries de Fourier. KUKRETI \& ISSA (1993), com formulações semelhantes as citadas por YANG \& LU (1992), analisaram um tanque cilíndrico, onde a função de distribuição de pressão (SNEDDON, 1958) considerou que a placa de fundo fosse circular.

Em HEMSLEY (1990a,b) são apresentadas várias formulações do MEF para análise da interação solo-estrutura, onde o maciço de solos é modelado pelo MEC, o que acarreta em uma matriz final não simétrica, conseqüentemente ocorrendo um aumento no número de incógnitas resultando então um aumento no tempo de processamento computacional necessário para a resolução do sistema.

FATEMI-ARDAKAMI, em 1987, desenvolveu uma formulação em que tanto o maciço de solos como a placa são modelados pelo MEC. Neste caso, a matriz final do sistema de equações também não é simétrica, entretanto, devido ao fato 
de que a dimensão do problema fica reduzida, característica do MEC, o número de incógnitas é bem menor que o das formulações anteriores. Neste trabalho, entretanto, a interface placa-solo é dividida em células retangulares, em que tanto a reação do maciço de solos como os deslocamentos da placa são supostas constantes, de forma que promove resultados não muito precisos, quando comparados com os obtidos por outras formulações.

PAIVA \& BUTTERFIELD (1994), apresentaram uma formulação baseada no MEC para resolução de problemas de interação placa-solo, onde o módulo de reação de base elástica foi assumido variando linearmente num elemento de superfície triangular e as integrais de domínio destes elementos foram transformadas em integrais sobre o seu contorno evitando assim a singularidade em $1 / r$ da solução fundamental para o maciço de solos. Os resultados obtidos a partir desta formulação mostraram boa concordância com os de outros autores.

CALDERÓN (1997) apresentou um estudo sobre a interação placa-meio contínuo, onde a placa foi modelada através do MEC, utilizando as equações de deslocamentos de Kirchhoff acrescidas de uma integral de domínio para representar a reação do maciço de solos. O meio contínuo foi modelado também pelo MEC, onde foram utilizadas as soluções fundamentais de Boussinesq-Cerruti e Mindlin (citadas em NAKAGUMA, 1979). Os resultados obtidos foram comparados com os métodos da reciprocidade dual e de formulação alternativa (VENTURINI, 1988), o que levou a resultados satisfatórios. Concluiu-se também que o modelo de Winkler é muito pobre e deve ser evitado neste tipo de análise, pois modelos aproximados levaram a resultados errôneos no caso de contatos em cavidades devido a não consideração do confinamento dado pela região do domínio próxima a superfície de contato.

Um dos tipos de fundações geralmente utilizado é o "radier", ou seja, uma placa apoiada sobre o maciço de solos recebendo carregamentos da 
superestrutura. Com o objetivo de diminuir os recalques na placa oriundos do peso da superestrutura são utilizadas estacas formando assim uma estrutura composta. A principal simplificação feita na análise desta estrutura é considerar que todo o peso é absorvido pelas estacas. Esta simplificação é feita devido ao fato de que a análise do problema real é muito complexa.

Dentre os trabalhos apresentados para a análise de grupos de estacas ligadas por uma placa considerada rígida, podem ser citados os desenvolvidos por BATTERFIELD \& BANERJEE (1971b), DAVIS \& POULOS (1972) e POULOS \& DAVIS (1980).

Para o caso de placa flexível, em 1978, HAIN \& LEE, estenderam a formulação proposta por POULOS \& DAVIS (1971), para uma análise, via MEF, da interação entre o maciço de solos, as estacas e a placa.

PAIVA (1993), apresentou uma formulação do MEC para o estudo da interação placa-estaca-solo, onde a placa foi considerada tanto rígida quanto flexível e as estacas foram consideradas rígidas e representadas por um único elemento de contorno. A interface placa-solo é dividida em elementos de contorno triangulares e admitiu-se que as tensões no maciço de solos variaram linearmente no domínio de cada elemento.

Em POULOS (1994), assim como em FATEMI (1987), as estacas foram representadas por molas, cujos os coeficientes elásticos foram obtidos a partir de um programa para a análise da interação estaca-solo e as equações referentes aos pontos localizados no topo das estacas são escritas através das relações cargadeslocamentos para duas estacas.

Um caso particular de placa com rigidez finita foi apresentado por BROWN \& WIESNER (1975), onde se analisou uma longa sapata flexível apoiada em estacas. No entanto, nesta modelagem utilizou-se simplificações da teoria das 
vigas e a reação do maciço de solos foi considerada constante em toda a extensão da sapata.

MENDONÇA (1997), apresentou um estudo sobre a interação placa-estacasolo, onde o maciço de solos foi considerado um espaço semi-infinito, isótropo, homogêneo, elástico linear e ideal, analisado pelo MEC utilizando as soluções fundamentais de Mindlin. A placa foi desenvolvida pelo MEF utilizando para isto os elementos DKT e HSM. E a estaca foi considerada como um único elemento completamente imerso num meio contínuo, tendo as tensões da interface aproximadas por um polinômio do segundo grau no fuste e uniformemente distribuídas na base. Os resultados obtiveram boa concordância quando comparados com outros métodos, principalmente com o de PAIVA (1993).

Vários autores que trabalharam com estacas carregadas lateralmente consideraram o maciço de solos como um meio elástico contínuo. Todas as análises são semelhantes em princípio, mas as diferenças elevam-se extensamente nos detalhes relacionados a ação da estaca e nas características do maciço de solos.

DOUGLAS E DAVIS (1964), apresentaram uma teoria para o cálculo de deslocamentos e rotações em placas verticais delgadas, relativamente curtas e rígidas, com o topo livre e enterradas em um meio elástico sujeitas a um momento fletor e um carregamento horizontal no topo. A influência do maciço de solos no problema foi computada, através da integração da equação de MINDLIN (1936). Os resultados foram comparados com modelos experimentais utilizando gelatina e cera de parafina para simular o maciço de solos e levaram a resultados satisfatórios, concluindo-se que na modelagem matemática, condições impostas, tais como a adesão total entre a estaca e o maciço de solos, confirmaram-se visto que, resultados da teoria convergiram para um resultado comum em relação ao experimento com gelatina e divergiram dos experimentos com cera de parafina, 
onde não há praticamente aderência entre a placa e o maciço de solos no lado onde se aplica a carga lateral.

Ainda em 1964, SPILLERS \& STOLL comprovaram teoricamente a necessidade de se discretizar o maciço de solos como um meio contínuo em contraposição ao modelo de Winkler ou método da reação de base, que não leva em consideração a continuidade do maciço de solos, como se fazia até então. O maciço de solos foi considerado como um meio contínuo, isótropo, homogêneo e semi-infinito e analisado para condições de pequenas deformações. Utilizou-se o trabalho de Mindlin, como base para a solução. A estaca foi analisada pela teoria das vigas e os deslocamentos entre a estaca e o maciço de solos foram compatibilizados. Além da conclusão relatada em relação a continuidade do maciço de solos, propôs-se também nesta publicação a utilização de um meio contínuo elasto-plástico examinado anteriormente por FREUDENTHAL (1958) para aproximar ainda mais o maciço de solos idealizado do material real. Os resultados obtidos pelos processos teóricos foram comparados, levando a resultados de deslocamentos maiores por parte do modelo elasto-plástico devido ao incremento de plastificação, mas apresentando resultados compatíveis com testes feitos em campo.

POULOS (1971), apresentou um método para o cálculo de deslocamentos e rotações em uma estaca vertical situada em um meio elástico contínuo, isótropo, homogêneo e semi-infinito, sujeita a um carregamento lateral e um momento fletor aplicados no topo da estaca. Para a representação do maciço de solos utilizou-se as soluções fundamentais de Mindlin. A estaca foi discretizada pelo método das diferenças finitas (PALMER \& THOMPSON, 1948; GLESER, 1953). Foram apresentados coeficientes de influência para estacas flexíveis, relações comprimento-diâmetro para estacas de topo fixo e livre. Comparações feitas com a análise de reação de base (Modelo de Winkler), mostraram uma superestimação 
de rotações e deslocamentos na estaca, mas razoáveis estimativas para os momentos. A análise foi estendida para a inclusão do efeito da plastificação local entre o maciço de solos e a estaca, concluindo-se a partir deste fator a ocorrência de alterações na relação carga-deslocamento para estacas relativamente flexíveis. Comparações foram feitas com testes de campo realizados por GLESER (1953) para estacas com topo fixo cravadas em solo arenoso e por KÉRISEL \& ADAM (1967) para estacas com topo livre cravadas em solos argilosos, concluindo-se que o tratamento teórico do problema leva a resultados razoáveis quando comparados com testes experimentais dentro das suas limitações. Uma limitação importante em relação as situações práticas é a determinação do módulo de Young para o maciço de solos principalmente em areias devido ao seu aumento linear em relação a profundidade, sendo aconselhado a utilizar o teste de carregamento de estaca em escala real para obtenção deste. Dentre as vantagens deste método pode-se citar a possibilidade de estimativas de movimentos em estacas através de fatores tais como, comprimento e rigidez da estaca, estimativas de deslocamentos imediatamente após a aplicação da carga e deslocamentos devido a consolidação do maciço de solos. Também puderam ser feitas significativas análises lógicas dos efeitos de plastificação local.

Além das análises anteriores, POULOS (1971) também estendeu o método citado acima (análises neste sentido já haviam sido estudadas por HRENNIKOFF, 1950; PRIDDLE, 1963; FRANCIS, 1964; SAUL, 1968) para grupos de estacas, fazendo primeiramente a interação entre duas estacas idênticas carregadas igualmente e depois estendeu-se o método para grupos gerais de estacas através da superposição de efeitos.

Observou-se um aumento dos deslocamentos horizontais e rotações das estacas em relação aos deslocamentos e rotações referentes a uma estaca isolada. Concluiu-se que as maiores variáveis que influenciam os deslocamentos e 
as distribuições de carga de um grupo são o espaçamento entre estacas, a relação comprimento por diâmetro $(\mathrm{L} / \mathrm{d})$ e o coeficiente de flexibilidade, $\mathrm{K}_{\mathrm{R}}$, definido como sendo a relação entre ao rigidez da estaca pelo produto do módulo de Young do maciço de solos e o comprimento da estaca elevado à quarta potência. Um significante resultado obtido foi que o deslocamento é muito mais dependente da largura do grupo do que do número de estacas do mesmo, tal que em consideração ao deslocamento uma relativa economia pode ser feita com a utilização de um número menor de estacas para espaçamentos relativamente grandes. Comparações limitadas entre relações teóricas e experimentais (FRAGIN, 1937; PRAKASH \& SARAN, 1967) de deslocamentos de grupos e deslocamentos de estacas isoladas mostram resultados compatíveis.

Em 1978, BANERJEE \& DAVIS apresentaram uma formulação do MEC para a análise deste problema supondo o módulo de elasticidade longitudinal do maciço de solos variando linearmente com a profundidade (solo de Gibson), podendo assim, idealizar o maciço de solos como sendo heterogêneo, ou seja, estendendo a análise para areias e argilas moles e considerando o maciço de solos como tendo duas camadas sob a ação de uma estaca. Foram feitos testes com cargas verticais, laterais e momentos aplicados no topo da estaca. Os testes foram comparados com modelos teóricos do método generalizado dos elementos de contorno (BANERJEE, 1976; BANERJEE \& BUTTERFIELD, 1977; BANERJEE \& DAVIS, 1977), com o MEF (usando 300 elementos lineares quadrilaterais axissimétricos), com o método de POULOS (1973) que utilizou a solução fundamental de Mindlin modificada e com testes experimentais realizados por ALIZADEH (1969), MCLELLAND \& FOCHT (1956), ALIZADEH \& DAVISSON (1970) e DAVISSON \& SALLEY (1970). Obteve-se com esta análise uma ótima concordância com os dados experimentais, em particular, às estimativas de momentos e deslocamentos horizontais devido ao carregamento lateral. Um outro 
importante fator apresentado nesta análise foi a extensão desta solução para análises elásticas mais gerais por meio do MEF ou do MEC.

KUHLEMEYER (1979), obteve as translações e rotações em estacas com carregamentos estáticos e dinâmicos através do MEF. Seus resultados foram avaliados com base nas soluções de NOVAK (1974) para o caso dinâmico e, devido a boa convergência entre os resultados, muitos problemas de campo puderam ser melhores avaliados e estimados a partir desta publicação.

RANDOLPH (1981), analisou o comportamento de estacas flexíveis discretizadas pelo MEF e imersas em um solo arenoso idealizado como sendo um meio elástico contínuo com módulo de elasticidade longitudinal variando linearmente com a profundidade (solo de Gibson) sob carregamento lateral. Seus resultados foram comparados com vários métodos já existentes e até mesmo com testes de campo, conduzindo-os a boas concordâncias. Dentre as comparações podem ser citados POULOS (1971a,b), GILL \& DEMARS (1970), McCLELLAND \& FOCHT, 1956, KUHLEMEYER (1979a) entre outros. Também foram apresentadas as equações quantificando o efeito da interação entre estacas vizinhas das quais foi possível deduzir o comportamento do grupo de estacas.

NATH (1989) apresentou um método de mapeamento por elementos finitos para análises de uma estaca carregada lateralmente, onde tanto o maciço de solos quanto a estaca foram considerados como partes integrais de um mesmo sólido contínuo, mas com propriedades diferentes. As condições de contorno e cargas aplicadas são transformadas apropriadamente para coordenadas polares e cilíndricas. Os resultados obtidos foram comparados com os de POULOS (1971) para estacas com topo livre e maciço de solos homogêneo. Também foram feitas comparações como os resultados obtidos por BANERJEE \& DAVIS (1978) para estaca com topo livre, módulo de Young do maciço de solos aumentando linearmente com a profundidade (solo de Gibson). Dessas comparações pode-se 
concluir que o método proposto leva a razoáveis concordâncias com os métodos tradicionais, além de sua idealização ser mais realística para o problema físico em questão, visto que o maciço de solos pode ser linear, não-linear, homogêneo, nãohomogêneo ou com camadas diferentes (estratificado).

Ainda em 1989, um estudo sobre a interação estaca-solo com carregamento lateral foi apresentado por VERRUIJT \& KOOIJAN através da combinação do MEF e do MDF representando o maciço de solos e a estaca, respectivamente. Esta publicação teve como objetivo aproveitar as principais vantagens dos modelos de Winkler e de meio elástico contínuo para estacas isoladas em primeira instância e posteriormente estendê-lo para grupos de estacas e análises do comportamento elasto-plástico do maciço de solos. Conclui-se que o método pode ser utilizado, visto que, quando da comparação com outros métodos levou a bons resultados.

Com base nos métodos de análises para estacas isoladas em um meio elástico semi infinito (POULOS \& DAVIS, 1980) CHRISTOS ANAGNOSTOPOULOS \& MICHAEL (1993), apresentaram um trabalho onde foi investigado experimentalmente qualquer possível efeito de carregamento lateral sobre deslocamentos axiais e tensões na estaca, assim como a influência de cargas axiais sobre o deslocamento horizontal em solo argiloso. Este estudo foi desenvolvido utilizando-se o MEF e levando-se em conta a não linearidade física na análise do comportamento da estaca. Pode-se então concluir que a carga lateral aumenta significativamente o deslocamento axial da estaca, causa uma pequena redução nas tensões axiais próximas a superfície do terreno e tem um efeito previamente limitado sobre a carga axial última. Também constatou-se que a interação entre a resposta lateral e axial pode ser estudada pela análise não-linear de elementos finitos, enquanto os métodos convencionais não consideram esta interação, pois uma carga axial aplicada em uma estaca "i" causa influência 
somente no deslocamento axial "j" e vice-versa, não interferindo assim no deslocamento normal.

Em 1993, CHEN \& POULOS, apresentaram um estudo sobre a interação estaca-solo sob carregamento lateral feito através de uma combinação dos métodos dos elementos finitos (técnica desenvolvida por YEGIAN \& WRIGHT em 1973) e infinitos (técnica desenvolvida por DAMJANIC \& OWEN em 1984). Foram feitos primeiramente testes comparativos com estacas isoladas e posteriormente com grupos de estacas assumindo-se sempre o maciço de solos como sendo coesivo. Observou-se que a resistência lateral última do maciço de solos é maior para o caso de estacas isoladas e que esta é principalmente controlada pela adesão estaca-solo e pelas propriedades do sistema.

Ainda em 1993, FERRO desenvolveu um trabalho sobre a interação MEC/MEF para a análise de fundações por estacas. Neste estudo o maciço de solos foi considerado como um meio elástico contínuo, isótropo, homogêneo, semiinfinito e ideal, discretizado pelo MEC através das soluções fundamentais de Mindlin. A estaca foi analisada pela teoria das vigas (consideradas como elemento de barra) e a interação com a superestrutura foi possível através do uso de um software com essa finalidade específica (COSMOS/M, 1988). Os resultados obtidos foram comparados com testes experimentais e com outras metodologias já desenvolvidas levando em todos os casos à bons resultados tanto para deslocamentos quanto para as forças de interação.

O comportamento de estacas flexíveis cravadas em duas camadas de areia, sendo a primeira areia fofa sobre uma segunda camada de areia compactada, sob uma carga excêntrica e inclinada foi apresentado por SASTRY \& MEYERHOF (1994). Observou-se que os resultados obtidos (momentos máximos, capacidade de carga lateral, deslocamentos horizontais de estacas flexíveis e pressões laterais do maciço de solos) destes testes quando comparados com estimativas teóricas 
baseadas no conceito de uma profundidade de cravamento efetivo de estacas com rigidez equivalente (POULOS, 1980), apresentaram pouca discrepância nas estimativas. Estas análises também foram comparadas com resultados de alguns testes de campo.

Estudos semelhantes para solos homogêneos e estratificados já haviam sido feitos (BRINCH HANSEN, 1961; CHARI \& MEYERHOF, 1983; MEYERHOF \& SASTRY 1985, 1987; MEYERHOF et al., 1981, 1988; SASTRY \& MEYERHOF 1986, 1987). O conceito de profundidade efetiva foi também estudado anteriormente (MEYERHOF et al., 1988, YALCIN \& MEYERHOF, 1991), assim como o comportamento de modelos de estacas flexíveis instrumentadas (SASTRY \& MEYERHOF, 1990).

POULOS \& CHEN (1995) apresentaram um estudo com base na interação MEC/MEF para o problema de escavação no maciço de solos, em camadas de argilas estratificadas, para a posterior cravação de estacas. Foram construídas tabelas apresentando momentos fletores máximos e deflexões em estacas isoladas, assim como fatores chaves que influenciam na resposta destas estacas, tais como, profundidade de escavação, propriedade do maciço de solos e condições de contorno na cabeça da estaca.

Também em 1995, KEMING SUN desenvolveu uma aproximação numérica e um estudo paramétrico para análise da interação estaca-solo sob carregamento lateral, com base no método de VLASOV \& LEONTIEV (1966), anteriormente estudado por JONES \& XENOPHONTOS (1977) e SCOTT (1981), através de um parâmetro $\gamma \circ$ qual controla a redução das tensões no maciço de solos à medida que se distancia da estaca. O método proposto utilizou o cálculo variacional para a obtenção da equação diferencial governante do sistema. Este método foi verificado para dois tipos de modelos de maciço de solos, um material elástico homogêneo e o outro, um meio estratificado. O método proposto foi comparado com outros 
métodos já analisados e também com ensaios experimentais levando a bons resultados. Este permitiu o registro de vários parâmetros de interesse da engenharia, tais como, deslocamentos, rotações, momentos fletores e forças cortantes para diferentes solos e condições da estaca.

Em 1996, BRANSBY \& SPRINGMAN analisaram o comportamento de grupos de estacas sujeitas a pressões laterais à curto prazo devido a deformação de uma camada de argila oriunda da sobrecarga adjacente, através de uma modelagem feita pelo método dos elementos finitos em 3-D. Os resultados foram comparados com testes de modelos centrífugos o que levou a obtenção de bons resultados. Os efeitos das diferentes tensões e deformações "in situ" comumente em protótipos e testes de modelos centrífugos também foram estudados com particular interesse nas relações de transferência de carga e comportamento da deformação do maciço de solos em torno das estacas.

\section{3) Trabalho Desenvolvido}

Apresentam-se neste trabalho várias formulações via combinação do MEF e também do MDF com o MEC para a análise da interação de estacas verticais e/ou inclinadas com o maciço de solo, com ou sem blocos de capeamento rígido sujeitas à cargas horizontais e verticais.

A estaca é modelada pelo MDF e também pelo MEF. No caso da utilização deste ultimo método, várias funções polinomiais de graus diferentes são utilizadas para aproximar os deslocamentos e a forças da interface. É também apresentado um elemento finito final considerado eficiente e constituído por 4 pontos de colocação e 14 parâmetros nodais.

O maciço de solos é modelado pelo MEC como um meio contínuo, elásticolinear, semi-infinito, isótropo e homogêneo. 
Através da combinação destes métodos de análise obtém-se um sistema final de uma fundação enrijecida por estacas verticais e/ou horizontais. Após a resolução deste sistema, conseqüentemente, são obtidos os deslocamentos e rotações nos nós do elemento e suas respectivas tensões de contato estaca-solo.

São apresentados, ao longo deste trabalho, vários exemplos envolvendo as formulações propostas.

\section{4) Conteúdo do Trabalho}

No capítulo 2 é apresentada a teoria do MEC envolvendo as equações da elasticidade linear de corpos tridimensionais, as equações integrais de contorno e as soluções fundamentais de Kelvin, Mindlin e Boussinesq-Cerruti.

No capítulo 3 são feitas as análises de estacas sob carregamento lateral propriamente ditas. Serão mostradas as teorias provenientes do MDF e do MEF para análise da estaca (via teoria das vigas) com vários pontos nodais e conseqüentemente a variação dos polinômios e funções de forma, além da particularização para deslocamentos em uma única direção (eixo $X_{1}$ ) e rotações somente em torno de $X_{2}$. Também será apresentada da formulação via elementos de contorno para consideração do maciço de solos suposto como sendo um meio contínuo, ideal, elástico-linear, semi-infinito, isótropo e homogêneo.

No capítulo 4 tratar-se-á do caso de expansão do problema em questão para duas direções $\left(\mathrm{X}_{1}\right.$ e $\left.\mathrm{X}_{2}\right)$. Tanto neste capítulo, quanto no anterior, serão apresentados exemplos numéricos para todos os casos, visto que neste capítulo é apresentada uma formulação para uma estaca com 4 pontos de colocação e 5 parâmetros nodais em cada direção e posteriormente estendido para o caso de grupos de estacas. Também será apresentado uma solução para o problema de interação grupo de estacas-solo com capeamento rígido. Deve-se ressaltar que no presente estudo considera-se que não existe contato entre o capeamento e o solo. 
No capítulo 5 será apresentado o desenvolvimento de uma formulação para o tratamento de estacas isoladas solicitadas por cargas verticais. Também aqui serão apresentadas exemplos numéricos e comparações feitas com modelos de outros autores.

No capítulo 6 serão apresentados os processos de acoplamento e expansão das parcelas referentes as forças e deslocamentos, do caso de estacas sujeitas a carregamentos verticais, às matrizes e vetores já desenvolvidas para o caso de estacas solicitadas por cargas horizontais. Ocasionando assim o surgimento de um modelo final com 14 parâmetros nodais, incluindo deslocamentos verticais, horizontais e rotações, com a opção de se trabalhar, não somente com estacas isoladas, mas também com grupos destas. A utilização de blocos rígidos (sem contato com o solo), bem como a formulação para a representação de estacas inclinadas, também será mostrada neste capítulo. Exemplos e comparações numéricas deste modelo com os de outros autores para todos estes casos serão apresentados no decorrer deste capítulo.

No capítulo 7 serão feitas as conclusões finais decorrentes do emprego do método dos elementos de contorno e do método dos elementos finitos na interação estaca-solo. 


\section{CAPÍTULO 2 \\ MÉTODO DOS ELEMENTOS DE CONTORNO}

\section{1) Introdução}

Neste capítulo são apresentadas as equações para análise elástica linear em sólidos tridimensionais, assim como as equações integrais básicas para a utilização do MEC relacionando os problemas elásticos reais e os fundamentais.

\subsection{1) Generalidades}

$\mathrm{Na}$ análise de problemas elásticos, há necessidade de se determinar as variáveis associadas aos campos de deslocamentos, deformações e tensões. A partir das relações e teoremas fornecidos pela teoria da elasticidade, uma das formas de se obter as soluções é através do método dos elementos de contorno que consiste em uma representação integral que é escrita envolvendo-se dois tipos de problemas. O primeiro tipo é associado ao problema fundamental que é definido por um domínio infinito $\Omega^{*}$ e representado pelas componentes $\mathrm{U}_{\mathrm{ij}}^{*}$ (tensor de deslocamentos fundamentais de ordem 2), $\mathrm{p}_{\mathrm{ij}}^{*}$ (tensor de forças de superfície fundamentais de ordem 2), $\sigma_{\mathrm{ijk}}^{*}$ (tensor de tensões fundamentais de ordem 3) e $\varepsilon_{\mathrm{ijk}}^{*}$ (tensor de deformações fundamentais de ordem 3 ). Já o segundo tipo representa o problema real e é definido em um domínio finito $\Omega$, contido na região $\Omega^{*}$, representado assim as componentes vetoriais $u_{i}, p_{i}, \sigma_{i j}$ e $\varepsilon_{i j}$, caracterizado pelas condições de contorno naturais e essenciais. 


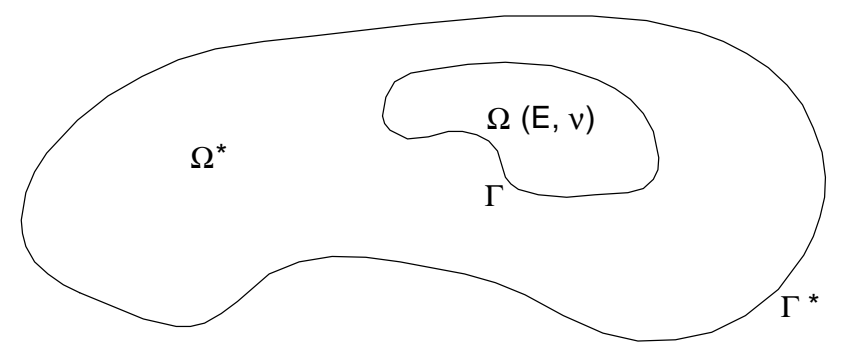

Fig. 2.1 - Domínio $\Omega$, contido em $\Omega^{*}$.

\section{2) Soluções Fundamentais}

A solução fundamental pode ser definida como sendo a resposta em um ponto "p" (ponto campo), devido a aplicação de um carregamento unitário " $F_{i}$ " no ponto "s" (ponto fonte).

A equação governante dos sólidos elásticos para carregamento concentrado é descrita como:

$$
\frac{1}{1-2 v} u_{i k, j k}^{*}+u_{i j, k k}^{*}+\frac{1}{G} \delta(s, p) \delta_{i j}=0
$$

Onde:

$\delta(s, p)$ : distribuição Delta de Dirac

$\delta_{\mathrm{ij}}$ : delta de Kronecker

v, G: constantes elásticas, coeficiente de Poisson e módulo de elasticidade transversal, respectivamente.

E sendo assim denominada como equação fundamental de deslocamentos $u_{i j}^{*}$

\subsection{1) Solução Fundamental de Kelvin}

As soluções fundamentais de Kelvin para problemas elásticos fundamentais definidos em um meio infinito $\Omega^{*}$ foram apresentadas por LOVE (1944), para um material elástico, homogêneo e isótropo, submetidos à ação de forças unitárias concentradas, conforme mostra a figura 2.2. 


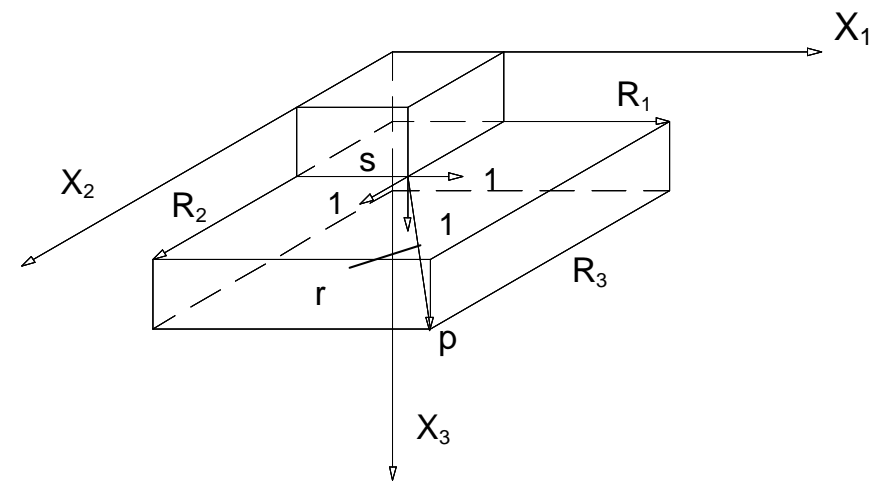

Fig. 2.2 - Figura adaptada de NAKAGUMA (1979) - Problema de Kelvin

As expressões para deslocamentos e forças de superfície em termos dos seus respectivos tensores são dadas abaixo:

$$
\begin{aligned}
& u_{i j}^{*}=\frac{1}{16 \pi(1-v) G r}\left[(3-4 v) \delta_{i j}+r_{, i},{ }_{, j}\right] \quad(i, j=1,2,3) \\
& P_{i j}^{*}=-\frac{1}{8 \pi(1-v) r^{2}}\left\{r_{i}, n_{i}\left[(1-2 v) \delta_{i j}+3 r_{i}, r_{j}\right]-(1-2 v)\left(n_{j}, r_{, i}-n_{i}, r_{j}\right)\right\}
\end{aligned}
$$

\subsection{2) Solução Fundamental de Mindlin}

Mindlin apresentou soluções fundamentais empregadas para domínios semi-infinitos, homogêneos, isótropos e elástico-linear, quando submetidas à ação de uma carga unitária concentrada. Assumindo-se que a superfície definida em $\mathrm{X}_{3}$ $=0$ esteja livre de forças de superfície e considerada como superfície de contorno $(\Gamma)$.

$\mathrm{Na}$ figura 2.3 é mostrada a representação geométrica do problema fundamental de Mindlin. 


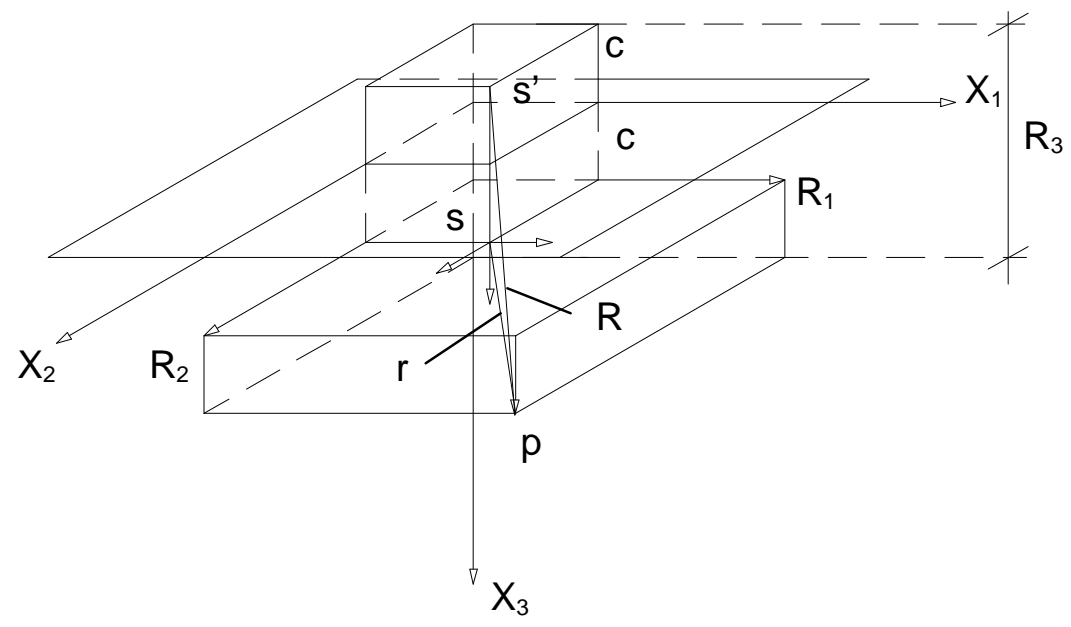

Fig. 2.3 - Figura Adaptada de NAKAGUMA (1979) - Problema de Mindlin A seguir serão apresentadas as soluções fundamentais para deslocamentos extraídas do trabalho de MINDLIN (1936):

$$
\begin{aligned}
& \mathrm{u}_{11}^{*}=\mathrm{Kd}\left\{\frac{3-4 v}{\mathrm{r}}+\frac{1}{\mathrm{R}}+\frac{\mathrm{r}_{1}^{2}}{\mathrm{r}^{3}}+\frac{(3-4 v) \mathrm{r}_{1}^{2}}{\mathrm{R}^{3}}+\frac{2 \mathrm{cz}}{\mathrm{R}^{3}}\left(1-\frac{3 \mathrm{r}_{1}^{2}}{\mathrm{R}^{2}}\right)+\right. \\
& \left.+\frac{4(1-v)(1-2 v)}{R+R_{3}}\left[1-\frac{r_{1}^{2}}{R\left(R+R_{3}\right)}\right]\right\} \\
& \mathrm{u}_{12}^{*}=\mathrm{Kdr}_{1} \mathrm{r}_{2}\left\{\frac{1}{\mathrm{r}^{3}}+\frac{3-4 v}{\mathrm{R}^{3}}-\frac{6 \mathrm{cz}}{\mathrm{R}^{5}}-\frac{4(1-\mathrm{v})(1-2 v)}{\mathrm{R}\left(\mathrm{R}+\mathrm{R}_{3}\right)^{2}}\right\} \\
& \mathrm{u}_{13}^{*}=\operatorname{Kdr}_{1}\left\{\frac{\mathrm{r}_{3}}{\mathrm{r}^{3}}+\frac{(3-4 v) \mathrm{r}_{3}}{\mathrm{R}^{3}}-\frac{6 c z R_{3}}{\mathrm{R}^{5}}+\frac{4(1-v)(1-2 v)}{\mathrm{R}\left(\mathrm{R}+\mathrm{R}_{3}\right)}\right\} \\
& \mathrm{u}_{21}^{*}=\mathrm{u}_{12}^{*} \\
& \mathrm{u}_{22}^{*}=\mathrm{Kd}\left\{\frac{3-4 v}{\mathrm{r}}+\frac{1}{\mathrm{R}}+\frac{\mathrm{r}_{2}^{2}}{\mathrm{r}^{3}}+\frac{(3-4 v) \mathrm{r}_{2}^{2}}{\mathrm{R}^{3}}+\frac{2 \mathrm{cz}}{\mathrm{R}^{3}}\left(1-\frac{3 \mathrm{r}_{2}^{2}}{\mathrm{R}^{2}}\right)+\right. \\
& \left.+\frac{4(1-v)(1-2 v)}{R+R_{3}}\left[1-\frac{r_{2}^{2}}{R\left(R+R_{3}\right)}\right]\right\}
\end{aligned}
$$




$$
\begin{aligned}
u_{23}^{*} & =\frac{r_{2}}{r_{1}} u_{13}^{*} \\
u_{31}^{*} & =K d r_{1}\left\{\frac{r_{3}}{r^{3}}+\frac{(3-4 v) r_{3}}{R^{3}}+\frac{6 c z R_{3}}{R^{5}}-\frac{4(1-v)(1-2 v)}{R\left(R+R_{3}\right)}\right\} \\
u_{32}^{*}= & \frac{r_{2}}{r_{1}} u_{31}^{*} \\
u_{33}^{*}= & K d\left\{\frac{r_{3}^{2}}{r^{3}}+\frac{(3-4 v)}{r}+\frac{6 c z R_{3}^{2}}{R^{5}}+\frac{8(1-v)^{2}-(3-4 v)}{R}+\right. \\
& \left.+\frac{(3-4 v) R_{3}^{2}-2 c z}{R^{3}}\right\}
\end{aligned}
$$

onde:

$$
\begin{aligned}
& r=\left(r_{i} r_{i}\right)^{1 / 2} \\
& R=\left(R_{i} R_{i}\right)^{1 / 2} \\
& r_{i}=x_{i}(p)-x_{i}(s) \\
& R_{i}=x_{i}(p)-x_{i}\left(s^{\prime}\right) \\
& c=x_{3}(s)>0 \\
& z=x_{3}(p)>0 \\
& K d=\frac{1+v}{8 \pi E(1-v)}
\end{aligned}
$$

Por simplicidade e devido a facilidade de serem encontradas na literatura (NAKAGUMA, 1979; TELLES, 1986) as expressões de forças de superfície e tensões deixaram de ser apresentadas nesta seção. 


\subsection{3) Solução Fundamental de Boussinesq-Cerruti}

Um caso particular da solução fundamental de Mindlin, foi desenvolvido por esses dois autores, onde o primeiro (Boussinesq,1885) analisou o comportamento de superfícies de semi-espaços elásticos, homogêneos e isótropos submetidas a cargas concentradas normais a este plano. E o segundo (Cerruti,1882), em uma análise semelhante, levou em conta apenas os carregamentos tangenciais ao plano da superfície.

Esta representação geométrica esta descrita na figura 2.4.

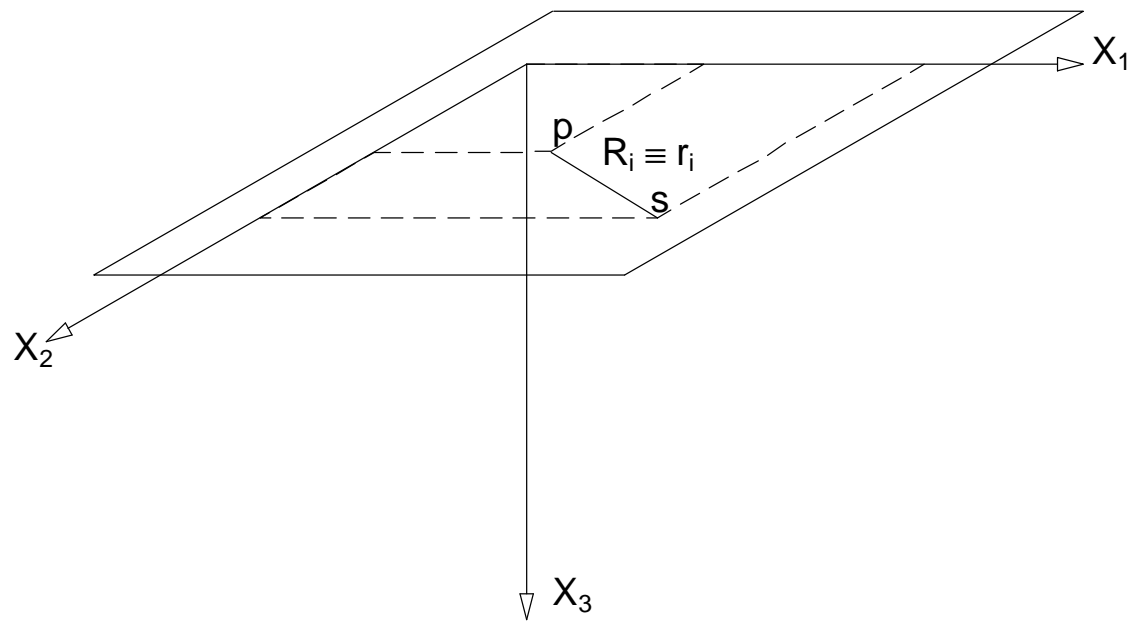

Fig. 2.4 - Figura adaptada de NAKAGUMA (1979) - Problema de Boussinesq-Cerruti

As equações de Boussinesq-Cerruti para deslocamentos fundamentais são descritas a seguir:

$$
\begin{array}{rl}
\mathrm{u}_{11}^{*} & =\mathrm{K}\left[(1-\mathrm{v})+\mathrm{vr},{ }_{1}^{2}\right] \\
\mathrm{u}_{12}^{*} & =\mathrm{Kvr},{ }_{1} \mathrm{r}_{2} \\
\mathrm{u}_{13}^{*} & =\mathrm{K}(0,5-\mathrm{v}) \mathrm{r},{ }_{1} \\
\mathrm{u}_{22}^{*} & =\mathrm{K}\left[(1-\mathrm{v})+\mathrm{vr}_{2}{ }_{2}\right] \\
\mathrm{u}_{23}^{*} & =\mathrm{K}(0,5-\mathrm{v}) \mathrm{r},{ }_{2} \\
\mathrm{u}_{33}^{*} & =\mathrm{K}(1-\mathrm{v}) \\
* & * \\
\mathrm{u}_{21} & =\mathrm{u}_{12} \\
\mathrm{u}_{32} & =-\mathrm{u}_{23}^{*} \\
\mathrm{u}_{32} & * \\
\mathrm{u}_{31} & =-\mathrm{u}_{13}^{*}
\end{array}
$$


Onde:

$$
\begin{aligned}
& \mathrm{K}=\frac{1}{2 \pi \mathrm{Gr}} \\
& \mathrm{e} \\
& \mathrm{X}_{3}(\mathrm{p})=0
\end{aligned}
$$

\section{3) Representação Integral para o Campo de Deslocamentos}

Divide-se em duas partes a representação integral para o campo de deslocamentos: a primeira recebe o nome de equação integral para pontos de domínio, pois o ponto fonte encontra-se neste. E a segunda devido ao ponto fonte encontrar-se no contorno do corpo, recebe o nome de equação integral para pontos de contorno.

Existem vários métodos para se obter a equação integral para pontos do domínio, dentre eles podem ser citados:

- Técnica dos Resíduos Ponderados e o

- Teorema da Reciprocidade.

Devido a grande utilização da técnica dos resíduos ponderados em vários métodos numéricos, esta será aqui apresentada.

A equação de equilíbrio de um corpo é dada por:

$$
\sigma_{i j, j}+b_{i}=0 \quad(i, j=1,2,3)
$$

onde "bi" são as componentes das forças volumétricas segundos os três eixos do sistema de coordenadas cartesianas.

Para que o equilíbrio do corpo esteja garantido, é necessário obter-se a solução das equações diferenciais de equilíbrio (2.6). A solução exata é viabilizada apenas em alguns casos particulares, de sorte que são adotadas soluções aproximadas. A integração sobre o domínio $\Omega$ de um integrando formado pelo produto de (2.6) por uma função ponderadora $\mathrm{u}_{\mathrm{ij}}^{*}$, pode ser escrito como:

$$
\int_{\Omega}\left(\sigma_{i j, j}+b_{i}\right) u_{i j}^{*} d \Omega=0 \quad(i, j=1,2,3)
$$

Admitindo-se agora $\mathrm{u}_{\mathrm{ij}}^{*}$ como sendo a solução fundamental relativa a uma carga unitária de direção "i" e deslocamento na direção "j", satisfazendo assim a seguinte equação de equilíbrio, 


$$
\sigma_{\mathrm{ij}, \mathrm{j}}^{*}+\delta(\mathrm{s}, \mathrm{p}) \delta_{\mathrm{ij}}=0
$$

Pode-se integrar duas vezes por partes a equação (2.7) resultando:

$$
-\int_{\Omega} \sigma_{i j, j}^{*} u_{i} d \Omega+\int_{\Gamma} u_{i} p_{i j}^{*} d \Gamma=\int_{\Omega} b_{i} u_{i j}^{*} d \Omega+\int_{\Gamma} p_{i} u_{i j}^{*} d \Gamma
$$

E sabendo-se que a integração de uma função Delta de Dirac ao longo de um domínio fornece um valor unitário, obtém-se:

$$
\int_{\Omega} \delta(\mathrm{s}, \mathrm{p}) \delta_{\mathrm{ij}} \mathrm{u}_{\mathrm{j}} \mathrm{d} \Omega=\delta_{\mathrm{ij}} \mathrm{u}_{\mathrm{j}}=\mathrm{u}_{\mathrm{i}}
$$

Substituindo-se agora a integração descrita em (2.10) na equação (2.9), têm-se:

$$
u_{i}=-\int_{\Gamma} p_{i j}^{*} u_{j} d \Gamma+\int_{\Gamma} u_{i j}^{*} p_{j} d \Gamma+\int_{\Omega} u_{i j}^{*} b_{j} d \Omega
$$

Esta equação integral é conhecida como Identidade Somigliana e só é válida para pontos do domínio. Através dela obtém-se deslocamentos para os pontos fontes no interior do domínio real $(\Omega)$, uma vez conhecidos $u_{j}$ e $p_{j}$ para todos os pontos do contorno.

Dividindo-se o contorno em $\Gamma_{1}$ e $\Gamma_{2}$, onde são prescritos os deslocamentos (condições essenciais) e as forças de superfície (condições naturais) respectivamente, obtém-se:

$$
\int_{\Omega} \sigma_{i j, j}^{*} u_{i} d \Omega+\int_{\Omega} b_{i} u_{i j}^{*} d \Omega=-\int_{\Gamma_{1}} p_{i} u_{i j}^{*} d \Gamma+\int_{\Gamma_{2}} p_{i} u_{i j}^{*} d \Gamma+\int_{\Gamma_{1}} u_{i} p_{i j}^{*} d \Gamma+\int_{\Gamma_{2}} u_{i} p_{i j}^{*} d \Gamma
$$

onde:

$$
\Gamma=\Gamma_{1}+\Gamma_{2}
$$

Devido a necessidade da obtenção de equações integrais para pontos de contorno, alguns artifícios matemáticos serão utilizados. Um artifício é ampliar o domínio original $(\Omega+\Gamma)$, através da adição de uma superfície esférica de contorno $\Gamma_{\varepsilon}$ e domínio $\Omega_{\varepsilon}$, formando assim um novo domínio $\Omega+\Omega_{\varepsilon}$ e um novo contorno $\Gamma-\bar{\Gamma}+\Gamma \varepsilon$, para o sistema como mostra a figura (2.5). 


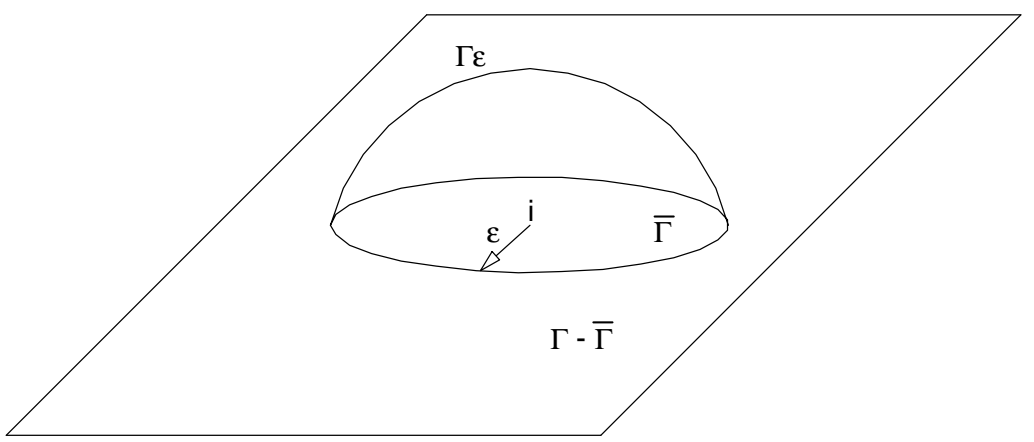

Fig. 2.5 - Ponto fonte situado no contorno

Para este domínio modificado, a equação 2.12 pode ser escrita na seguinte forma:

$$
u_{i}=-\int_{\Gamma-\bar{\Gamma}+\Gamma \varepsilon} p_{i j}^{*} u_{j} d \Gamma+\int_{\Gamma-\Gamma+\Gamma \varepsilon} u_{i j}^{*} p_{j} d \Gamma+\int_{\Omega+\Omega_{\varepsilon}} u_{i j}^{*} b_{j} d \Omega
$$

Com a finalidade de retornar ao domínio inicial, no qual o ponto "s" pertence ao contorno, faz-se $\varepsilon \rightarrow 0$ e conseqüentemente $\Omega_{\varepsilon} \rightarrow 0$ e $\Gamma_{\varepsilon} \rightarrow 0$, ou seja:

$$
\begin{aligned}
\mathrm{u}_{\mathrm{i}} & =\lim _{\Gamma \varepsilon \rightarrow 0}\left[-\int_{\Gamma-\bar{\Gamma}} \mathrm{p}_{\mathrm{ij}}^{*} \mathrm{u}_{\mathrm{j}} \mathrm{d} \Gamma+\int_{\Gamma-\bar{\Gamma}} \mathrm{u}_{\mathrm{ij}}^{*} \mathrm{p}_{\mathrm{j}} \mathrm{d} \Gamma+\int_{\Omega} \mathrm{u}_{\mathrm{ij}}^{*} \mathrm{~b}_{\mathrm{j}} \mathrm{d} \Omega\right]+ \\
& +\lim _{\Gamma \varepsilon \rightarrow 0}\left[-\int_{\Gamma \varepsilon} \mathrm{p}_{\mathrm{ij}}^{*} \mathrm{u}_{\mathrm{j}} \mathrm{d} \Gamma+\int_{\Gamma \varepsilon} \mathrm{u}_{\mathrm{ij}}^{*} \mathrm{p}_{\mathrm{j}} \mathrm{d} \Gamma+\int_{\Omega \varepsilon} \mathrm{u}_{\mathrm{ij}}^{*} \mathrm{~b}_{\mathrm{j}} \mathrm{d} \Omega\right]
\end{aligned}
$$

Computando-se agora o limite dos termos referentes a $\Gamma-\bar{\Gamma}$, obtém-se:

$$
\begin{aligned}
& \lim _{\varepsilon \rightarrow 0}\left[\int_{\Gamma-\bar{\Gamma}} p_{i j}^{*} u_{j} d \Gamma\right]=\int_{\Gamma} p_{i j}^{*} u_{j} d \Gamma \\
& \lim _{\varepsilon \rightarrow 0}\left[\int_{\Gamma-\bar{\Gamma}} u_{i j}^{*} p_{j} d \Gamma\right]=\int_{\Gamma} u_{i j}^{*} p_{j} d \Gamma
\end{aligned}
$$

Para as parcelas de domínio, verifica-se que quando $\varepsilon \rightarrow 0$ a integral de $\Omega$ representa todo o domínio do problema, enquanto que $\Omega_{\varepsilon}$ tende a zero:

$$
\lim _{\varepsilon \rightarrow 0}\left[\int_{\Omega+\Omega \varepsilon} \mathrm{u}_{\mathrm{ij}}^{*} \mathrm{~b}_{\mathrm{j}} \mathrm{d} \Omega\right]=\int_{\Omega} \mathrm{u}_{\mathrm{ij}}^{*} \mathrm{~b}_{\mathrm{j}} \mathrm{d} \Omega
$$

Considerando-se agora a primeira parcela do segundo termo, observa-se que os valores de $\mathrm{u}_{\mathrm{ij}}^{*}$ são da ordem de $1 / \varepsilon$, enquanto que os valores obtidos do contorno $\Gamma_{\varepsilon}$, são da ordem de $\varepsilon^{2}$, concluindo-se que: 


$$
\lim _{\varepsilon \rightarrow 0}\left[\int_{\Gamma \varepsilon} \mathrm{u}_{\mathrm{ij}}^{*} \mathrm{p}_{\mathrm{j}} \mathrm{d} \Gamma\right]=0
$$

Restando agora analisar a segunda parcela do segundo termo da equação (2.14), que apresenta forte singularidade ao contrário das duas outras parcelas deste mesmo termo da equação em questão. Esta singularidade ocasiona uma descontinuidade da função $\mathrm{p}_{\mathrm{ij}}^{*}$ apresentada no limite. Visto que a integração dos valores do tensor $\mathrm{p}_{\mathrm{ij}}^{*}$ no contorno $\Gamma \varepsilon$ tem ordem $1 / \varepsilon^{2}$ e os termos resultantes do diferencial na superfície são de ordem $\varepsilon^{2}$, conclui-se que para $\varepsilon \rightarrow 0$, existe valor definido, que é um valor independente. Admitindo-se a parcela da equação (2.14), em questão, em termos de forças e considerando que o ponto fonte ("s") pertença a um contorno smooth (sem angulosidade), tem-se que:

$$
\lim _{\varepsilon \rightarrow 0}\left[\int_{\Gamma \varepsilon} p_{i j}^{*} u_{j} d \Gamma\right]=u_{j} \lim _{\varepsilon \rightarrow 0}\left[\int_{\Gamma \varepsilon} p_{i j}^{*} d \Gamma\right]=\delta_{i j} u_{j}
$$

Desta forma pode-se escrever a equação geral de deslocamentos para pontos de domínio e de contorno, como sendo:

$$
\mathrm{C}_{\mathrm{ij}} \mathrm{u}_{\mathrm{i}}=-\int_{\Gamma} \mathrm{p}_{\mathrm{ij}}^{*} \mathrm{u}_{\mathrm{j}} \mathrm{d} \Gamma+\int_{\Gamma} \mathrm{u}_{\mathrm{ij}}^{*} \mathrm{p}_{\mathrm{j}} \mathrm{d} \Gamma+\int_{\Omega} \mathrm{u}_{\mathrm{ij}}^{*} \mathrm{~b}_{\mathrm{j}} \mathrm{d} \Omega
$$

onde pode-se tomar os seguintes valores para $\mathrm{C}_{\mathrm{ij}}(\mathrm{s})$ :

Solução de Mindlin:

$$
s \in \Omega \rightarrow \mathrm{C}_{\mathrm{ij}}(\mathrm{s})=\delta_{\mathrm{ij}}
$$

Solução de Boussinesq-Cerruti:

(quando "s" se encontra no plano da superfície)

$s \in X_{3}(s)=0 \rightarrow C_{i j}(s)=\delta_{i j}$

Para efeito de praticidade $\delta_{i j}$ é colocado na forma matricial, isto é:

$$
\delta_{\mathrm{ij}}=[\mathrm{I}]
$$

onde a matriz [I] é uma matriz identidade de ordem 3. 


\section{CAPÍTULO 3 \\ ESTACAS VERTICAIS ISOLADAS SUBMETIDAS À \\ CARREGAMENTOS LATERAIS EM UMA DIREÇÃO}

\section{1) Introdução}

Neste capítulo serão apresentadas as diversas análises feitas com várias discretizações realizadas em estacas isoladas e imersas em um meio semi-infinito, homogêneo, isótropo e elástico-linear, submetidas à carregamentos horizontais agindo em uma única direção $\left(\mathrm{X}_{1}\right)$.

Os principais métodos utilizados nesta pesquisa serão descritos detalhadamente neste capítulo, sendo alguns outros métodos apenas citados devido a repetitividade no processo de obtenção de soluções.

Também serão apresentados exemplos e comparações com resultados teóricos e experimentais de outros autores que serviram para o desenvolvimento de posteriores conclusões à respeito das hipóteses aqui adotadas.

\section{2) Hipóteses Básicas}

Abaixo estão citados alguns dos diversos fatores que influenciam 0 comportamento real do conjunto estaca-solo:

- Propriedades físicas do solo e da estaca;

- Tipo de execução das estacas;

- Espaçamento entre as estacas;

- Ordem de escavação;

- Nível de carregamento aplicado;

- Geometria do sistema;

- Reologia do solo.

Neste trabalho nem todos os fatores foram considerados para a análise numérica do problema. Dentre os que foram, podem ser citados a seguir as hipóteses simplificadoras em questão:

- O espaçamento entre estacas é tomado como a distância de eixo a eixo (caso a ser visto no capítulo 4 - grupos de estacas);

- O solo e a estaca são admitidos trabalhando no regime elástico-linear; 
- É admitido que as estacas estão totalmente imersas em um semiespaço, elástico linear, homogêneo e isótropo.

- O solo e as estacas estão livres de tensões iniciais decorrentes da instalação das mesmas.

- A superfície das estacas são admitidas rugosas, de forma que inibe o deslizamento na região da superfície de contato estaca-solo;

- As forças volumétricas são desprezadas;

- As estacas estão sujeitas apenas a carregamentos horizontais (esta hipótese é válida somente para os capítulos 3 e 4);

- Existe compatibilidade de deslocamentos entre o solo e a estaca.

\section{3) Interação de um Meio Tridimensional com Estruturas de Barras}

Para o caso de estacas imersas em um meio contínuo, é necessário adicionar um termo a equação geral de deslocamentos (2.20) correspondente à aplicação de uma carga distribuída ao longo das estacas (VENTURINI, 1988), sendo feito este acréscimo a partir do limite de forças volumétricas. A figura 3.1 mostra esta representação no espaço tridimensional.

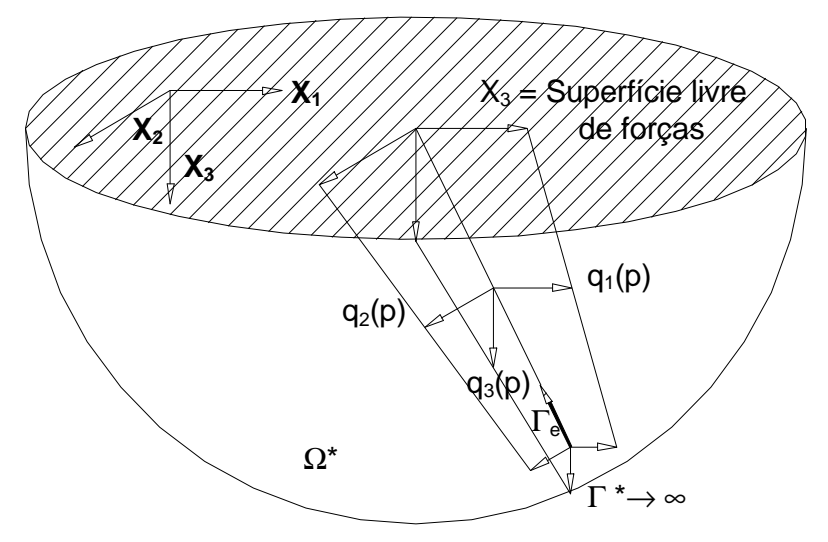

Fig. 3.1 - Domínio tridimensional com linhas de cargas.

Modificando a equação de deslocamentos (2.20) pode-se escrever agora que:

$$
\mathrm{C}_{\mathrm{ij}} \mathrm{u}_{\mathrm{i}}=-\int_{\Gamma} \mathrm{p}_{\mathrm{ij}}^{*} \mathrm{u}_{\mathrm{j}} \mathrm{d} \Gamma+\int_{\Gamma} \mathrm{u}_{\mathrm{ij}}^{*} \mathrm{p}_{\mathrm{j}} \mathrm{d} \Gamma+\int_{\Omega} \mathrm{u}_{\mathrm{ij}}^{*} \mathrm{~b}_{\mathrm{j}} \mathrm{d} \Omega+\int_{\Gamma \mathrm{e}} \mathrm{u}_{\mathrm{ij}}^{*} \mathrm{q}_{\mathrm{j}}^{\mathrm{e}} \mathrm{d} \Gamma
$$

Onde:

$\mathrm{q}_{\mathrm{j}}^{\mathrm{e}}$ : representa as forças de interação aplicadas no meio tridimensional; 
$\Gamma_{\mathrm{e}}$ : representa a superfície de contato estaca-solo quando procura-se obter a influência de uma estaca sobre ela mesma e representa a linha de carga onde essas forças estão aplicadas quando procura-se obter a influência entre estacas distintas.

$\mathrm{Na}$ equação (3.1), algumas modificações serão feitas, isto é , para as posteriores aplicações pode-se desprezar a parcela referente as forças volumétricas, e como serão usadas as soluções fundamentais de Mindlin não levando em consideração casos de escavações, conseqüentemente as duas primeiras parcelas do segundo termo da equação (3.1) podem também ser eliminadas.

E como visto no capítulo anterior, $\mathrm{C}_{\mathrm{ij}}(\mathrm{s})$, para este caso recebe valores unitários (matriz identidade). Após todas estas alterações chega-se a seguinte equação:

$$
\mathrm{u}_{\mathrm{i}}(\mathrm{s})=\sum_{\mathrm{e}=1}^{\mathrm{Ne}} \int_{\Gamma \mathrm{e}} \mathrm{u}_{\mathrm{ij}}^{*}(\mathrm{~s}, \mathrm{p}) \mathrm{q}_{\mathrm{j}}^{\mathrm{e}}(\mathrm{p}) \mathrm{d} \Gamma(\mathrm{p})
$$

Sendo "Ne" o número de estacas do sistema.

\subsection{1) Discretização da Representação Integral}

A equação (3.2), pode ser representada na forma algébrica da seguinte maneira:

$$
\{\mathrm{u}\}=\sum_{\mathrm{e}=1}^{\mathrm{Ne}}\left[\int\left[\mathrm{U}^{*}\right]\{\bar{\phi}\}^{\mathrm{T}} \mathrm{d} \Gamma\right]\{\mathrm{P}\}
$$

onde:

$\{u\}$ : é o vetor de deslocamentos dos pontos de colocação.

$\left[\mathrm{U}^{\star}\right]$ : é a matriz de soluções fundamentais de Mindlin.

$\{\bar{\phi}\}^{\mathrm{T}}$ : é o vetor de funções interpoladoras para as forças de interação.

$\{P\}$ : é o vetor de forças da interface estaca-solo.

Ne: é o número de linhas de carga ou de estacas.

Pode-se então escrever a equação (3.3) na forma matricial:

$\{u\}=[G]\{P\}$ 
Onde:

$$
[\mathrm{G}]=\sum_{\mathrm{e}=1}^{\mathrm{Ne}} \int_{\Gamma \mathrm{e}}\left[\mathrm{U}^{*}\right]\{\bar{\phi}\}^{\mathrm{T}} \mathrm{d} \Gamma
$$

A seguir serão apresentadas as várias combinações entre os métodos (MDF, MEF e o MEC) utilizadas e desenvolvidas aqui para a finalidade de se obter uma formulação compatível com a já citada em Mendonça, 1997.

\subsection{2) Sub-Elementação da Integração}

Visto que não haverá singularidade na integração da estaca, uma vez que, a menor distância entre o ponto fonte e o campo será o raio da estaca, e também admitindo-se que a estaca para diversos casos a serem analisados no capítulo subseqüente será tratada como um único elemento, pode-se então dividi-la em vários sub-elementos conseguindo assim diminuir o número de pontos de Gauss a serem utilizados sem perder o número de contribuições decorrentes dos coeficientes de influência dos deslocamentos no solo. A este processo dá-se o nome de Sub-Elementação da Integração (MENDONÇA, 1997; MON-MA, 1996).

\section{4) Análise Elástica em Estacas Isoladas}

\subsection{1) Método Adaptado de POULOS (1971a)}

Várias formulações foram propostas para a análise de estacas com cargas horizontais e considerando o solo como meio contínuo (Douglas \& Davis, 1964; Spillers \& Stoll, 1964; Lenci, Maurice \& Madignier (1968); Matthewson, 1969; Banerjee, 1978; Banerjee \& Davies, 1978; e Poulos, 1971a, 1972). Todas as formulações são idênticas em princípios, mas divergem com a extensão das hipóteses. Nesta seção serão descritas as análises realizadas por POULOS (1971a) para estacas flutuantes (considerando que a camada de solo incompressivel esteja no infinito), diferindo-se apenas na distribuição das forças da interface, onde para o presente estudo as estacas são representadas como linhas de cargas imersas em um meio semi infinito e Poulos considerou-as como áreas de cargas, onde estas forças eram aplicadas ao longo de uma área constituída pelo diâmetro da estaca e o comprimento da mesma. 
Como pode ser visto na figura 3.2, a estaca é assumida como uma barra vertical, com largura (ou diâmetro no caso de estaca circular) "d", comprimento "L" e constante de flexibilidade " $E_{p} l_{p}$ ".

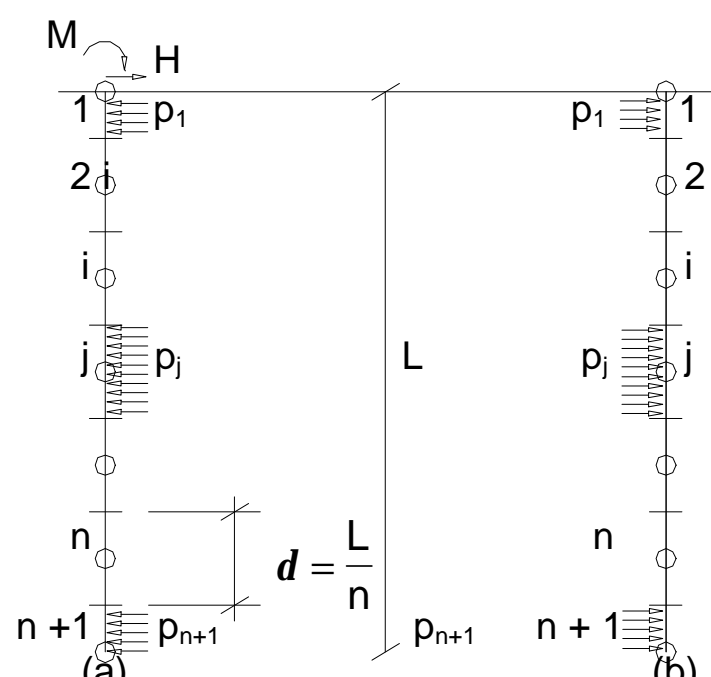

(a)

Fig. 3.2 - Figura adaptada de POULOS (1980) - Estaca Flutuante; a) Tensões e cargas externas agindo sobre a estaca; b) Solo adjacente à estaca e suas tensões

A estaca é dividida em " $n+1$ " elementos todos tendo comprimento $\delta$, exceto para o topo e a ponta, os quais têm comprimento $\delta / 2$. Cada elemento é submetido a uma força horizontal uniforme "p", o qual é assumido na interface estaca-solo. O solo é admitido como sendo um material elástico-linear, ideal, semi-infinito, homogêneo, isótropo, tendo módulo de Young, $E_{s}$, e coeficiente de Poisson, $v_{s}$, constantes. O solo também não é afetado na presença da estaca.

Se o solo é considerado em condições puramente elásticas e levando-se em conta a hipótese de que o solo adere à estaca por completo, pode-se assumir que os deslocamentos tanto do solo quanto da estaca são idênticos.

Nesta formulação, são compatibilizados os deslocamentos da estaca e do solo para o centro dos elementos, exceto para a ponta e o topo da estaca.

Como já dito anteriormente (eq. 3.2), os deslocamentos do solo para todos os pontos ao longo da estaca são expressos, da seguinte forma:

$$
\mathrm{u}_{\mathrm{j}}(\mathrm{s})=\sum_{\mathrm{i}=1}^{\mathrm{Ne}} \int_{\Gamma_{\mathrm{i}}} \mathrm{u}_{\mathrm{ij}}^{*} \operatorname{Pid} \Gamma \mathrm{i}
$$

sendo que:

$$
[G]=\int_{\Gamma i} u_{i j}^{*} d \Gamma i
$$


Onde:

[G]: é a matriz de ordem $(n+1) \times(n+1)$ e

j: é o número de pontos de colocação nas linhas de cargas

Os vetores e a matriz da equação anterior (3.6) já foram descritos na equação (3.4 e 3.5), faltando apenas mencionar que os coeficientes de influência de deslocamentos no solo contidos na matriz "[G]" serão obtidos pela integração da equação de Mindlin utilizando-se a "Regra da Quadratura de Gauss" (BREBBIA \& DOMINGUES, 1984).

Apesar da equação (3.6) ser para um solo com $E_{s}$ uniforme (constante), o caso de $E_{s}$ variando ao longo da profundidade (estaca imersa em areias ou argila mole) pode também ser considerado assumindo-se que a mesma equação de Mindlin é válida, mas utilizando agora o valor de $E_{s}$ para o ponto de colocação em questão (POULOS \& DAVIS, 1980).

A equação diferencial de flexão das vigas, é:

$$
\mathrm{E}_{\mathrm{p}} \mathrm{I}_{\mathrm{p}} \frac{\partial^{4} \mathrm{u}}{\partial \mathrm{z}^{4}}+\{\mathrm{P}\}=0
$$

Esta equação pode ser transformada em um sistema de equações lineares utilizando-se o método das diferenças finitas englobando pontos de 2 a "n".

\subsubsection{1) Condições de Contorno}

As condições de contorno são utilizadas para a ponta e o topo da estaca com a finalidade de eliminar deslocamentos fictícios dos pontos fora da estaca inerentes à formulação das diferenças finitas.

No topo da estaca algumas condições podem ser consideradas:

\section{a) Condições de contorno para estacas com topo livre}

Admite-se que:

Cortante $=\mathrm{E}_{\mathrm{p}} \mathrm{I}_{\mathrm{p}}\left(\frac{\partial^{3} \mathrm{u}}{\partial \mathrm{z}^{3}}\right)=\mathrm{H}$

isto é,

$$
-u_{-2}+2 u_{-1}-2 u_{2}+u_{3}=\frac{H^{3}}{E_{p} I_{p} n^{3}}
$$

e

$$
\text { Momento }=\mathrm{E}_{\mathrm{p}} \mathrm{I}_{\mathrm{p}}\left(\frac{\partial^{2} \mathrm{u}}{\partial \mathrm{z}^{2}}\right)=\mathrm{M}
$$


ou seja,

$\mathrm{u}_{2}-2 \mathrm{u}_{1}+\mathrm{u}_{-1}=\frac{\mathrm{ML}^{2}}{\mathrm{E}_{\mathrm{p}} \mathrm{I}_{\mathrm{p}} \mathrm{n}^{2}}$

b) Condições de contorno para estacas com topo fixo

Para este caso também é válida a equação (3.8) e sendo fixo o topo admite-se que:

$$
\begin{aligned}
& \text { Rotação }=E_{p} I_{p} \frac{\partial u}{\partial z}=0 \\
& \text { isto é, } \\
& u_{2}-u_{-1}=0
\end{aligned}
$$

\section{c) Condições de Contorno para a ponta da estaca}

Assume-se que a ponta da estaca está livre de vinculações, resultando:

Cortante $=E_{p} I_{p} \frac{\partial^{3} u}{\partial z^{3}}=0$

resultando em,

$-\mathrm{u}_{\mathrm{n}-1}+2 \mathrm{u}_{\mathrm{n}}-2 \mathrm{u}_{\mathrm{n}+2}+\mathrm{u}_{\mathrm{n}+3}=0$

e

Momento $=\mathrm{E}_{\mathrm{p}} \mathrm{I}_{\mathrm{p}}\left(\frac{\partial^{2} \mathrm{u}}{\partial \mathrm{z}^{2}}\right)=0$

ou seja,

$\mathrm{u}_{\mathrm{n}}-2 \mathrm{u}_{\mathrm{n}+1}+\mathrm{u}_{\mathrm{n}+2}=0$

Os índices dos parâmetros de deslocamentos laterais podem ser observados na figura 3.2.

A seguir serão descritos os sistemas de equações para os casos de estacas com topo livre e com topo fixo.

\subsubsection{2) Estaca com Topo Livre}

Escrevendo-se a equação (3.7) pelo MDF com as coerentes condições de contorno para a ponta e o topo, obtém-se: 
$-\left\{P_{p}\right\}=\frac{E_{p} I_{p} n^{4}}{L^{4}}[D]\left\{u_{p}\right\}+\frac{E_{p} I_{p} n^{4}}{L^{4}}\{A\}$

onde:

$\left\{u_{p}\right\}$ : é o vetor $n-1$ de deslocamentos da estaca

[D]: é a matriz $(n-1) \times(n+1)$ de coeficientes das diferenças finitas

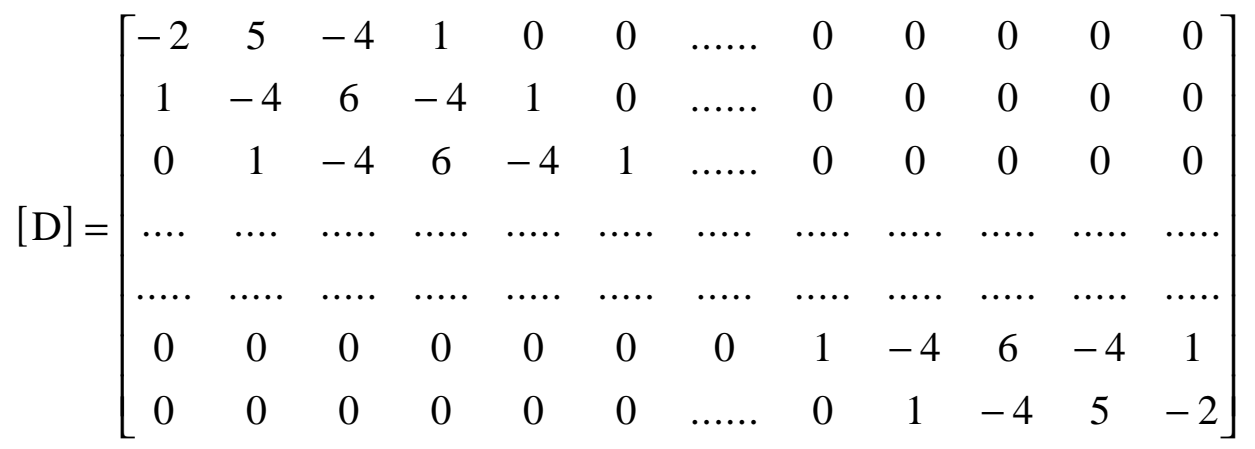

$\{A\}:$ é o vetor de forças externas decorrentes das condições de contorno

$$
\{A\}=\left\{\begin{array}{c}
\frac{M L^{2}}{n^{2} E_{p} I_{p}} \\
0 \\
0 \\
\cdot \\
\cdot \\
0 \\
0
\end{array}\right\}
$$

Compatibilizando-se apenas os deslocamentos (para o presente método não são compatibilizadas as forças de interação) na interface entre o solo e a estaca, isto é, $\left\{u_{p}\right\}=\left\{u_{s}\right\}$, obtém-se:

$$
\left[[\mathrm{I}]+\mathrm{K}_{\mathrm{R}} \mathrm{n}^{4}[\mathrm{D}][\mathrm{G}]\right]\{\mathrm{P}\}=\{\mathrm{B}\}
$$

onde:

$\{B\}$ : é o vetor $n$ - 1 de forças decorrentes das condições de contorno.

$$
\{\mathrm{B}\}=\left\{\begin{array}{c}
-\frac{\mathrm{Mn}^{2}}{\mathrm{~L}^{2}} \\
0 \\
0 \\
\cdot \\
0 \\
0
\end{array}\right\}
$$


[I] : é uma matriz unitária $n-1 \times n+1$

$K_{R}=\frac{E_{p} I_{p}}{E_{s} L^{4}}$

$\mathrm{K}_{\mathrm{R}}$ : é o coeficiente de flexibilidade relacionado ao solo e a estaca, sendo este um valor adimensional limitado em $\infty$ para uma estaca infinitamente rígida e 0 para uma estaca com comprimento infinito.

Visto que, neste método uma das variáveis de $K_{R}$ é o módulo de elasticidade longitudinal do solo, $E_{s}$, este será retirado das soluções fundamentais utilizadas no cálculo dos coeficientes de influência do solo que constituem a matriz [G].

Na tabela 3.1 (Poulos, 1980) são mostrados alguns valores de $K_{R}$ utilizando módulo de elasticidade longitudinal secante do solo (Es) que podem ser considerados nos casos de análise puramente elástica e apenas como aproximação.

Tab. 3.1a) - Típicos Valores de $\mathrm{K}_{\mathrm{R}}$ para Solos Argilosos.

\begin{tabular}{|l|c|c|c|c|c|c|}
\hline & \multicolumn{2}{|c|}{ Argila Mole } & \multicolumn{2}{c|}{ Argila Média } & \multicolumn{2}{c|}{ Argila Rija } \\
\hline Tipos de Estaca & \multicolumn{5}{|c|}{ Comprimento da estaca (pés) } \\
\hline & $\mathbf{2 0}$ & $\mathbf{5 0}$ & $\mathbf{2 0}$ & $\mathbf{5 0}$ & $\mathbf{2 0}$ & $\mathbf{5 0}$ \\
\hline Concreto-1 pé (diâm.) & $6,2.10^{-3}$ & $1,6.10^{-4}$ & $3,1.10^{-3}$ & $8,0.10^{-5}$ & $1,2.10^{-3}$ & $3,1.10^{-5}$ \\
\hline Concreto-3pés (diâm.) & $5,0.10^{-1}$ & $1,3.10^{-2}$ & $2,5.10^{-1}$ & $6,4.10^{-3}$ & $9,4.10^{-2}$ & $2,4.10^{-3}$ \\
\hline Madeira-1 pé (diâm.) & $3,1.10^{-3}$ & $7,9.10^{-5}$ & $1,5.10^{-3}$ & $3,8.10^{-5}$ & $6,0.10^{-4}$ & $1,5.10^{-5}$ \\
\hline $\begin{array}{l}\text { Aço Perfil H- 14 pol. x } \\
\text { 14 pol. x 117 lib. }\end{array}$ & $2,7.10^{-2}$ & $6,9.10^{-4}$ & $1,3.10^{-2}$ & $3,4.10^{-4}$ & $5,0.10^{-3}$ & $1,3.10^{-4}$ \\
\hline
\end{tabular}

Tab. 3.1b) Típicos Valores de $\mathrm{K}_{\mathrm{R}}$ para Solos Arenosos.

\begin{tabular}{|l|c|c|c|c|}
\hline & \multicolumn{2}{|c|}{ Areia Grossa } & \multicolumn{2}{c|}{ Areia Fina } \\
\hline \multicolumn{1}{|c|}{ Tipos de Estaca } & \multicolumn{2}{|c|}{ Comprimento da estaca (pés) } \\
\hline & 20 & 50 & 50 & 20 \\
\hline Concreto - 1 pé (diâm.) & $3,7.10^{-3}$ & $9,5.10^{-5}$ & $9,2.10^{-4}$ & $2,4.10^{-5}$ \\
\hline Concreto - 3 pés (diâm.) & $3,0.10^{-1}$ & $7,7.10^{-3}$ & $7,5.10^{-2}$ & $1,9.10^{-3}$ \\
\hline madeira - 1 pé (diâm.) & $1,8.10^{-3}$ & $4,6.10^{-5}$ & $4,7.10^{-4}$ & $1,2.10^{-5}$ \\
\hline $\begin{array}{l}\text { Aço Perfil H - 14 pol. x } \\
\text { 14 pol. x 117 lib. }\end{array}$ & $1,6.10^{-2}$ & $4,1.10^{-4}$ & $4,0.10^{-3}$ & $1,0.10^{-4}$ \\
\hline
\end{tabular}


As equações de equilíbrio horizontal e de momento promovem as duas equações restantes para esta análise.

A condição de equilíbrio horizontal requer que:

$\mathrm{P}_{1} \frac{\delta}{2}+\mathrm{P}_{2} \delta+\ldots \ldots \ldots \ldots \ldots \ldots+\mathrm{P}_{\mathrm{n}} \delta+\mathrm{P}_{\mathrm{n}+1} \frac{\delta}{2}-\mathrm{H}=0$

Ou seja:

$\{\mathrm{E}\}^{\mathrm{T}}\{\mathrm{P}\}=\frac{\mathrm{Hn}}{\mathrm{L}}$

onde:

n: é o número de divisões da estaca em elementos menos um.

$\{E\}^{T}$ : é um vetor linha $n+1$, com

$E_{j}=1$ para $1<j<n+1$,

$E_{j}=0.5$ para $j=1$ ou $j=n+1$

$E$ a condição de equilíbrio de momento requer que:

$\mathrm{P}_{1} \frac{\delta}{2} \frac{\delta}{4}+\mathrm{P}_{2} \delta\left(\frac{\delta}{2}+\frac{\delta}{2}\right)+\ldots \ldots \ldots \ldots \ldots \ldots . . . \mathrm{M}=0$

Portanto:

$\{C\}^{\mathrm{T}}\{\mathrm{P}\}=-\frac{\mathrm{n}^{2} \mathrm{M}}{\mathrm{L}^{2}}$

onde:

$\{C\}^{T}$ : é um vetor linha $n+1$ com

$\mathrm{C}_{\mathrm{j}}=\mathrm{j}-1$ para $1<\mathrm{j}<\mathrm{n}+1$

$\mathrm{C}_{1}=0.125$

$\mathrm{C}_{n+1}=0.5 \mathrm{n}-0.125$

Implementando estas duas equações na equação (3.14) pode-se então resolver o sistema obtendo-se então as $n+1$ forças de interface incógnitas do sistema estaca-solo. E substituindo-as na equação (3.13) obtém-se os deslocamentos e rotações do problema.

\subsubsection{3) Estaca com Topo Fixo (Restringido)}

Por analogia à equação (3.14) tem-se agora:

$\left[[\mathrm{I}]+\mathrm{K}_{\mathrm{R}} \mathrm{n}^{4}\left[\mathrm{D}_{1}\right]\left[\mathrm{G}_{1}\right]\right]\{\mathrm{P}\}=0$ 
onde:

$\left[D_{1}\right]$ : é a matriz $n-1 \times n+1$ de coeficientes de diferenças finitas.

A equação de equilíbrio horizontal é idêntica a anterior (eq. 3.15), mas a equação do momento deve ser alterada. Para a condição de estaca com topo fixo em um bloco, inicialmente determina-se o momento necessário para anular-se a

rotação $\left(\mathrm{v}_{\text {(solo/estaca) }}^{\prime}\right)$ e a correspondente distribuição de tensões ao longo da estaca, com isso a equação de equilíbrio de momento pode então ser escrita da seguinte maneira:

$\left\{\mathrm{C}_{1}\right\}^{\mathrm{T}}\{\mathrm{P}\}=0$

onde:

$\left\{\mathrm{C}_{1}\right\}^{\mathrm{T}}$ : é um vetor linha $\mathrm{n}+1$ com

$\mathrm{C}_{\mathrm{ij}}=\mathrm{C}_{\mathrm{j}}+\left(\frac{2}{3} \mathrm{~K}_{\mathrm{R}} \mathrm{n}^{4}\right)\left(-\mathrm{g}_{2 \mathrm{j}}+\mathrm{g}_{3 \mathrm{j}}\right)$

$\mathrm{g}_{\mathrm{ij}}$ : são coeficientes oriundos da integração sobre as soluções fundamentais

e $C_{j}$ é definido na equação (3.16)

Através das equações (3.17), (3.18) e (3.19) é possível determinar novamente as forças de interface e posteriormente os deslocamentos.

\subsection{2) Abordagem via MEC/MEF}

Este método é desenvolvido admitindo-se a estaca com 4 pontos de nodal, mas com 5 parâmetros nodais, sendo 4 de deslocamentos laterais ao longo do seu fuste e mais uma rotação na cabeça da estaca, permitindo assim a consideração do momento fletor (fig. 3.3). 


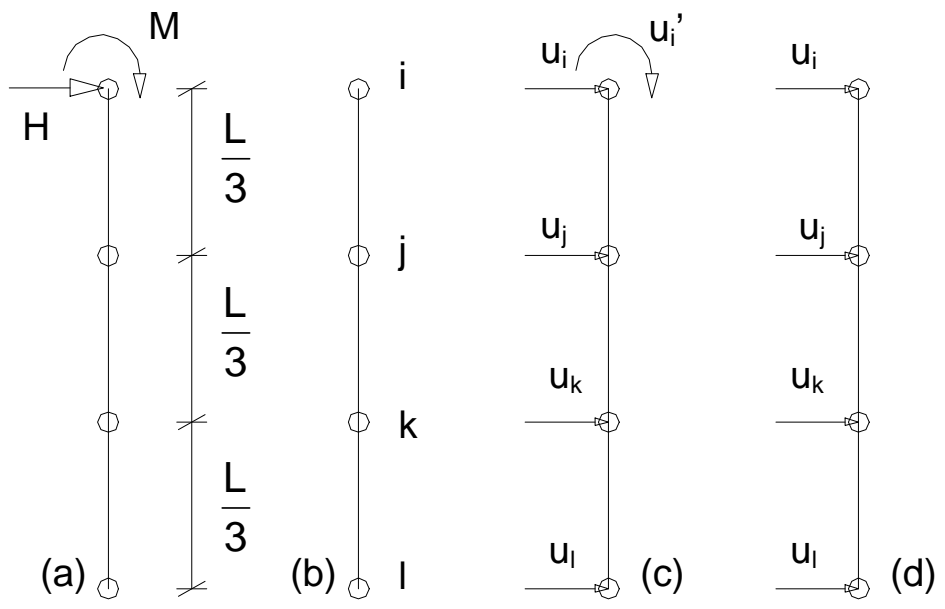

Fig. 3.3 - Discretização do Problema; a) Forças no topo da estaca; b) Pontos de colocação na estaca; c) Parâmetros nodais na estaca; d) Parâmetros nodais no solo.

As forças da interface variam cubicamente ao longo da estaca (fig. 3.4).

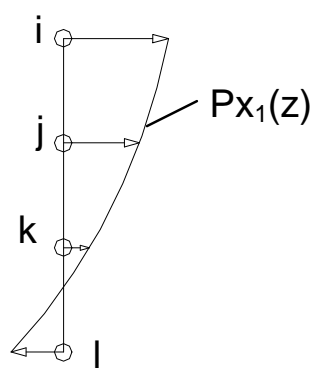

Fig. 3.4 - Forças de interação variando cubicamente ao longo da estaca.

Considerando a estaca como um elemento finito com as condições de vinculações descritas na figura 3.3 , adota-se para este caso um polinômio do $4^{\circ}$ grau como função aproximadora de deslocamentos, isto é:

$$
\mathrm{u}_{\mathrm{ap}}(\mathrm{z})=\mathrm{Az}^{4}+\mathrm{Bz}^{3}+\mathrm{Cz}^{2}+\mathrm{Dz}+\mathrm{E}
$$

Sabendo-se que:

$$
\begin{aligned}
& \mathrm{p} / \mathrm{z}=0 \rightarrow \mathrm{u}_{\mathrm{ap}}(0)=\mathrm{E}=\mathrm{u}_{\mathrm{i}} \\
& \mathrm{p} / \mathrm{z}=\frac{\mathrm{L}}{3} \rightarrow \mathrm{u}_{\mathrm{ap}}\left(\frac{\mathrm{L}}{3}\right)=\mathrm{A}\left(\frac{\mathrm{L}}{3}\right)^{4}+\mathrm{B}\left(\frac{\mathrm{L}}{3}\right)^{3}+\mathrm{C}\left(\frac{\mathrm{L}}{3}\right)^{2}+\mathrm{D}\left(\frac{\mathrm{L}}{3}\right)+\mathrm{E}=\mathrm{u}_{\mathrm{j}} \\
& \mathrm{p} / \mathrm{z}=\frac{2 \mathrm{~L}}{3} \rightarrow \mathrm{u}_{\mathrm{ap}}\left(\frac{2 \mathrm{~L}}{3}\right)=\mathrm{A}\left(\frac{2 \mathrm{~L}}{3}\right)^{4}+\mathrm{B}\left(\frac{2 \mathrm{~L}}{3}\right)^{3}+\mathrm{C}\left(\frac{2 \mathrm{~L}}{3}\right)^{2}+\mathrm{D}\left(\frac{2 \mathrm{~L}}{3}\right)+\mathrm{E}=\mathrm{u}_{\mathrm{k}}(3.21 \mathrm{c}) \\
& \mathrm{p} / \mathrm{z}=\mathrm{L} \rightarrow \mathrm{u}_{\mathrm{ap}}(\mathrm{L})=\mathrm{AL}^{4}+\mathrm{BL}^{3}+\mathrm{CL}^{2}+\mathrm{DL}+\mathrm{E}=\mathrm{u}_{1}
\end{aligned}
$$


A quinta equação é obtida derivando-se o polinômio uma vez $\left(\mathrm{u}_{\mathrm{ap}}^{\prime}(\mathrm{z})\right)$ e substituindo posteriormente "z" por zero, considerando assim a rotação no topo do elemento, ou seja, na cota $\mathrm{X}_{3}=0$.

Portanto:

$$
\begin{aligned}
& \mathrm{u}_{\mathrm{ap}}^{\prime}(\mathrm{L})=4 \mathrm{z}^{3} \mathrm{~A}+3 \mathrm{z}^{2} \mathrm{~B}+2 \mathrm{zC}+\mathrm{D}=\mathrm{u}_{\mathrm{i}}^{\prime} \\
& \mathrm{p} / \mathrm{z}=0 \rightarrow \mathrm{u}_{\mathrm{ap}}^{\prime}(0)=\mathrm{D}=\mathrm{u}_{\mathrm{i}}^{\prime}
\end{aligned}
$$

Colocando na forma matricial, tem-se:

$$
\left[\begin{array}{ccccc}
0 & 0 & 0 & 0 & 1 \\
0 & 0 & 0 & 1 & 0 \\
\frac{\mathrm{L}^{4}}{81} & \frac{\mathrm{L}^{3}}{27} & \frac{\mathrm{L}^{2}}{9} & \frac{\mathrm{L}}{3} & 1 \\
\frac{16 \mathrm{~L}^{4}}{81} & \frac{8 \mathrm{~L}^{3}}{27} & \frac{4 \mathrm{~L}^{2}}{9} & \frac{2 \mathrm{~L}}{3} & 1 \\
\mathrm{~L}^{4} & \mathrm{~L}^{3} & \mathrm{~L}^{2} & \mathrm{~L} & 1
\end{array}\right]\left\{\begin{array}{l}
\mathrm{A} \\
\mathrm{B} \\
\mathrm{C} \\
\mathrm{D} \\
\mathrm{E}
\end{array}\right\}=\left\{\begin{array}{c}
\mathrm{u}_{\mathrm{i}} \\
\mathrm{u}_{\mathrm{i}}^{\prime} \\
\mathrm{u}_{\mathrm{j}} \\
\mathrm{u}_{\mathrm{k}} \\
\mathrm{u}_{1}
\end{array}\right\}
$$

Esta equação pode ser representada da seguinte forma:

$$
[\mathrm{C}]\{\alpha\}=\left\{\delta_{\mathrm{e}}\right\}
$$

Isolando o vetor $\{\alpha\}$ tem-se:

$$
\{\alpha\}=[C]^{-1}\left\{\delta_{e}\right\}
$$

Portanto:

$$
\begin{aligned}
& \mathrm{u}_{\mathrm{ap}}(\mathrm{z})=\left\{\begin{array}{lllll}
\mathrm{z}^{4} & \mathrm{z}^{3} & \mathrm{z}^{2} & \mathrm{z} & 1
\end{array}\right\}[\mathrm{C}]^{-1}\left\{\delta_{\mathrm{e}}\right\} \\
& \text { ou } \\
& \mathrm{u}_{\mathrm{ap}}(\mathrm{z})=\{\phi\}^{\mathrm{T}}[\mathrm{C}]^{-1}\left\{\delta_{\mathrm{e}}\right\} \\
& \text { e } \\
& \mathrm{u}_{\mathrm{ap}}(\mathrm{z})^{\prime \prime}=\left\{\phi^{\prime \prime}\right\}^{\mathrm{T}}[\mathrm{C}]^{-1}\left\{\delta_{\mathrm{e}}\right\}
\end{aligned}
$$

E admitindo-se que o polinômio aproximador das forças de interface é cúbico, tem-se que:

$$
\mathrm{P}_{\mathrm{X}_{1}}(\mathrm{z})=\mathrm{Az}^{3}+\mathrm{Bz}^{2}+\mathrm{Cz}+\mathrm{D}
$$

Este polinômio pode ser escrito em função dos valores das forças da interface nos pontos de colocação da seguinte forma:

$$
\begin{aligned}
& \mathrm{P}_{\mathrm{X}_{1}}(\mathrm{z})=\phi_{1} \mathrm{P}_{1}+\phi_{2} \mathrm{P}_{2}+\phi_{3} \mathrm{P}_{3}+\phi_{4} \mathrm{P}_{4} \\
& \text { ou } \\
& \mathrm{P}_{\mathrm{X}_{1}}(\mathrm{z})=\{\bar{\phi}\}^{\mathrm{T}}\{\mathrm{P}\}
\end{aligned}
$$


Para esta equação referente ao solo, agora trabalhar-se-ão com funções de forma cúbicas que são mostradas na figura 3.5.
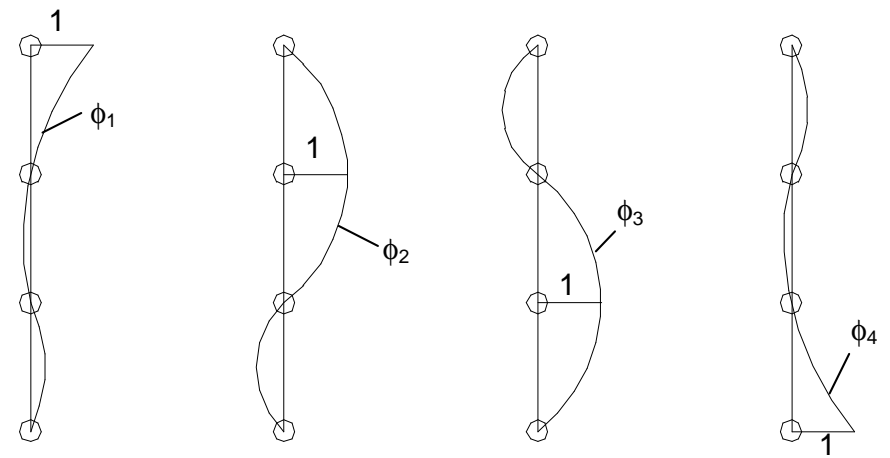

Fig. 3.5 - Elemento contínuo e suas respectivas funções de interpolação $\left(\phi_{1}, \phi_{2}, \phi_{3}\right.$, e $\left.\phi_{4}\right)$

Onde:

$$
\{\bar{\phi}\}=\left\{\begin{array}{l}
\phi_{1} \\
\phi_{2} \\
\phi_{3} \\
\phi_{4}
\end{array}\right\}=\underbrace{\left\{\begin{array}{c}
-4.5 \xi^{3}+9 \xi^{2}-5.5 \xi+1 \\
13.5 \xi^{3}-22.5 \xi^{2}+9 \xi \\
-13.5 \xi^{3}+18 \xi^{2}-4.5 \xi \\
4.5 \xi^{3}-4.5 \xi^{2}+\xi
\end{array}\right\}}_{\text {funções de forma }}
$$

Sabendo-se que:

$\xi=\frac{Z}{L}$, sendo "z" a cota do ponto de colocação e "L" o comprimento total da estaca.

A energia potencial total de uma estrutura é dada pela soma da energia potencial de deformação com a energia potencial do carregamento externo aplicado.

$\Pi=\mathrm{U}+\Omega^{\prime}$

Onde:

U: representa a energia potencial de deformação

$\Omega$ ': representa a energia potencial das cargas externas.

Portanto, para a estaca, pode-se escrever:

$\Pi=\frac{\mathrm{E}_{\mathrm{p}} \mathrm{I}_{\mathrm{p}}}{2} \int_{0}^{\mathrm{L}} \mathrm{u}_{\mathrm{ap}}{ }^{\prime \prime}(\mathrm{z})^{2} \mathrm{dz}+\int \mathrm{P}_{\mathrm{X}_{1}}(\mathrm{z}) \mathrm{u}_{\mathrm{ap}}(\mathrm{z}) \mathrm{dz}-\mathrm{F}_{1} \mathrm{u}_{\mathrm{i}}-\mathrm{M}_{2} \mathrm{u}_{\mathrm{i}}^{\prime}$

onde:

$\mathrm{F}_{1}$ : Força lateral externa aplicada no topo da estaca na direção $X_{1}$;

$\mathrm{M}_{2}$ : Momento externo aplicado no topo da estaca;

e 


$$
\mathrm{u}_{\mathrm{ap}}(\mathrm{z})^{\prime \prime 2}=\left\{\delta_{\mathrm{e}}\right\}^{\mathrm{T}}[\mathrm{C}]^{-\mathrm{T}}\left\{\bar{\phi}^{\prime \prime}\right\}^{\mathrm{T}}\left\{\bar{\phi}^{\prime \prime}\right\}[\mathrm{C}]^{-1}\left\{\delta_{\mathrm{e}}\right\} \mathrm{dz}
$$

Substituindo na expressão da elástica tem-se que:

$$
\Pi=\frac{\mathrm{E}_{\mathrm{p}} \mathrm{I}_{\mathrm{p}}}{2} \int_{0}^{\mathrm{L}}\left\{\delta_{\mathrm{e}}\right\}^{\mathrm{T}}[\mathrm{C}]^{-\mathrm{T}}\left\{\bar{\phi}^{\prime \prime}\right\}^{\mathrm{T}}\left\{\bar{\phi}^{\prime \prime}\right\}[\mathrm{C}]^{-1}\left\{\delta_{\mathrm{e}}\right\} \mathrm{dz}-\left\{\delta_{e}\right\}^{\mathrm{t}}\{\mathrm{F}\}+\int_{0}^{\mathrm{L}}[\phi]^{\mathrm{T}}\{\mathrm{P}\}[\bar{\phi}][\mathrm{C}]^{-1}\left\{\delta_{\mathrm{e}}\right\} \mathrm{dz}(3.28)
$$

Admitindo-se que:

$$
\begin{aligned}
& {\left[\mathrm{K}_{\mathrm{c}}\right]=\frac{\mathrm{E}_{\mathrm{p}} \mathrm{I}_{\mathrm{p}}}{2}[\mathrm{C}]^{-\mathrm{T}}\left[\int_{0}^{\mathrm{L}}\left\{\bar{\phi}^{\prime \prime}\right\}^{\mathrm{T}}\left\{\bar{\phi}^{\prime \prime}\right\} \mathrm{dz}\right][\mathrm{C}]^{-1}} \\
& {[\mathrm{Q}]=\int_{0}^{\mathrm{L}}\{\phi\}^{\mathrm{T}}\{\bar{\phi}\}[\mathrm{C}]^{-1} \mathrm{dz}}
\end{aligned}
$$

Chegando-se finalmente em:

$$
\Pi=\left\{\delta_{\mathrm{e}}\right\}^{\mathrm{t}}\left[\mathrm{K}_{\mathrm{c}}\right]\left\{\delta_{\mathrm{e}}\right\}-\left\{\delta_{e}\right\}^{\mathrm{t}}\{\mathrm{F}\}+\left\{\delta_{e}\right\}^{\mathrm{t}}[\mathrm{Q}]\{\mathrm{P}\}
$$

Minimizando o funcional de energia potencial total, ou seja, derivando-se a equação 3.31 em função dos parâmetros nodais e igualando-se a zero, obtém-se o seguinte sistema de equações:

$$
\left[\mathrm{K}_{\mathrm{c}}\right]\left\{\delta_{\mathrm{e}}\right\}=\{\mathrm{F}\}-[\mathrm{Q}][\mathrm{P}\}
$$

Onde:

$$
\begin{aligned}
& {\left[\mathrm{K}_{\mathrm{c}}\right]=\frac{\mathrm{E}_{\mathrm{p}} \mathrm{I} \mathrm{p}}{40 \mathrm{~L}^{3}}\left[\begin{array}{ccccc}
23722 & 4084 \mathrm{~L} & -42876 & 26838 & -7684 \\
4084 \mathrm{~L} & 808 \mathrm{~L}^{2} & -6912 \mathrm{~L} & 3996 \mathrm{~L} & -1168 \mathrm{~L} \\
-42876 & -6912 \mathrm{~L} & 81648 & -55404 & 16632 \\
26838 & 3996 \mathrm{~L} & -55404 & 42282 & -13716 \\
-7684 & -1168 \mathrm{~L} & 16632 & -13716 & 4768
\end{array}\right]} \\
& {[\mathrm{Q}]=\frac{\mathrm{L}}{6720}\left[\begin{array}{cccc}
721 & 495 & -45 & 285 \\
38 \mathrm{~L} & 18 \mathrm{~L} & 18 \mathrm{~L} & 38 \mathrm{~L} \\
54 & 2430 & -486 & -486 \\
27 & -243 & 2673 & 567 \\
38 & -162 & 378 & 474
\end{array}\right]}
\end{aligned}
$$

Os demais termos do sistema (3.31) são descritos a seguir:

$$
\begin{aligned}
& \left\{\delta_{\mathrm{e}}\right\}^{\mathrm{T}}=\left\{\begin{array}{lllll}
\mathrm{u}_{\mathrm{i}} & \mathrm{u}_{\mathrm{i}}^{\prime} & \mathrm{u}_{\mathrm{j}} & \mathrm{u}_{\mathrm{k}} & \mathrm{u}_{1}
\end{array}\right\}=\left\{\mathrm{u}_{\mathrm{p}}\right\}^{\mathrm{T}} \\
& \{\mathrm{F}\}^{\mathrm{T}}=\left\{\begin{array}{lllll}
\mathrm{F}_{1} & \mathrm{M}_{1} & 0 & 0 & 0
\end{array}\right\} \\
& \{\mathrm{P}\}^{\mathrm{T}}=\left\{\begin{array}{llll}
\mathrm{P}_{1} & \mathrm{P}_{2} & \mathrm{P}_{3} & \mathrm{P}_{4}
\end{array}\right\}
\end{aligned}
$$

Com base nas deduções anteriores, pode ser feita agora a interação MEC/MEF. 
Para que haja compatibilidade entre as matrizes e vetores dos dois métodos é necessário que seja feita a expansão dos que possuírem menor ordem. Este procedimento será descrito a seguir.

Da equação geral de deslocamentos do MEC (eq. 3.6), tem-se que a equação do solo é:

$\left\{u_{s}\right\}_{4 \times 1}=[G]_{4 \times 4}\left\{P_{s}\right\}_{4 \times 1}$

onde,

$\left\{\mathrm{u}_{\mathrm{S}}\right\}_{4 \times 1}$ : representa apenas os deslocamentos laterais no solo;

$\left\{\mathrm{P}_{\mathrm{s}}\right\}$ : é o vetor de forças de interação;

[G]: é a matriz de coeficientes de influência nos deslocamentos do solo.

A equação da estaca como citado anteriormente, é a seguinte:

$\left[\mathrm{K}_{\mathrm{c}}\right]_{5 \times 5}\left\{\mathrm{u}_{\mathrm{p}}\right\}_{5 \times 1}=\{\mathrm{F}\}_{5 \times 1}-[\mathrm{Q}]_{5 \times 4}\left\{\mathrm{P}_{\mathrm{p}}\right\}_{4 \times 1}$

onde,

$\left\{u_{p}\right\}$ : é o vetor de deslocamentos na estaca composto por todos os nós do elemento finito;

$\left\{\mathrm{P}_{\mathrm{p}}\right\}$ : é o vetor de forças de interação composto por todos os nós do elemento de finito;

$\left[\mathrm{K}_{\mathrm{c}}\right]$ : é a matriz de rigidez da estaca;

[Q]: é a matriz de transformação;

$\{F\}$ : é o vetor de carregamentos externos (forças nodais equivalentes).

Colocando a equação do solo em função das forças de interação, obtém-se:

$\left\{P_{s}\right\}_{4 \times 1}=[G]_{4 \times 4}^{-1}\left\{u_{s}\right\}_{4 \times 1}$

Levando-se em consideração as condições de compatibilidade de deslocamentos e de equilíbrio ao longo da interface estaca-meio contínuo, isto é:

$\left\{u_{s}\right\}=\left\{u_{p}\right\}$

$\mathrm{e}$

$\left\{\mathrm{P}_{\mathrm{s}}\right\}+\left\{\mathrm{P}_{\mathrm{p}}\right\}=0$

Pode-se substituir na equação proveniente do MEF, ou seja: 


$$
\left[\mathrm{K}_{\mathrm{c}}\right]_{5 \times 5}\left\{\mathrm{u}_{\mathrm{p}}\right\}_{5 \times 1}=\{\mathrm{F}\}_{5 \times 1}-[\mathrm{Q}]_{5 \times 4}[\mathrm{G}]_{4 \times 4}^{-1}\left\{\mathrm{u}_{\mathrm{s}}\right\}_{4 \times 1}
$$

Onde:

$$
[\mathrm{Q}]_{5 \times 4}[\mathrm{G}]_{4 \times 4}^{-1}=[\mathrm{M}]_{5 \times 4}
$$

Existe agora a necessidade de se expandir a matriz [M] para se obter a mesma ordem da matriz $\left[\mathrm{K}_{\mathrm{c}}\right.$. Para isso é colocada uma coluna de zeros na matriz [M] referente a não consideração da rotação pelo solo, resultando em:

$$
\therefore[\bar{M}]=\left[\begin{array}{lllll}
\mathrm{m}_{11} & 0 & \mathrm{~m}_{13} & \mathrm{~m}_{14} & \mathrm{~m}_{15} \\
\mathrm{~m}_{21} & 0 & \mathrm{~m}_{23} & \mathrm{~m}_{24} & \mathrm{~m}_{25} \\
\mathrm{~m}_{31} & 0 & \mathrm{~m}_{33} & \mathrm{~m}_{34} & \mathrm{~m}_{35} \\
\mathrm{~m}_{41} & 0 & \mathrm{~m}_{43} & \mathrm{~m}_{44} & \mathrm{~m}_{45} \\
\mathrm{~m}_{51} & 0 & \mathrm{~m}_{53} & \mathrm{~m}_{54} & \mathrm{~m}_{55}
\end{array}\right]_{5 X 5}
$$

Conseqüentemente, aumenta-se também o vetor de deslocamentos da equação do solo, tendo-se:

$$
\left\{u_{s}\right\}=\left\{\begin{array}{lllll}
u_{i} & u_{i}^{\prime} & u_{j} & u_{k} & u_{1}
\end{array}\right\}
$$

Da compatibilidade de deslocamentos, isto é:

$\left\{u_{s}\right\}=\left\{u_{p}\right\}=\{\bar{U}\}$, tem-se que:

$\left[\left[\mathrm{K}_{\mathrm{c}}\right]_{5 \times 5}+[\overline{\mathrm{M}}]_{5 \times 5}\right]\{\overline{\mathrm{U}}\}_{5 \times 1}=\{\mathrm{F}\}_{5 \times 1}$

Finalizando:

$[\overline{\mathrm{K}}]_{5 \times 5}\{\overline{\mathrm{U}}\}_{5 \times 1}=\{\mathrm{F}\}_{5 \times 1}$

sendo,

$[\overline{\mathrm{K}}]_{5 \times 5}$ : a matriz final do sistema de interação (MEC/MEF);

$\{\overline{\mathrm{U}}\}_{5 \times 1}$ : o vetor que engloba todos os deslocamentos considerados no sistema, inclusive a rotação;

$\{\mathrm{F}\}_{5 \times 1}$ : o vetor de cargas externas aplicadas no topo da estaca (força horizontal concentrada e Momento fletor). 


\subsection{3) Avaliações dos Modelos}

A seguir serão apresentados exemplos numéricos analisados com as formulações apresentadas anteriormente e comparados com ensaios experimentais realizados por KÉRISEL \& ADAM (1967) e um modelo proposto por VALLABHAN \& SIVAKUMAR (1986), sendo os dois citados no trabalho de FERRO (1993).

Além disso também serão feitas comparações com algumas formulações análogas desenvolvidas durante este trabalho, que para evitar um processo repetitivo, não foram aqui apresentadas.

\section{a) Exemplo 1}

A figura 3.6 mostra uma estaca de 6,096 m de comprimento, com diâmetro igual a 0,6096 m e submetida a uma carga horizontal de 181,60 kN aplicada na direção $X_{1}$ e um momento em torno do eixo $X_{2}$ de $-95,826 \mathrm{kN} . \mathrm{m}$, atuando separadamente. O módulo de Young da estaca é admitido como sendo $21111000 \mathrm{kN} / \mathrm{m}^{2}$ e a relação entre os módulos do solo e da estaca igual a 100 $\left(\mathrm{k}=\frac{\mathrm{E}_{\text {estaca }}}{\mathrm{E}_{\text {solo }}}\right)$. O coeficiente de Poisson do solo é igual a 0,2.

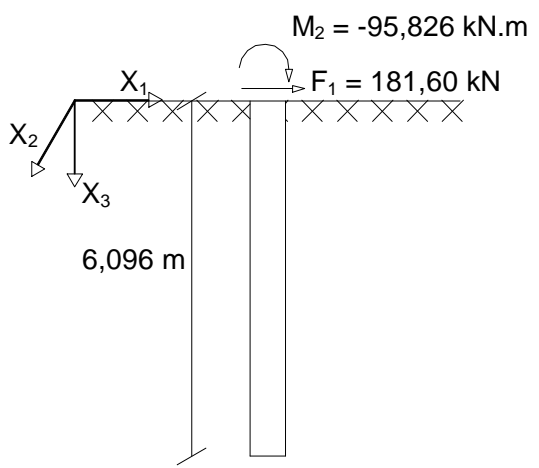

Fig. 3.6 - Figura adaptada de FERRO (1993) - Estaca em meio semi-infinito sujeita a uma carga horizontal e a um momento.

Os deslocamentos obtidos com a formulação de Poulos Modificada e os obtidos por Vallabhan \& Sivakumar estão indicados nas figuras 3.7a e 3.7b, indicando uma coerência existente entre as formulações. 


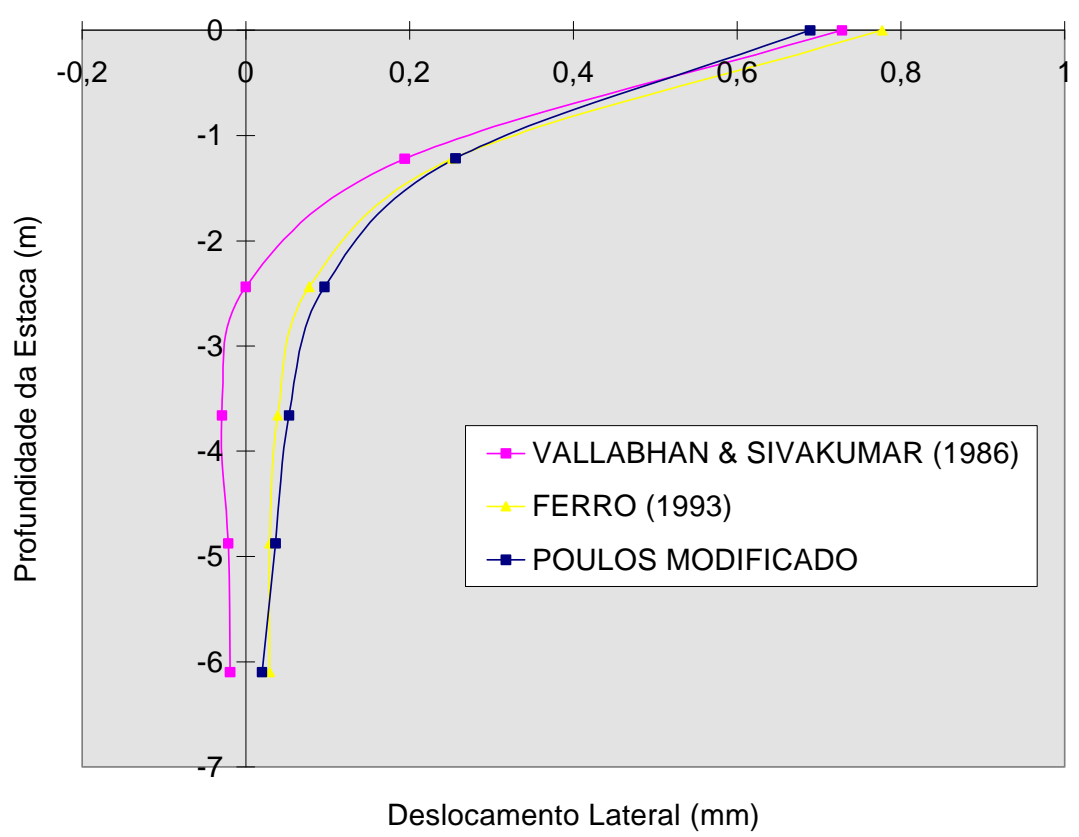

Fig. 3.7a) - Deslocamento horizontal devido a carga de 181,60 kN.

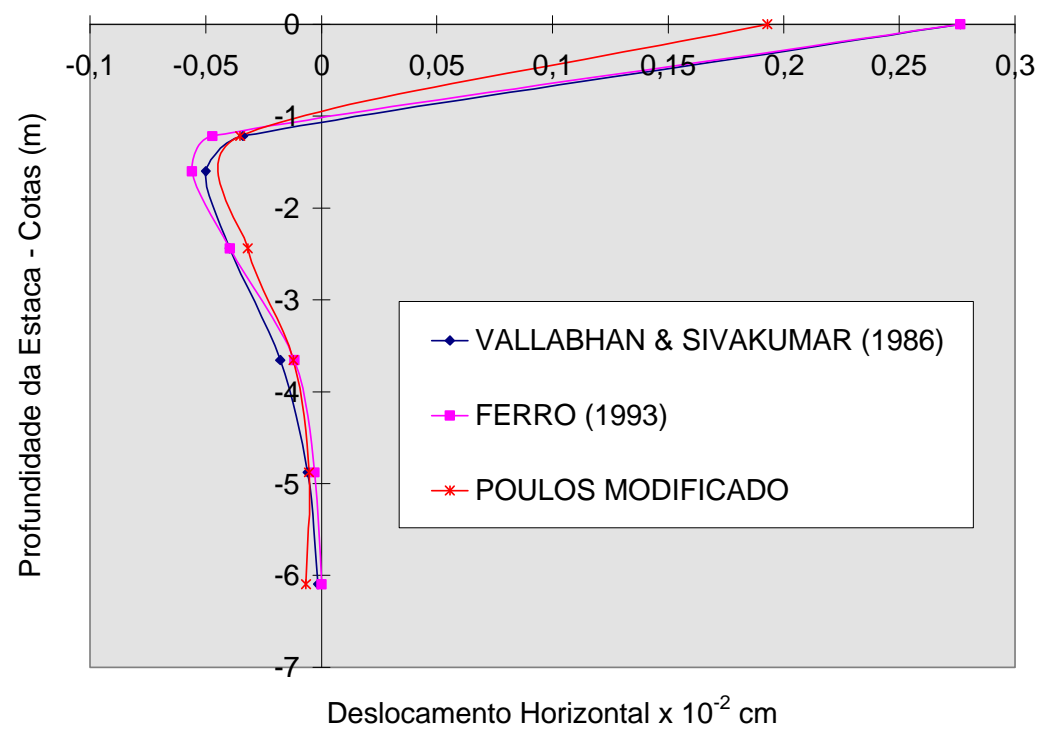

Fig. 3.7b) - Deslocamento horizontal devido ao momento de $-95,826$ kN.m.

\section{b) Exemplo 2}

Em 1967, Kérisel \& Adam, realizaram um ensaio para estaca cravada em solo argiloso, com comprimento de $4,65 \mathrm{~m}$ e diâmetro equivalente de 0,3573 m, submetida a uma carga horizontal $F_{1}=60 \mathrm{kN}$ e a um momento $M_{2}=-69 \mathrm{kN} \cdot \mathrm{m}$. $O$ módulo de elasticidade longitudinal da estaca é igual a $2,0 e+7 \mathrm{kN} / \mathrm{m}^{2}$, e o do solo 
(determinado experimentalmente, com base na média dos três primeiros metros) é igual a $9233 \mathrm{kN} / \mathrm{m}^{2}$ e $v_{\mathrm{s}}$ é igual a 0,3. Valores estes também assumidos por FERRO (1993) aqui usados com o objetivo de comparações de resultados.

A figura 3.8 apresenta os deslocamentos laterais ao longo da estaca constatando-se uma concordância entre os valores medidos e os calculados.

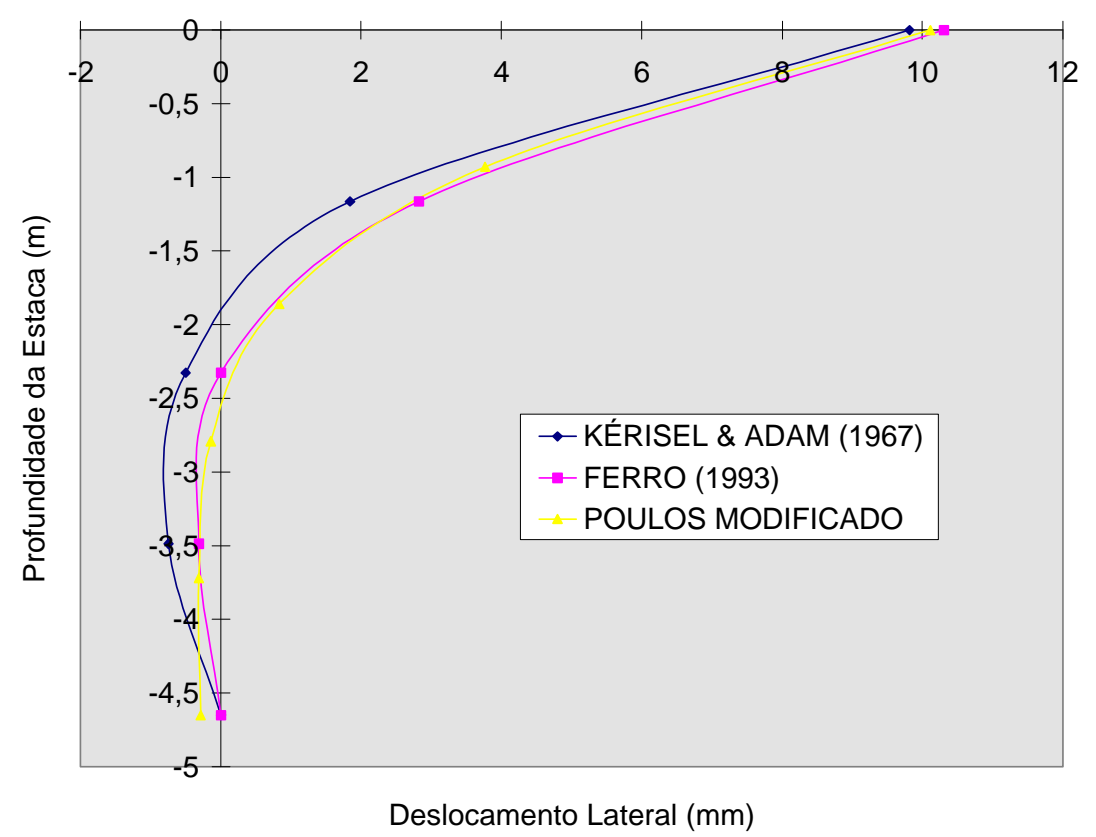

Fig. 3.8 - Deslocamento horizontal na direção $X_{1}$ ao longo da estaca.

\section{c) Exemplo 3}

Neste exemplo (idem à 3.4.3a) observa-se o comportamento da estaca discretizada em elementos finitos com 5 parâmetros nodais e função de forma das forças de interface cúbica (MEF_5PAR_FÇ3ํำ. Percebe-se nas figuras à seguir que houve uma melhora nos resultados devido ao refinamento feito nas forças de interface, mas ocorre uma discrepância significativa com relação ao deslocamentos laterais, quando se aplica somente um momento na cabeça da estaca. Um dos problemas que pode ter causado esta inconsistência é a consideração do parâmetro de rotação apenas no topo da estaca. 


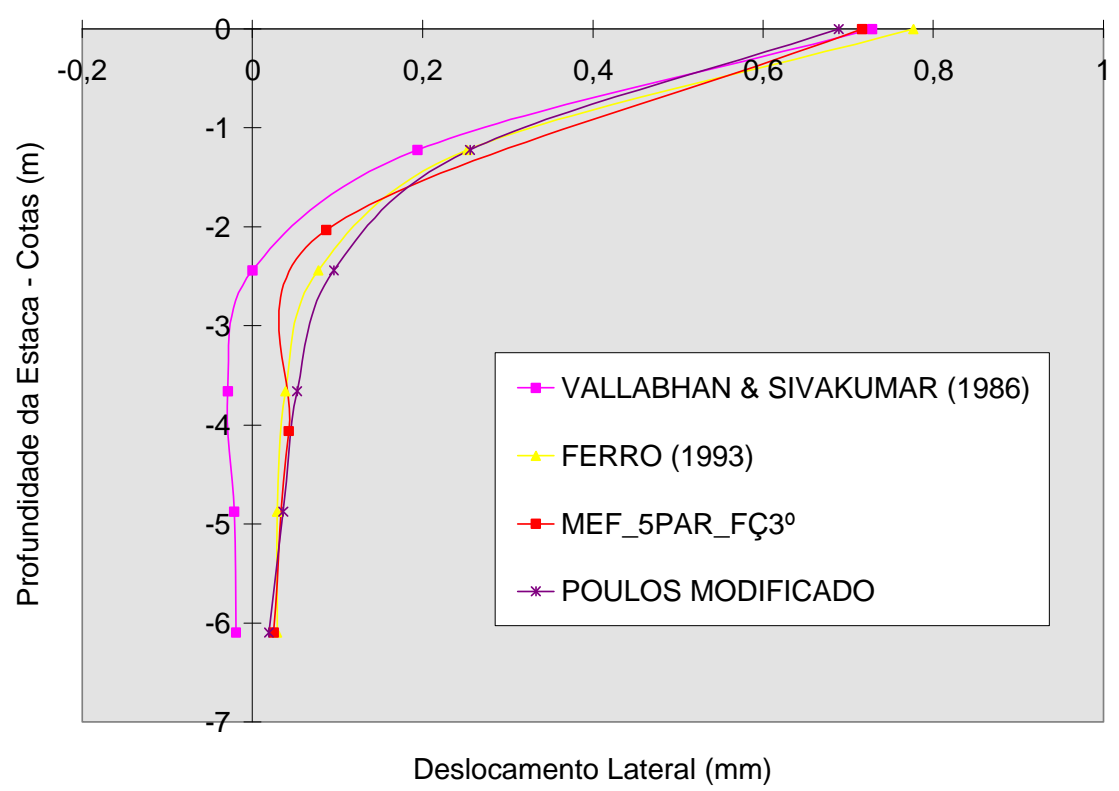

Fig. 3.9a) - Deslocamento Horizontal devido a carga de 181,60 kN.

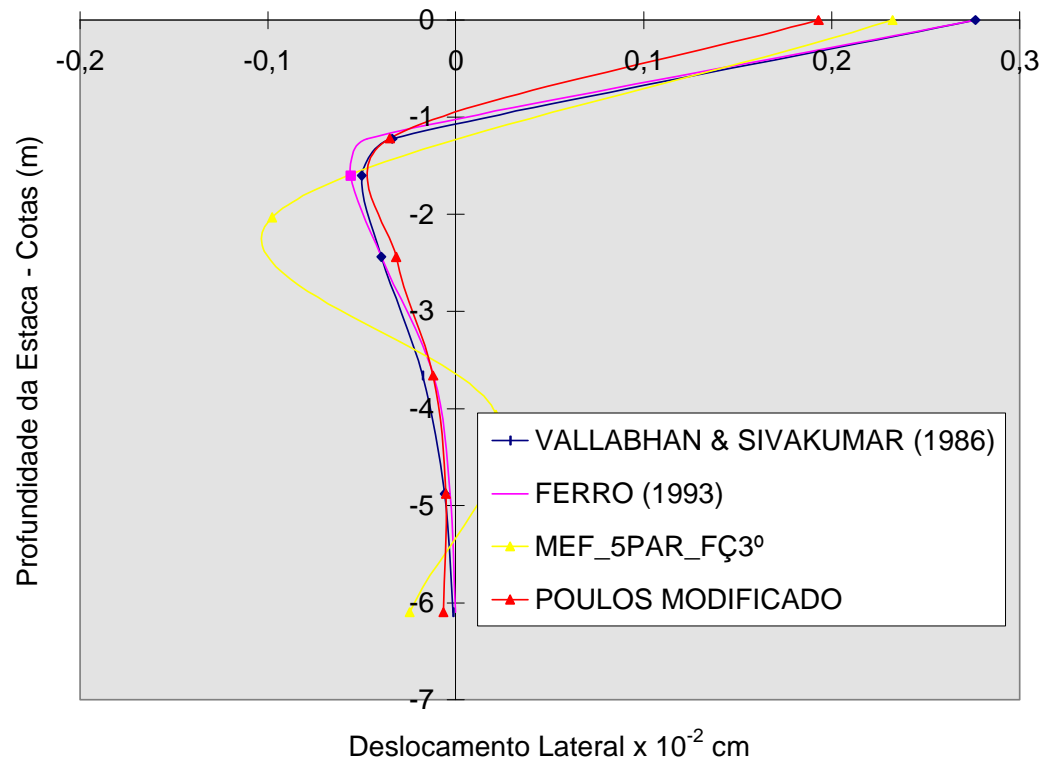

Fig. 3.9b) - Deslocamento horizontal devido ao momento de $-95,826$ kN.m

\section{d) Exemplo 4}

O mesmo comportamento apresentado no exemplo $3.4 .3 \mathrm{~b}$, pode ser observado na figura 3.10, para o caso de uma estaca com 5 parâmetros nodais e funções de formas cúbicas. 


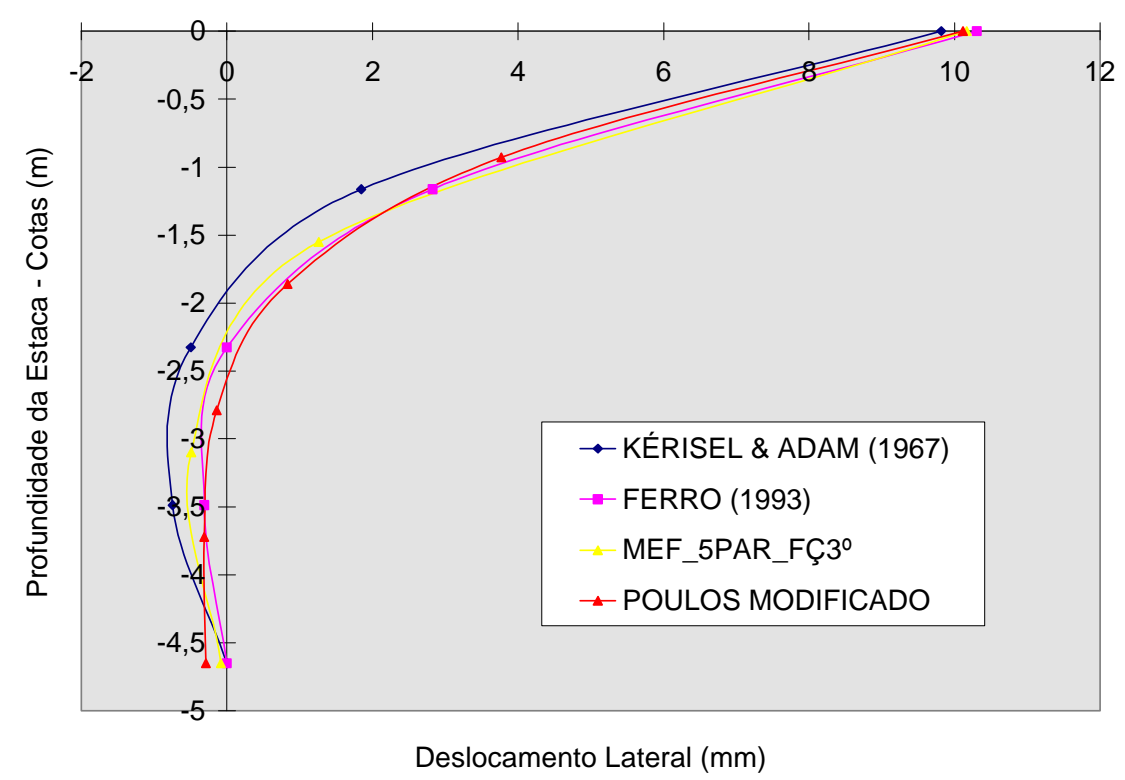

Fig. 3.10 - Deslocamento horizontal na direção $X_{1}$ ao longo da estaca.

\section{e) Exemplo 5}

Visto que este modelo anterior (MEF_5PAR_FÇ3ํํ) será futuramente utilizado na extensão do método, um exemplo apresentado em POULOS (1980), que obteve o deslocamento horizontal no topo da estaca para vários comprimentos desta. Na figura 3.11 é apresentada a análise de uma estaca de concreto com topo livre e diâmetro igual a 1 pé, em condições puramente elásticas e sujeita somente a um carregamento horizontal unitário. Adotou-se para este exemplo a resistência característica do concreto de $18 \mathrm{MPa}$. Além desses modelos também será apresentado a combinação MEC/MDF adaptada de Poulos (seção 3.4.1).

Percebe-se na figura 3.11 que para solos moles, uma rápida redução nos deslocamentos ocorre com o aumento do comprimento até aproximadamente um comprimento de 30 pés. Acima desta medida verifica-se que os movimentos diminuem mais lentamente (intervalo entre 30 e 55 pés) ou quase nem se alteram (acima de 55 pés), sendo estes resultados consistentes com o conceito de comprimento efetivo, freqüentemente empregado na teoria de reação de base (POULOS, 1980). 


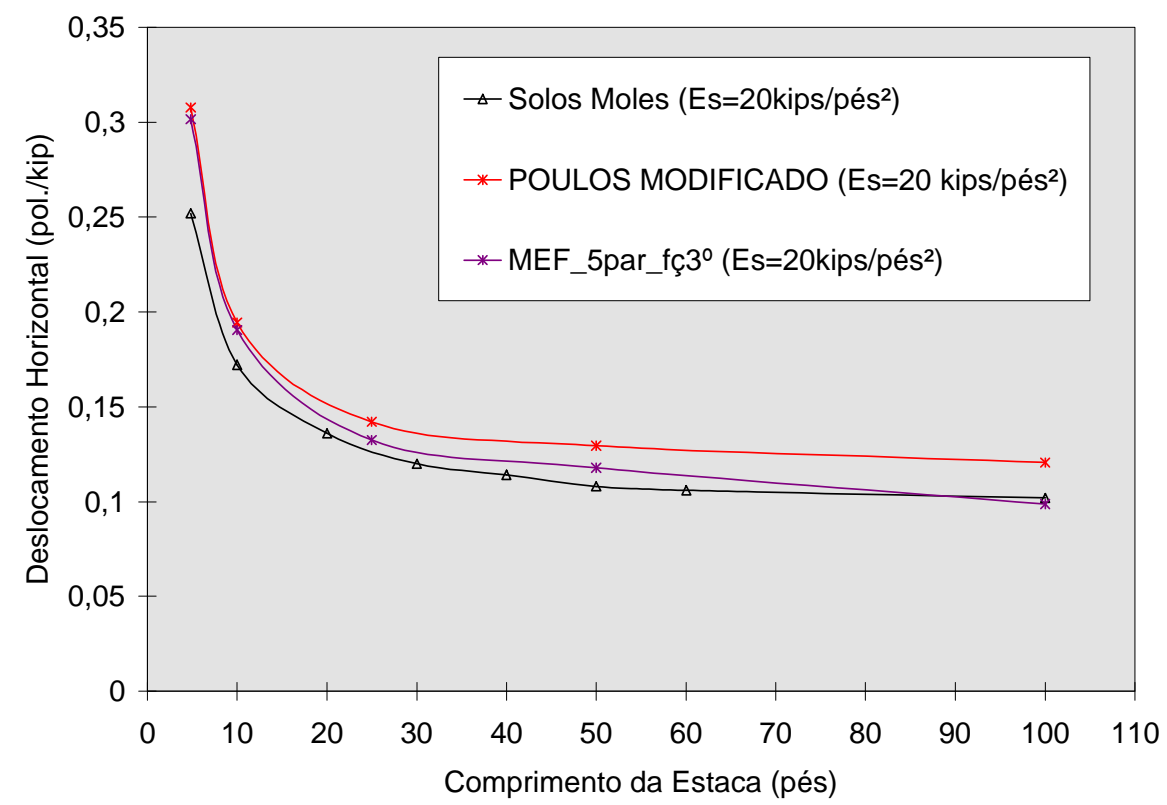

Fig. 3.11 - Influência do comprimento da estaca e do módulo do solo no deslocamento da estaca.

\section{f) Exemplo 6}

Neste exemplo admitiu-se a estaca discretizada em 4 parâmetros nodais sendo todos referentes à deslocamentos laterais e com forças de interação constantes (MEF_4PAR_FÇ_CTE). Este método assim como os posteriores citados nos exemplos subseqüentes não serão descritos, pois podem ser obtidos de forma análoga ao método descrito no item 3.4.2.

Repetindo-se aqui o exemplo da seção (3.4.3a) verifica-se também a obtenção de bons resultados no que diz respeito somente ao carregamento lateral externo como mostra a figura 3.12, mas devido a não consideração do momento o método necessita de ser otimizado. 


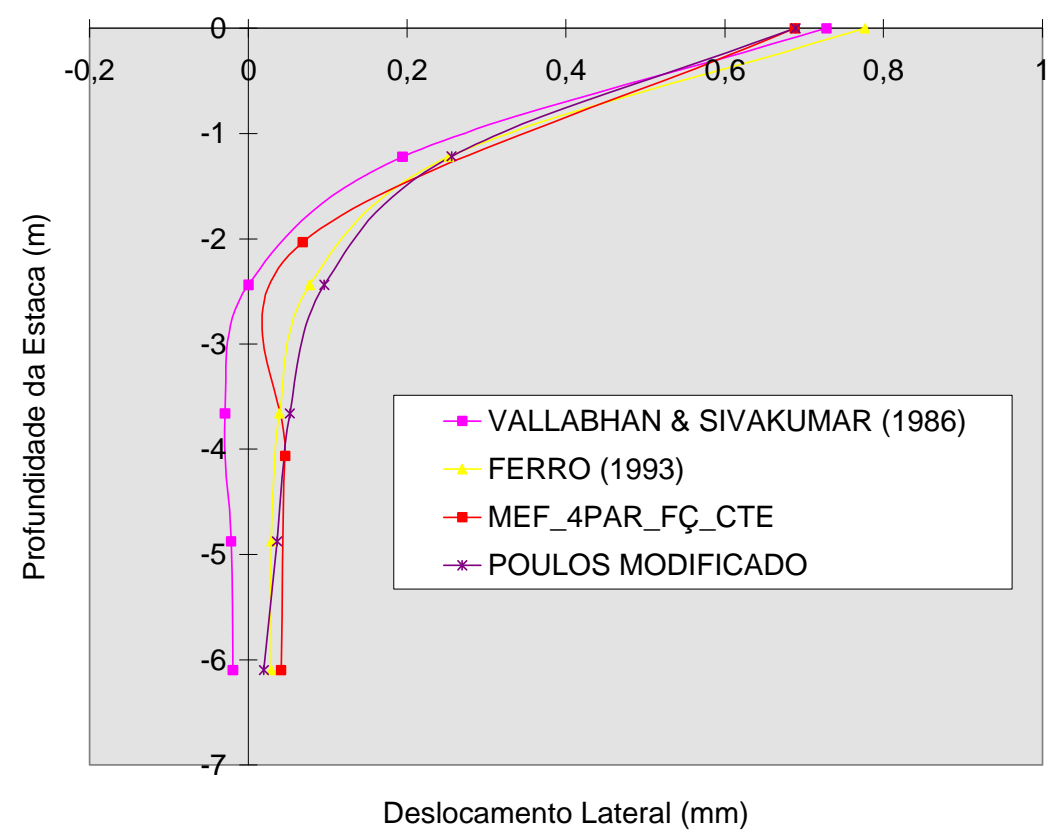

Fig. 3.12 - Deslocamento horizontal devido a carga de 181,60 kN.

\section{g) Exemplo 7}

Um modelo comparativo com relação ao citado anteriormente (seção 3.4.3.f), foi desenvolvido, mas utilizando-se agora de funções de forma cúbicas (MEF_4PAR_FÇ3ํ) mostrando uma melhora nos resultados no que diz respeito somente ao carregamento lateral.

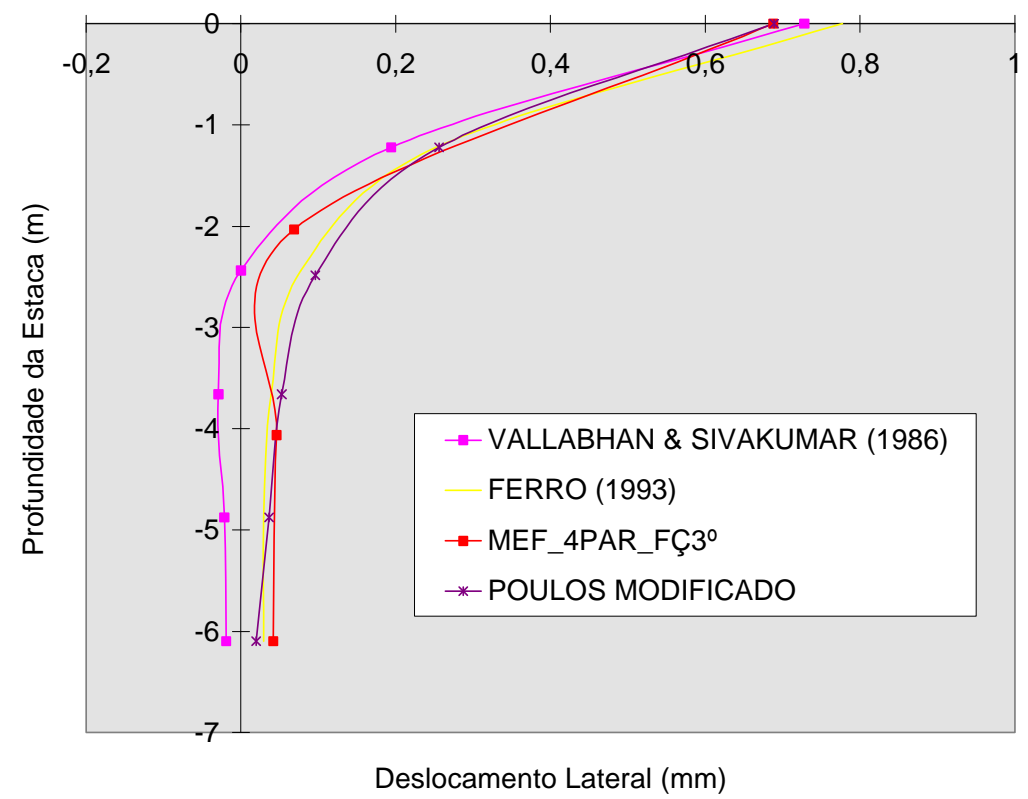

Fig. 3.13 - Deslocamento horizontal devido a carga de 181,60 kN. 


\section{h) Exemplo 8}

O exemplo apresentado aqui, é idêntico ao apresentado no item (3.4.3a), mas agora admitindo-se um modelo discretizado com 5 parâmetros nodais sendo quatro deslocamentos horizontais ao longo da estaca e uma rotação no topo (idem 3.4.2) e forças de interação constantes (MEF_5PAR_FÇ_CTE).

O gráfico (fig. 3.14) mostrado a seguir representa os deslocamentos e 0 comportamento da estaca sob um carregamento lateral.

Observa-se uma diminuição dos deslocamentos na cabeça da estaca provavelmente ocasionada da consideração dos coeficientes de rotação (fig. 3.14a).

Também é mostrado uma discrepância na figura 3.14b (salvo o ponto de colocação no topo da estaca), provavelmente devido a não consideração das parcelas de rotação correspondentes aos demais pontos da estaca.

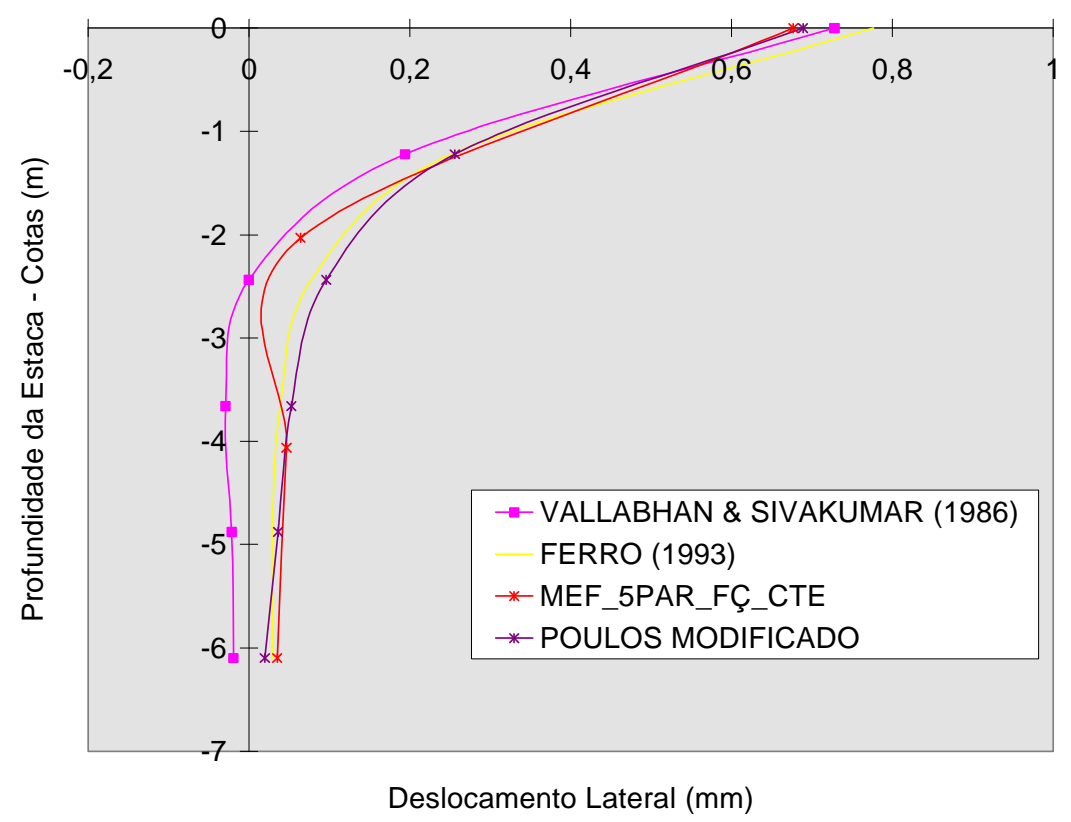

Fig. 3.14a) - Deslocamento Horizontal devido a carga de 181,60 kN. 


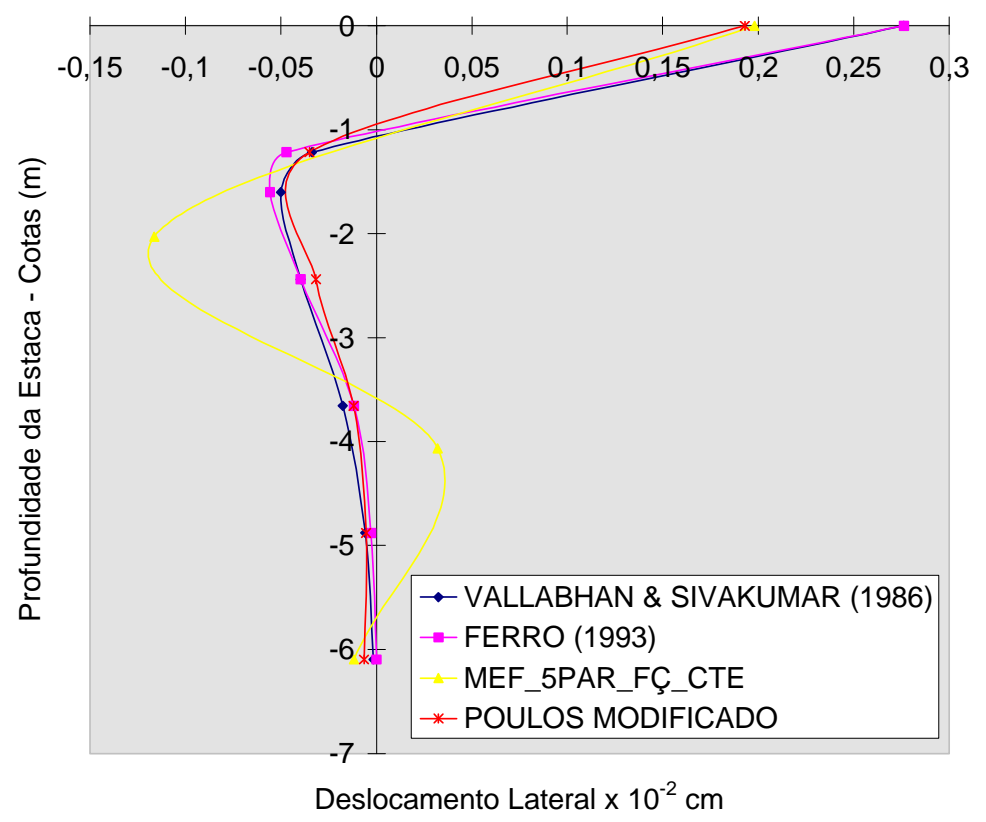

3.14b) - Deslocamento horizontal devido ao momento de $-95,826$ kN.m.

\section{i) Exemplo 9}

Neste exemplo (idem ao exemplo da seção 3.4.3b) é apresentada na figura 3.15 o comportamento da estaca sob ação de uma força lateral e um momento fletor. Obtendo-se também para este caso resultados compatíveis com relação aos analisados anteriormente por Kérisel \& Adam (1967) e Ferro (1993).

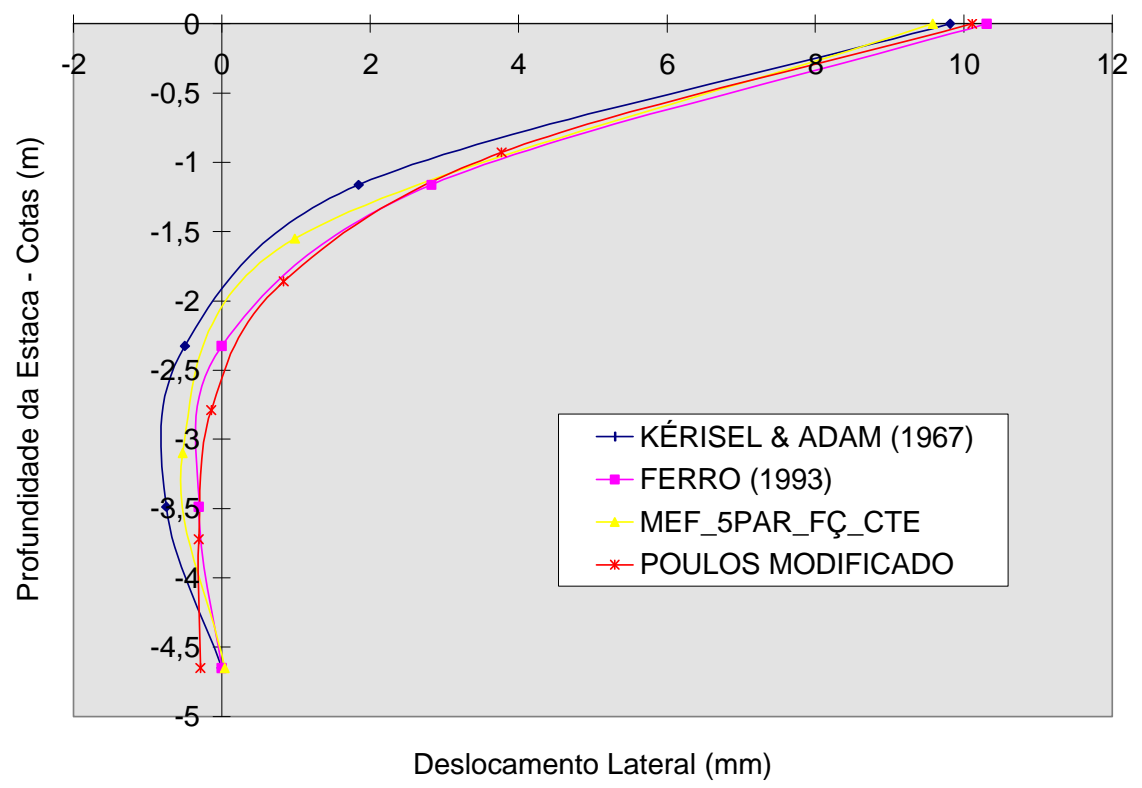

Fig. 3.15 - Deslocamento horizontal devido a uma carga lateral (60 kN) na direção $\mathrm{X}_{1}$ e um momento $(-69 \mathrm{kN} . \mathrm{m})$ em torno de $\mathrm{X}_{2}$. 


\section{j) Exemplo 10}

Como já citado anteriormente, aqui será apresentado novamente o exemplo de VALLABHAN \& SILVAKUMAR (1986). Para este exemplo utilizou-se um modelo constituído por cinco parâmetros nodais de deslocamentos laterais e forças de interação aproximadas por um polinômio do quarto grau (MEF_5PAR_FÇ4º).

Concluiu-se que para este caso o modelo converge muito bem com relação aos resultados obtidos pelos outros modelos. A figura 3.16 mostra o desempenho do modelo aqui avaliado quando comparado com os demais.

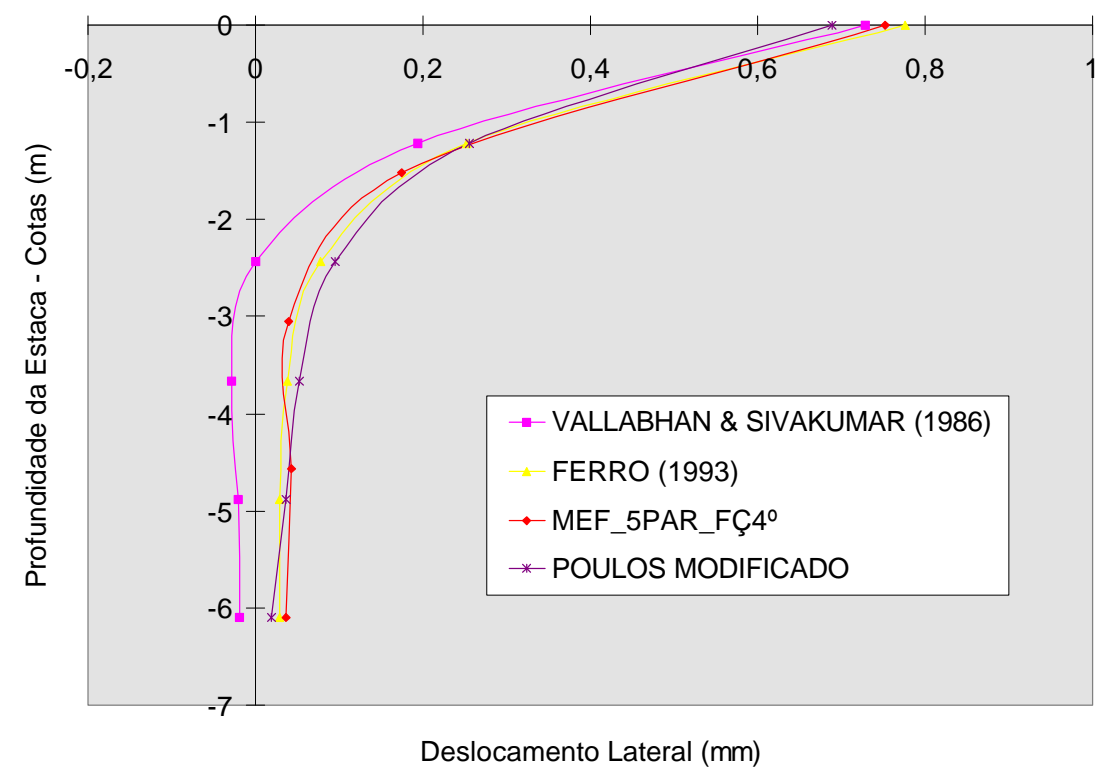

Fig. 3.16 - Deslocamento horizontal devido a carga de 181,60 kN.

\section{k) Exemplo 11}

O exemplo apresentado aqui é semelhante ao do item 3.4.3a. Sendo que no presente caso, o modelo é discretizado em 6 pontos de colocação igualmente espaçados ao longo da estaca e tendo cada um deles um parâmetro nodal de deslocamento horizontal. As forças da interface estaca solo foram aproximadas por um polinômio de grau cinco (MEF_6PAR_FÇ5ํㅜ).

Este modelo levou também à resultados coerentes e mostrou que quase não há discrepância e/ou distorções ao longo da estaca quando se aumentam os pontos de colocação (conseqüentemente aumentando o grau do polinômio). 


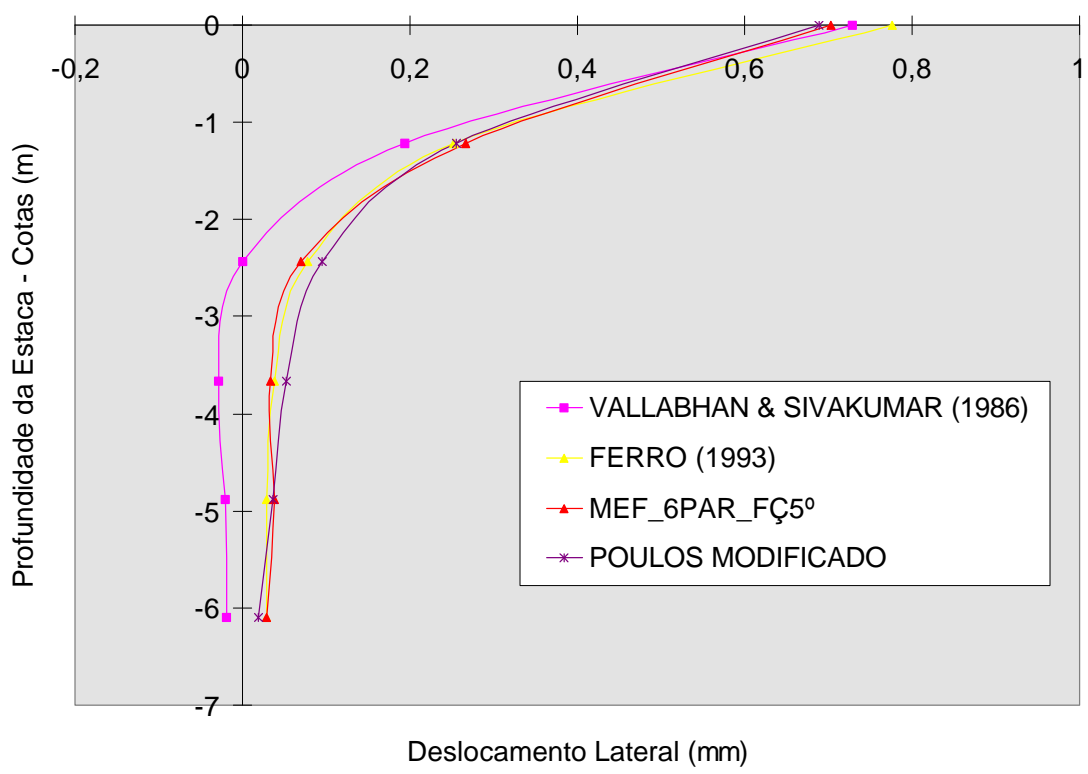

Fig. 3.17 - Deslocamento horizontal devido a carga de 181,60 kN. 


\section{CAPÍTULO 4}

\section{GRUPOS DE ESTACAS VERTICAIS SUBMETIDOS À CARREGAMENTOS LATERAIS EM DUAS DIREÇÕES}

\section{1) Introdução}

Neste capítulo, a formulação desenvolvida para a análise elástica em estacas isoladas, será estendida para o estudo de grupos de estacas.

Com base no método citado no item 3.4.2 agora serão colocadas forças externas horizontais na duas direções $\left(X_{1}\right.$ e $\left.X_{2}\right)$ e também momentos fletores em torno desses dois eixos. Este modelo (seção 3.4.2) foi escolhido porque além de conduzir a bons resultados levando em consideração a rotação na cabeça da estaca, possuir somente quatro pontos de colocação (e funções de forma cúbicas) facilitando assim a posterior implementação de todas estas características no programa PILE desenvolvido por MENDONÇA (1997) que também considerou a estaca como um único elemento com quatro pontos nodais.

Finalizando este capítulo serão colocados blocos de capeamento rígido sobre grupos de estacas, simulando assim a utilização de placa rígida ("radier estaqueado"), onde serão permitidas as imposições de condições de contorno no topo de todas as estacas.

Todos os modelos apresentados aqui serão exemplificados numericamente podendo assim obter-se conclusões sobre os resultados encontrados e a validade do método.

\section{2) Estacas Carregadas em Duas direções}

Primeiramente será descrita a teoria para estacas isoladas com carregamentos horizontais em duas direções, sendo depois estendida para grupos de estacas.

Aqui será feita a combinação do MEC com o MEF para um elemento (estaca) com 10 parâmetros nodais independentes 5 à 5 como mostra a figura 4.1. 


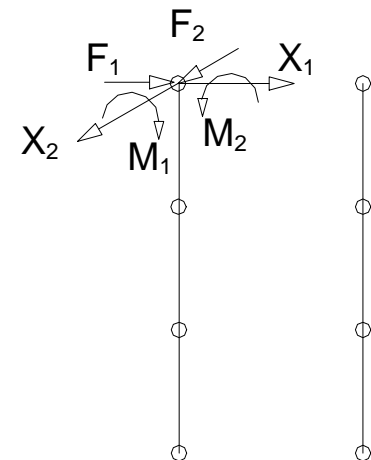

\begin{tabular}{l|ll}
$\mathrm{X}_{3}$ & $(\mathrm{a}) \quad(\mathrm{b})$
\end{tabular}

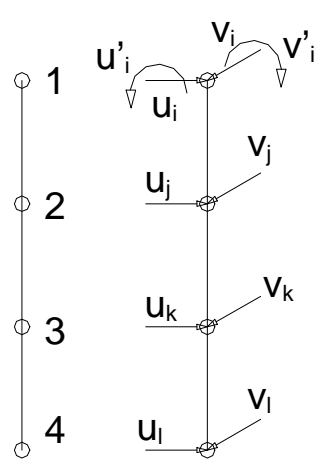

(c)

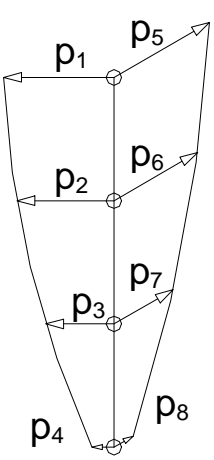

(d)

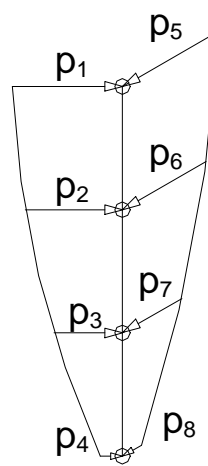

(e)

Fig. 4.1 - Discretização do Problema; a) Cargas externas aplicadas no topo da estaca; b) Pontos de colocação da estaca; c) Parâmetros nodais do elemento nas duas direções; d) Forças da interface agindo no elemento; e) Forças da interface agindo no solo.

O polinômio aproximador de deslocamentos para as duas direções será o mesmo, isto é:

$$
\mathrm{u}_{\mathrm{ap}}(\mathrm{z})=\mathrm{v}_{\mathrm{ap}}(\mathrm{z})=\mathrm{Az}^{4}+\mathrm{Bz}^{3}+\mathrm{Cz}^{2}+\mathrm{Dz}+\mathrm{E}
$$

e para as rotações:

$$
\mathrm{u}_{\mathrm{ap}}{ }^{\prime}(\mathrm{z})=\mathrm{v}_{\mathrm{ap}}{ }^{\prime}(\mathrm{z})=4 \mathrm{Az}^{3}+3 \mathrm{Bz}^{2}+2 \mathrm{Cz}+\mathrm{D}
$$

Como as forças de interação são aproximadas por um polinômio cúbico (para as duas direções também), essas forças são modeladas da seguinte forma:

$$
\mathrm{P}_{\mathrm{X}_{1}}(\mathrm{z})=\mathrm{P}_{\mathrm{X}_{2}}(\mathrm{z})=\mathrm{A}_{1} \mathrm{z}^{3}+\mathrm{B}_{1} \mathrm{z}^{2}+\mathrm{C}_{1} \mathrm{z}+\mathrm{D}_{1}
$$

Pelo método da energia potencial total, obtém-se que:

$$
\begin{aligned}
\Pi_{\mathrm{ap}}= & \frac{\mathrm{E}_{\mathrm{p}} \mathrm{I}_{\mathrm{p}}}{2} \int_{0}^{\mathrm{L}} \mathrm{u}_{\mathrm{ap}}^{\prime \prime}(\mathrm{z})^{2} \mathrm{dz}+\frac{\mathrm{E}_{\mathrm{p}} \mathrm{I}_{\mathrm{p}}}{2} \int_{0}^{\mathrm{L}} \mathrm{v}_{\mathrm{ap}}^{\prime \prime}(\mathrm{z})^{2} \mathrm{dz}+\int_{0}^{\mathrm{L}} \mathrm{P}_{\mathrm{X}_{1}}(\mathrm{z}) \mathrm{u}_{\mathrm{ap}}(\mathrm{z}) \mathrm{dz}+ \\
& +\int_{0}^{\mathrm{L}} \mathrm{P}_{\mathrm{X}_{2}}(\mathrm{z}) \mathrm{v}_{\mathrm{ap}}(\mathrm{z}) \mathrm{dz}-\mathrm{F}_{1} \mathrm{u}_{1}-\mathrm{F}_{2} \mathrm{v}_{1}-\mathrm{M}_{2} \mathrm{u}_{1}^{\prime}-\mathrm{M}_{1} \mathrm{v}_{1}^{\prime}
\end{aligned}
$$

Na determinação da matriz de rigidez [Kc], tem-se já determinados os seus coeficientes (eq. 3.33), havendo apenas algumas alterações nos sinais de alguns termos referentes à direção $X_{2}$ devido a rotação em torno de $X_{1}$ ser positiva, portanto: 


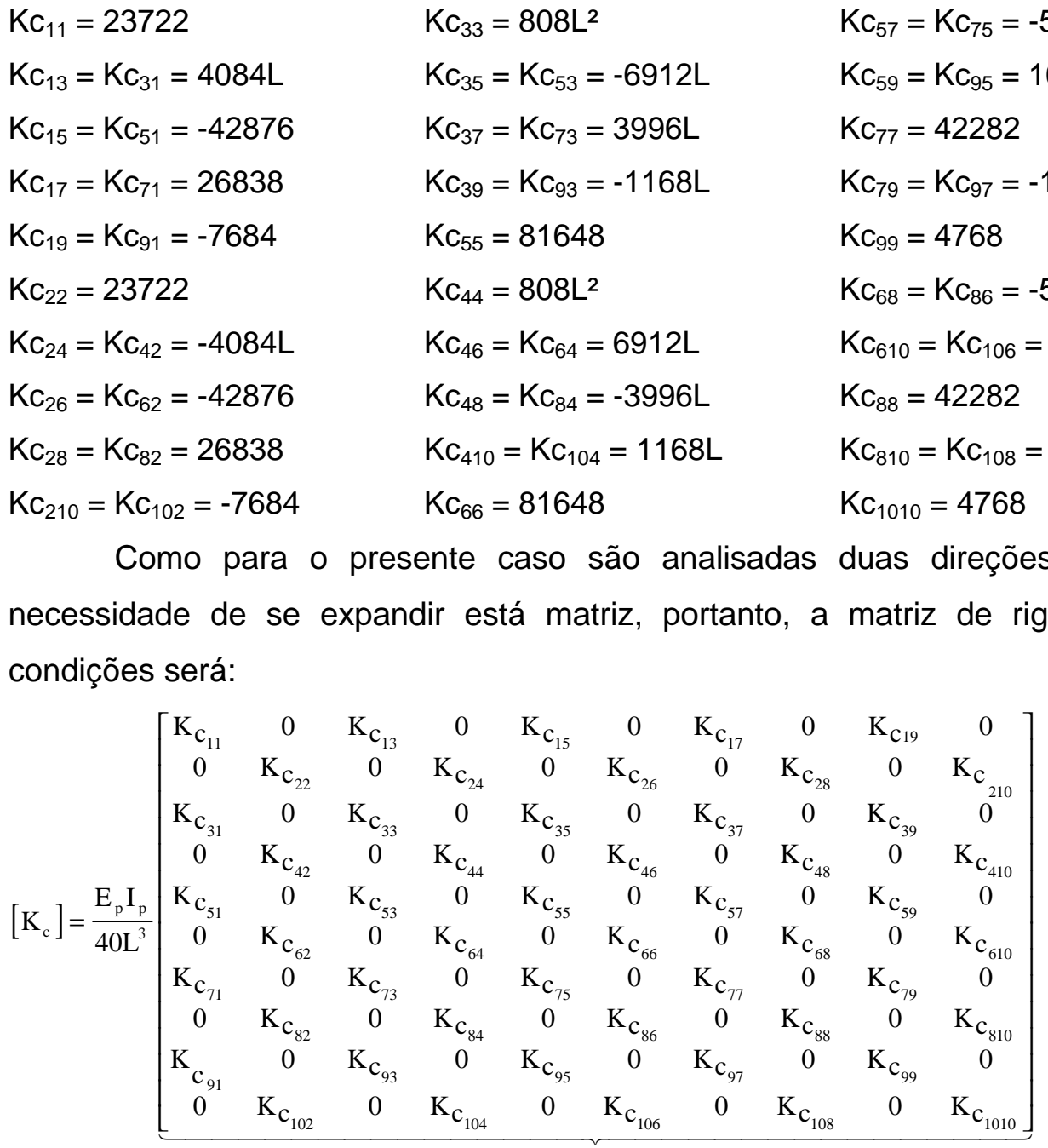
Matriz de Rigidez para o presente caso

Sendo o vetor de forças:

$$
\{\mathrm{F}\}^{\mathrm{T}}=\left\{\begin{array}{llllllllll}
\mathrm{F}_{1} & \mathrm{~F}_{2} & \mathrm{M}_{1} & \mathrm{M}_{2} & 0 & 0 & 0 & 0 & 0 & 0
\end{array}\right\}
$$

E o vetor de parâmetros nodais (deslocamentos e rotações nas duas direções) é:

$$
\left\{u_{p}\right\}^{T}=\left\{\begin{array}{llllllllll}
u_{i} & v_{i} & u_{i}^{\prime} & v_{i}^{\prime} & u_{j} & v_{j} & u_{k} & v_{k} & u_{1} & v_{1}
\end{array}\right\}
$$

Como já visto anteriormente também (eq. 3.34), sabe-se que os termos da matriz [Q] de transformação das componentes de forças nodais em forças nodais equivalentes para um polinômio cúbico são:
$\mathrm{q}_{11}=721$
$\mathrm{q}_{21}=38 \mathrm{~L}$
$\mathrm{q}_{31}=54$
$\mathrm{q}_{41}=27$
$\mathrm{q}_{51}=38$
$q_{12}=495$
$\mathrm{q}_{22}=18 \mathrm{~L}$
$\mathrm{q}_{32}=2430$
$\mathrm{q}_{42}=-243$
$q_{52}=-162$
$q_{13}=-45$
$\mathrm{q}_{23}=18 \mathrm{~L}$
$q_{33}=-486$
$q_{43}=2673$
$q_{53}=378$
$\mathrm{q}_{14}=285$
$\mathrm{q}_{24}=38 \mathrm{~L}$
$q_{34}=-486$
$q_{44}=567$
$q_{54}=474$ 
Havendo aqui também uma pequena alteração com relação à direção $X_{2}$, sendo esta somente nos sinais da quarta linha.

Para o caso de se ter forças de interação agindo nas duas direções, a matriz [Q] pode ser montada da seguinte maneira:

$$
[\mathrm{Q}]=\left[\begin{array}{cccccccc}
\mathrm{q}_{11} & 0 & \mathrm{q}_{12} & 0 & \mathrm{q}_{13} & 0 & \mathrm{q}_{14} & 0 \\
0 & \mathrm{q}_{11} & 0 & \mathrm{q}_{12} & 0 & \mathrm{q}_{13} & 0 & \mathrm{q}_{14} \\
\mathrm{q}_{21} & 0 & \mathrm{q}_{22} & 0 & \mathrm{q}_{23} & 0 & \mathrm{q}_{24} & 0 \\
0 & -\mathrm{q}_{21} & 0 & -\mathrm{q}_{22} & 0 & -\mathrm{q}_{23} & 0 & -\mathrm{q}_{24} \\
\mathrm{q}_{31} & 0 & \mathrm{q}_{32} & 0 & \mathrm{q}_{33} & 0 & \mathrm{q}_{34} & 0 \\
0 & \mathrm{q}_{31} & 0 & \mathrm{q}_{32} & 0 & \mathrm{q}_{33} & 0 & \mathrm{q}_{34} \\
\mathrm{q}_{41} & 0 & \mathrm{q}_{42} & 0 & \mathrm{q}_{43} & 0 & \mathrm{q}_{44} & 0 \\
0 & \mathrm{q}_{41} & 0 & \mathrm{q}_{42} & 0 & \mathrm{q}_{43} & 0 & \mathrm{q}_{44} \\
\mathrm{q}_{51} & 0 & \mathrm{q}_{52} & 0 & \mathrm{q}_{53} & 0 & \mathrm{q}_{54} & 0 \\
0 & \mathrm{q}_{51} & 0 & \mathrm{q}_{52} & 0 & \mathrm{q}_{53} & 0 & \mathrm{q}_{54}
\end{array}\right]
$$

E o vetor de forças de interação é dado por:

$$
\{\mathrm{P}\}^{\mathrm{T}}=\left\{\begin{array}{llllllll}
\mathrm{p}_{1} & \mathrm{p}_{5} & \mathrm{p}_{2} & \mathrm{p}_{6} & \mathrm{p}_{3} & \mathrm{p}_{7} & \mathrm{p}_{4} & \mathrm{p}_{8}
\end{array}\right\}
$$

Na discretização do solo tem-se que:

$$
\left\{\mathrm{u}_{\mathrm{s}}\right\}=[\mathrm{G}]\left\{\mathrm{P}_{\mathrm{s}}\right\}
$$

onde:

$$
\begin{aligned}
& \left\{\mathrm{u}_{\mathrm{s}}\right\}^{\mathrm{T}}=\left\{\begin{array}{llllllll}
\mathrm{u}_{\mathrm{i}} & \mathrm{v}_{\mathrm{i}} & \mathrm{u}_{\mathrm{j}} & \mathrm{v}_{\mathrm{j}} & \mathrm{u}_{\mathrm{k}} & \mathrm{v}_{\mathrm{k}} & \mathrm{u}_{1} & \mathrm{v}_{1}
\end{array}\right\} \\
& \mathrm{e} \\
& \left\{\mathrm{P}_{\mathrm{s}}\right\}^{\mathrm{T}}=\left\{\begin{array}{llllllll}
\mathrm{p}_{1} & \mathrm{p}_{5} & \mathrm{p}_{2} & \mathrm{p}_{6} & \mathrm{p}_{3} & \mathrm{p}_{7} & \mathrm{p}_{4} & \mathrm{p}_{8}
\end{array}\right\}
\end{aligned}
$$

Podendo-se observar nos dois últimos vetores que, para os deslocamentos no solo não são consideradas as rotações em torno dos eixos e conseqüentemente haverá expansão das matrizes e vetores relacionados ao solo.

$\mathrm{Na}$ equação (4.11), para cada ponto de colocação, o deslocamento horizontal é dado da seguinte maneira:

$$
\mathrm{u}_{\mathrm{i}}(\mathrm{s})=\int_{\Gamma} \mathrm{u}_{\mathrm{ij}}^{*}(\mathrm{~s}, \mathrm{p}) \bar{\phi}_{\mathrm{j}}^{\mathrm{T}}(\mathrm{p}) \mathrm{d} \Gamma(\mathrm{p}) \mathrm{P}_{\mathrm{j}}(\mathrm{p})
$$

Pela "Regra da Quadratura de Gauss" tem-se:

$$
\mathrm{u}_{\mathrm{i}}(\mathrm{s})=\frac{\mathrm{L}}{2} \sum_{\mathrm{m}=1}^{\mathrm{Ng}} \mathrm{u}_{\mathrm{ij}}^{*}(\mathrm{~s}, \mathrm{p}) \bar{\phi}_{\mathrm{j}}^{\mathrm{T}}(\mathrm{p}) \cdot \mathrm{w}_{\mathrm{m}} \cdot \mathrm{P}_{\mathrm{j}}(\mathrm{p})
$$

sendo que:

$\mathrm{Ng}$ : é o número de pontos de Gauss 
${ }_{\mathrm{m}}$ : é o peso de ponderação da integração de Gauss

Visto que nesta formulação não estão sendo considerados os deslocamentos e as forças verticais, o tensor de deslocamentos fundamentais é dado da seguinte forma:

$$
\mathrm{u}_{\mathrm{ij}}^{*}(\mathrm{~s}, \mathrm{p})=\left[\begin{array}{cc}
* & * \\
\mathrm{u}_{11} & \mathrm{u}_{12} \\
* & * \\
\mathrm{u}_{21} & \mathrm{u}_{22}
\end{array}\right]
$$

As soluções fundamentais citadas na equação (4.16) assim como as funções de forma $\left(\bar{\phi}_{\mathrm{i}}\right)$ que serão utilizadas no presente caso são descritas nos itens (2.2.2) e (3.4.2), respectivamente.

Portanto para o ponto nodal 1 tem-se:

$$
\left\{\begin{array}{l}
\mathrm{u}_{1} \\
\mathrm{v}_{1}
\end{array}\right\}=\left[\begin{array}{cc}
* & * \\
\mathrm{u}_{11} & \mathrm{u}_{12}^{*} \\
\mathrm{u}_{21} & \mathrm{u}_{22}^{*}
\end{array}\right]\left[\begin{array}{cccccccc}
\phi_{1} & 0 & \phi_{2} & 0 & \phi_{3} & 0 & \phi_{4} & 0 \\
0 & \phi_{1} & 0 & \phi_{2} & 0 & \phi_{3} & 0 & \phi_{4}
\end{array}\right]\left\{\begin{array}{l}
\mathrm{p}_{1} \\
\mathrm{p}_{5} \\
\mathrm{p}_{2} \\
\mathrm{p}_{6} \\
\mathrm{p}_{3} \\
\mathrm{p}_{7} \\
\mathrm{p}_{4} \\
p_{8}
\end{array}\right\}
$$

onde:

$\mathrm{v}_{1}$ : representa o deslocamento horizontal na direção $\mathrm{X}_{1}$ para o ponto "1" e $\mathrm{V}_{5}$ : representa o deslocamento horizontal na direção $\mathrm{X}_{2}$ para o ponto "1" Sendo este ponto "1" o ponto no topo da estaca.

Fazendo-se agora a interação MEC/MEF, onde, como já visto anteriormente, a equação do solo será:

$$
\left\{\mathrm{u}_{\mathrm{s}}\right\}_{8 \times 1}=[\mathrm{G}]_{8 \times 8}\left\{\mathrm{P}_{\mathrm{s}}\right\}_{8 \times 1}
$$

e a equação da estaca:

$$
\left[\mathrm{K}_{\mathrm{c}}\right]_{10 \times 10}\left\{\mathrm{u}_{\mathrm{p}}\right\}_{10 \times 1}=\{\mathrm{F}\}_{10 \times 1}-[\mathrm{Q}]_{10 \times 8}\left\{\mathrm{P}_{\mathrm{p}}\right\}_{8 \times 1}
$$

Invertendo a matriz de [G] do solo como já feito anteriormente:

$$
\left\{\mathrm{P}_{\mathrm{s}}\right\}_{8 \times 1}=[\mathrm{G}]_{8 \times 8}^{-1}\left\{\mathrm{u}_{\mathrm{s}}\right\}_{8 \times 1}
$$

Substituindo na equação da estaca:

$$
\left[\mathrm{K}_{\mathrm{c}}\right]_{10 \times 10}\left\{\mathrm{u}_{\mathrm{p}}\right\}_{10 \times 1}=\{\mathrm{F}\}_{10 \times 1}-[\mathrm{Q}]_{10 \times 8}[\mathrm{G}]_{8 \times 8}^{-1}\left\{\mathrm{u}_{\mathrm{s}}\right\}_{8 \times 1}
$$

Onde:

$$
[\mathrm{Q}]_{10 \times 8}[\mathrm{G}]_{8 \times 8}^{-1}=[\mathrm{M}]_{10 \times 8}
$$


Com o intuito de se obter a mesma ordem da matriz $\left[\mathrm{K}_{\mathrm{c}}\right]$ para a matriz $[\mathrm{M}]$ para que haja compatibilidade de deslocamentos, são colocadas agora duas colunas de zeros na matriz [M] referentes a não consideração das rotações em torno dos eixos $X_{1}$ e $X_{2}$ na equação do solo, e sendo assim a colunas à serem deslocadas serão a terceira e demais posteriores:

$$
\therefore[\bar{M}]=\left[\begin{array}{cccccccccc}
\mathrm{m}_{11} & \mathrm{~m}_{12} & 0 & 0 & \mathrm{~m}_{13} & \mathrm{~m}_{14} & \mathrm{~m}_{15} & \mathrm{~m}_{16} & \mathrm{~m}_{17} & \mathrm{~m}_{18} \\
\mathrm{~m}_{21} & \mathrm{~m}_{22} & 0 & 0 & \mathrm{~m}_{23} & \mathrm{~m}_{24} & \mathrm{~m}_{25} & \mathrm{~m}_{26} & \mathrm{~m}_{27} & \mathrm{~m}_{28} \\
\mathrm{~m}_{31} & \mathrm{~m}_{32} & 0 & 0 & \mathrm{~m}_{33} & \mathrm{~m}_{34} & \mathrm{~m}_{35} & \mathrm{~m}_{36} & \mathrm{~m}_{37} & \mathrm{~m}_{38} \\
\mathrm{~m}_{41} & \mathrm{~m}_{42} & 0 & 0 & \mathrm{~m}_{43} & \mathrm{~m}_{44} & \mathrm{~m}_{45} & \mathrm{~m}_{46} & \mathrm{~m}_{47} & \mathrm{~m}_{48} \\
\mathrm{~m}_{51} & \mathrm{~m}_{52} & 0 & 0 & \mathrm{~m}_{53} & \mathrm{~m}_{54} & \mathrm{~m}_{55} & \mathrm{~m}_{56} & \mathrm{~m}_{57} & \mathrm{~m}_{58} \\
\mathrm{~m}_{61} & \mathrm{~m}_{62} & 0 & 0 & \mathrm{~m}_{63} & \mathrm{~m}_{64} & \mathrm{~m}_{65} & \mathrm{~m}_{66} & \mathrm{~m}_{67} & \mathrm{~m}_{68} \\
\mathrm{~m}_{71} & \mathrm{~m}_{72} & 0 & 0 & \mathrm{~m}_{73} & \mathrm{~m}_{74} & \mathrm{~m}_{75} & \mathrm{~m}_{76} & \mathrm{~m}_{78} & \mathrm{~m}_{79} \\
\mathrm{~m}_{81} & \mathrm{~m}_{82} & 0 & 0 & \mathrm{~m}_{83} & \mathrm{~m}_{84} & \mathrm{~m}_{85} & \mathrm{~m}_{86} & \mathrm{~m}_{87} & \mathrm{~m}_{88} \\
\mathrm{~m}_{91} & \mathrm{~m}_{92} & 0 & 0 & \mathrm{~m}_{93} & \mathrm{~m}_{94} & \mathrm{~m}_{95} & \mathrm{~m}_{96} & \mathrm{~m}_{97} & \mathrm{~m}_{98} \\
\mathrm{~m}_{101} & \mathrm{~m}_{102} & 0 & 0 & \mathrm{~m}_{103} & \mathrm{~m}_{104} & \mathrm{~m}_{105} & \mathrm{~m}_{106} & \mathrm{~m}_{107} & \mathrm{~m}_{108}
\end{array}\right]_{10 \times 10}
$$

Devido a essa alteração também é aumentado o vetor de deslocamentos da equação do solo, tendo-se:

$$
\left\{\mathrm{u}_{\mathrm{s}}\right\}=\left\{\begin{array}{llllllllll}
\mathrm{v}_{1} & \mathrm{v}_{5} & \mathrm{v}_{1}^{\prime} & \mathrm{v}_{5}^{\prime} & \mathrm{v}_{2} & \mathrm{v}_{6} & \mathrm{v}_{3} & \mathrm{v}_{7} & \mathrm{v}_{4} & \mathrm{v}_{8}
\end{array}\right\}
$$

E da compatibilidade de deslocamentos tem-se que:

$$
\left[\left[\mathrm{K}_{\mathrm{c}}\right]_{10 \times 10}+[\overline{\mathrm{M}}]_{10 \times 10}\right]\{\overline{\mathrm{U}}\}_{10 \times 1}=\{\mathrm{F}\}_{10 \times 1}
$$

E finalmente chega-se a equação que contém todas as contribuições dos coeficientes de rigidez dos sistema, estando estes em função de todos os deslocamentos incluindo as duas rotações no topo da estaca. Também estão sendo considerados nesta equação todos as cargas externas que agem no sistema, com isso tem-se que:

$$
[\overline{\mathrm{K}}]_{10 \times 10}\{\overline{\mathrm{U}}\}_{10 \times 1}=\{\mathrm{F}\}_{10 \times 1}
$$

\subsection{1) Avaliação do Modelo}

\section{a) Exemplo 1}

Para este exemplo será admitido que as mesmas características do problema citado no item (3.4.3c) e que as forças externas aplicadas na direção $X_{1} e$ em torno do eixo $X_{2}$, serão agora também aplicadas em $X_{2}$ e em torno de $X_{1}$. Os 
resultados obtidos são apresentados na tabela 4.1, podendo-se observar uma coerência entre os valores.

Tab. 4.1 - Deslocamentos laterais e rotações em uma e em duas direções.

\begin{tabular}{|c|c|c|c|c|c|c|}
\hline \multirow{2}{*}{ Exemplos } & \multicolumn{2}{|c|}{ Ex. 3.4.3 c) } & \multicolumn{4}{c|}{ Ex. 4.2.1 a) } \\
\cline { 2 - 7 } & \multicolumn{2}{|c|}{ Uma Direção* } & \multicolumn{4}{c|}{ Duas Direções $^{*}$} \\
\cline { 2 - 7 } & $\mathrm{X}_{1}$ & rot. em $\mathrm{X}_{2}$ & $\mathrm{X}_{1}$ & $\mathrm{X}_{2}$ & rot. $\mathrm{X}_{2}$ & rot. $\mathrm{X}_{1}$ \\
\hline 0 & 0,7166 & $-0,6336.10^{-3}$ & 0,7166 & 0,7166 & $-0,6336.10^{-3}$ & $0,6336.10^{-3}$ \\
\hline $\mathrm{L} / 3$ & 0,0866 & & 0,0866 & 0,0866 & & \\
\hline $2 \mathrm{~L} / 3$ & 0,0426 & & 0,0426 & 0,0426 & & \\
\hline $\mathrm{L}$ & 0,0249 & & 0,0249 & 0,0249 & & \\
\hline
\end{tabular}

* Os deslocamentos horizontais estão em milímetros e as rotações em radianos. As rotações só foram calculadas para o topo da estaca. $O$ comprimento "L" da estaca para o presente exemplo é igual à 6,096 m.

\section{b) Exemplo 2}

Com o objetivo de confirmar que a formulação proposta permite a análise de estacas carregadas nas duas direções, são apresentados os resultados da análise uma estaca nessas condições. Este exemplo baseia-se no exemplo (3.4.3d) e os resultados obtidos são mostrados na tabela 4.2, afirmando desta forma que 0 método é eficaz agora para as duas direções.

Tab. 4.2 - Deslocamentos laterais e rotações em uma e em duas direções.

\begin{tabular}{|c|c|c|c|c|c|c|}
\hline \multirow{2}{*}{ Cotas } & \multicolumn{2}{|c|}{ Ex. 3.4.3 d) } & \multicolumn{4}{c|}{ Ex. 4.2 b) } \\
\cline { 2 - 7 } & \multicolumn{2}{|c|}{ Uma Direção } & \multicolumn{4}{c|}{ Duas Direções } \\
\cline { 2 - 7 } & $\mathrm{X}_{1}$ & rot. em $\mathrm{X}_{2}$ & $\mathrm{X}_{1}$ & $\mathrm{X}_{2}$ & rot. $\mathrm{X}_{2}$ & rot. $\mathrm{X}_{1}$ \\
\hline 0 & 10,1662 & $-0,9491.10^{-2}$ & 10,1662 & 10,1662 & $-0,9491.10^{-2}$ & $0,9491.10^{-2}$ \\
\hline $\mathrm{L} / 3$ & 1,2596 & & 1,2596 & 1,2596 & & \\
\hline $2 \mathrm{~L} / 3$ & $-0,4945$ & & $-0,4945$ & $-0,4945$ & & \\
\hline $\mathrm{L}$ & $-0,0816$ & & $-0,0816$ & $-0,0816$ & & \\
\hline
\end{tabular}

O comprimento " $\mathrm{L}$ " da estaca para o presente exemplo é igual à 4,65 m. 


\section{3) Grupos de Estacas Sujeitas a Carregamentos Horizontais nas Duas Direções}

Uma extensão do método de análise do comportamento de estacas isoladas pode ser feita através da consideração de grupos de estacas imersas em um meio contínuo.

POULOS (1971b), apresentou um método onde primeiramente estudou a interação entre duas estacas idênticas e depois estendeu o método para grupos gerais de estacas. Alguns desses resultados obtidos serão aqui discutidos posteriormente.
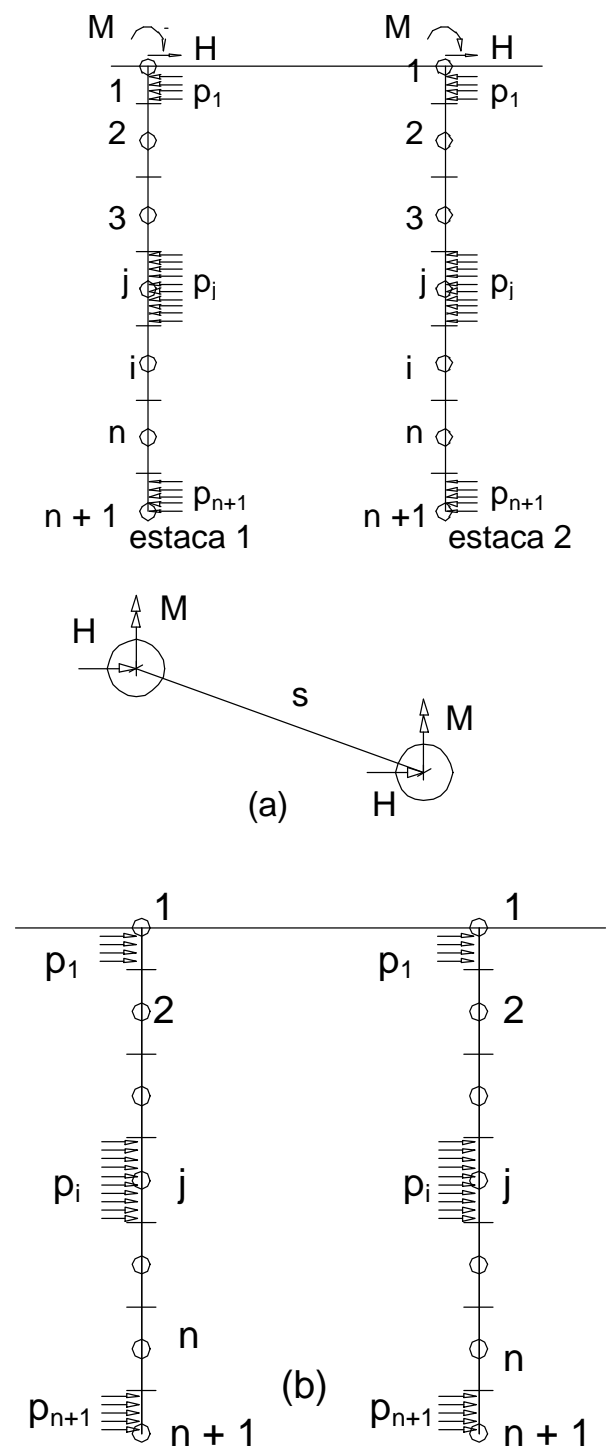

Fig. 4.2 - Forças e tensões interagindo no Problema; a) Forças e tensões agindo nas estacas; (b) Tensões agindo no solo. 
Para o modelo idealizado neste trabalho (seção 4.2) algumas considerações serão feitas à seguir.

A interferência entre as estacas será computada da seguinte forma:

- A influência de uma estaca sobre ela mesma será feita através da integração numérica (através da regra da quadratura de Gauss), onde os pontos de colocação são considerados no centro da estaca e os pontos de Gauss (pontos campo) no contorno desta, considerando nesta interface entre a estaca e o solo as forças de interação. Observando que a menor distância entre os pontos (fonte e campo) será o raio da estaca não haverá portanto singularidade no sistema;

- A influência de uma estaca sobre outra será feita também da mesma forma, alterando apenas neste caso a posição dos pontos de Gauss que serão colocados agora no centro da estaca em questão.

Admitindo que se estivesse trabalhando com duas estacas, ou seja, $\mathrm{Ne}=2$, ter-se-ia a seguinte matriz de coeficientes de influência do solo proveniente do MEC:

$$
[\mathrm{G}]_{16 \times 16}=\left[\begin{array}{ll}
{\left[\mathrm{MEC}_{11}\right]_{8 \times 8}} & {\left[\mathrm{MEC}_{12}\right]_{8 \times 8}} \\
{\left[\mathrm{MEC}_{21}\right]_{8 \times 8}} & {\left[\mathrm{MEC}_{22}\right]_{8 \times 8}}
\end{array}\right]_{16 \times 16}
$$

Onde:

$M_{11}$ : representa os coeficientes de rigidez provenientes do solo relativos a influência da estaca 1 sobre ela mesma.

$\mathrm{MEC}_{12}$ : representa os coeficientes de rigidez provenientes do solo relativos a influência da estaca 1 sobre a estaca 2.

$\mathrm{MEC}_{21}$ : representa os coeficientes de rigidez provenientes do solo relativos a influência da estaca 2 sobre a estaca 1.

$\mathrm{MEC}_{22}$ : representa os coeficientes de rigidez provenientes do solo relativos a influência da estaca 2 sobre ela mesma.

Para o MEF, basta apenas aumentar corretamente as matrizes $(10 \mathrm{Ne} \times 10 \mathrm{Ne})$ e vetores $(10 \mathrm{Ne})$ compatibilizando assim o problema, visto que não há influência entre os elementos, ou seja, de uma estaca na outra.

Para um problema composto por duas estacas, a matriz de rigidez será:

$$
\left[\mathrm{K}_{\mathrm{c}}\right]_{20 \times 20}=\left[\begin{array}{cc}
{\left[\mathrm{MEF}_{11}\right]_{10 \times 10}} & {[0]_{10 \times 10}} \\
{[0]_{10 \times 10}} & {\left[\mathrm{MEF}_{22}\right]_{10 \times 10}}
\end{array}\right]_{20 \times 20}
$$


Onde:

$\mathrm{MEF}_{11}$ : representa os coeficientes de rigidez provenientes da estaca relativos à influência da estaca 1 sobre ela mesma.

$\mathrm{MEF}_{22}$ : representa os coeficientes de rigidez provenientes da estaca relativos à influência da estaca 2 sobre ela mesma.

E a matriz de forças de transformação ficará assim:

$$
[\mathrm{Q}]_{20 \times 16}=\left[\begin{array}{cc}
{\left[\mathrm{Q}_{11}\right]_{10 \times 8}} & {[0]_{10 \times 8}} \\
{[0]_{10 \times 8}} & {\left[\mathrm{Q}_{22}\right]_{10 \times 8}}
\end{array}\right]_{20 \times 16}
$$

Sendo,

$Q_{11}$ : os coeficientes das forças de interação relativos somente à estaca 1.

$Q_{22}$ : os coeficientes das forças de interação relativos somente à estaca 2.

Enfatizando ainda o caso de se ter duas estacas, pode-se dizer que, fazendo as devidas combinações e expansões entre os métodos, chegar-se-á a seguinte matriz de fundação para o sistema:

$$
[\mathrm{T}]_{20 \times 20}=\left[\begin{array}{cc}
{\left[\mathrm{MEC}_{11}+\mathrm{MEF}_{11}\right]_{10 \times 10}} & {\left[\mathrm{MEC}_{12}\right]_{10 \times 10}} \\
{\left[\mathrm{MEC}_{21}\right]_{10 \times 10}} & {\left[\mathrm{MEC}_{22}+\mathrm{MEF}_{22}\right]_{10 \times 10}}
\end{array}\right]_{20 \times 20}
$$

Que nada mais é do que a superposição de efeitos existentes da combinação entre o MEC e MEF. Este processo pode ser estendido para grupos gerais de estacas.

\subsection{1) Avaliação do Modelo}

\section{a) Exemplo 1}

A seguir serão mostrados os deslocamentos e rotações em duas estacas idênticas com características já apresentadas anteriormente (item 3.4.3.c) e espaçadas 1,5 m (fig. 4.3), observando-se assim um aumento nos deslocamentos devido a influência de uma estaca na outra com relação ao exemplo feito com uma única estaca isolada. A figura 4.4 e a tabela 4.3, mostram este aumento de deslocamento lateral. 


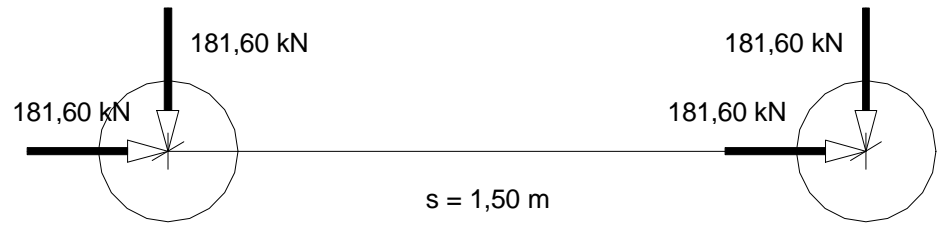

Fig. 4.3 - Situação em planta de duas estacas idênticas e com carregamento iguais em intensidade e sentido

Tab. 4.3 - Deslocamentos Laterais (em $\mathrm{mm}$ )

\begin{tabular}{|c|c|c|c|c|}
\hline \multirow{2}{*}{ Estacas } & \multicolumn{2}{|c|}{ Estaca Isolada } & \multicolumn{2}{c|}{ Duas Estacas } \\
\cline { 2 - 5 } & Direção $\mathbf{X}_{\mathbf{1}}$ & Direção $\mathbf{X}_{\mathbf{2}}$ & Direção $\mathbf{X}_{\mathbf{1}}$ & ${\text { Direção } \mathbf{X}_{\mathbf{2}}}^{\text {Estas }}$ \\
\hline 0,000 & 0,7166 & 0,7166 & 0.9415 & 0,8845 \\
\hline$-2,032$ & 0,0866 & 0,0866 & 0,1973 & 0,1788 \\
\hline$-4,064$ & 0,0426 & 0,0426 & 0,0935 & 0,0907 \\
\hline$-6,096$ & 0,0249 & 0,0249 & 0,0584 & 0,0580 \\
\hline
\end{tabular}

Nos deslocamentos ocorridos na direção $X_{1}$ ocorreu um aumento (no topo da estaca) em torno de $24 \%$ e na direção $X_{2}$ de aproximadamente $19 \%$, concluindo assim que no caso de estacas alinhadas, ocorre uma maior influência de uma sobre a outra na direção longitudinal entre elas.

As rotações na cabeça das estacas são as seguintes:

Para uma estaca isolada obteve-se a mesma rotação (em módulo) em torno dos dois eixos $\rightarrow \phi_{\times 2}=-0,6336 \times 10^{-3}$ (rad.) e $\phi_{x 1}=0,6336 \times 10^{-3}$ (rad.).

E para da análise de duas estacas idênticas obteve-se:

$\phi_{\times 2}=-0,6966 \times 10^{-3}$ (rad.) e $\phi_{x 1}=0,6737 \times 10^{-3}$ (rad.)

O aumento da rotação em torno do eixo $X_{2}$ foi de $14 \%$ e em torno de $X_{1}$ foi de $9 \%$ mostrando assim que, para as rotações, as diferenças entre os eixos não são tão significativas. 


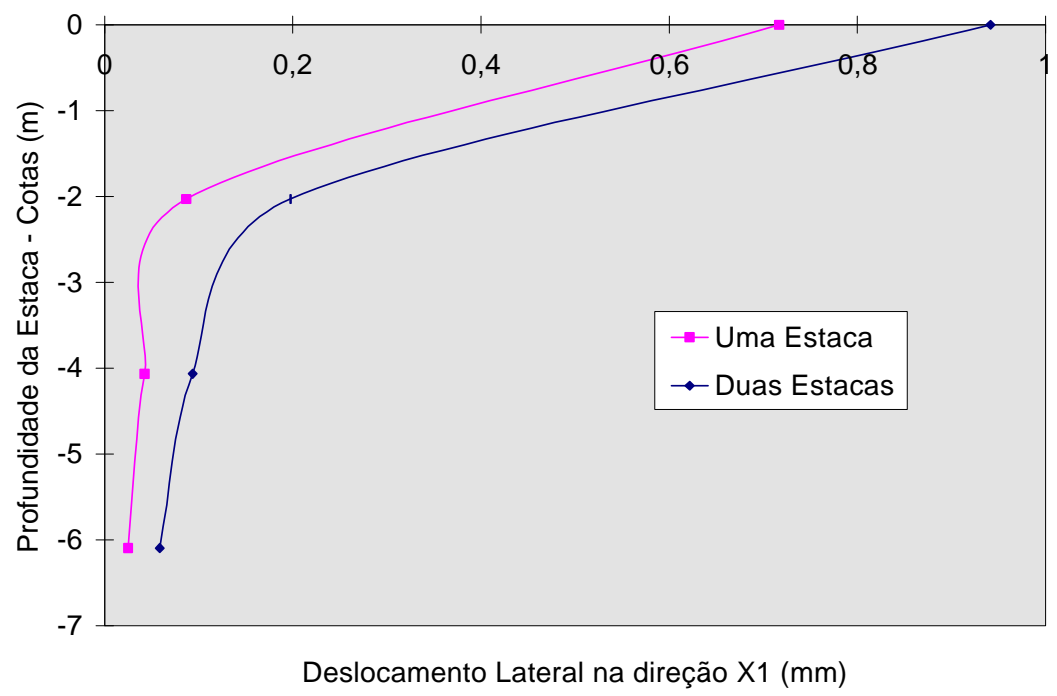

Fig. 4.4a) - Deslocamento Lateral de uma estaca isolada e de duas estacas idênticas na direção $X_{1}$.

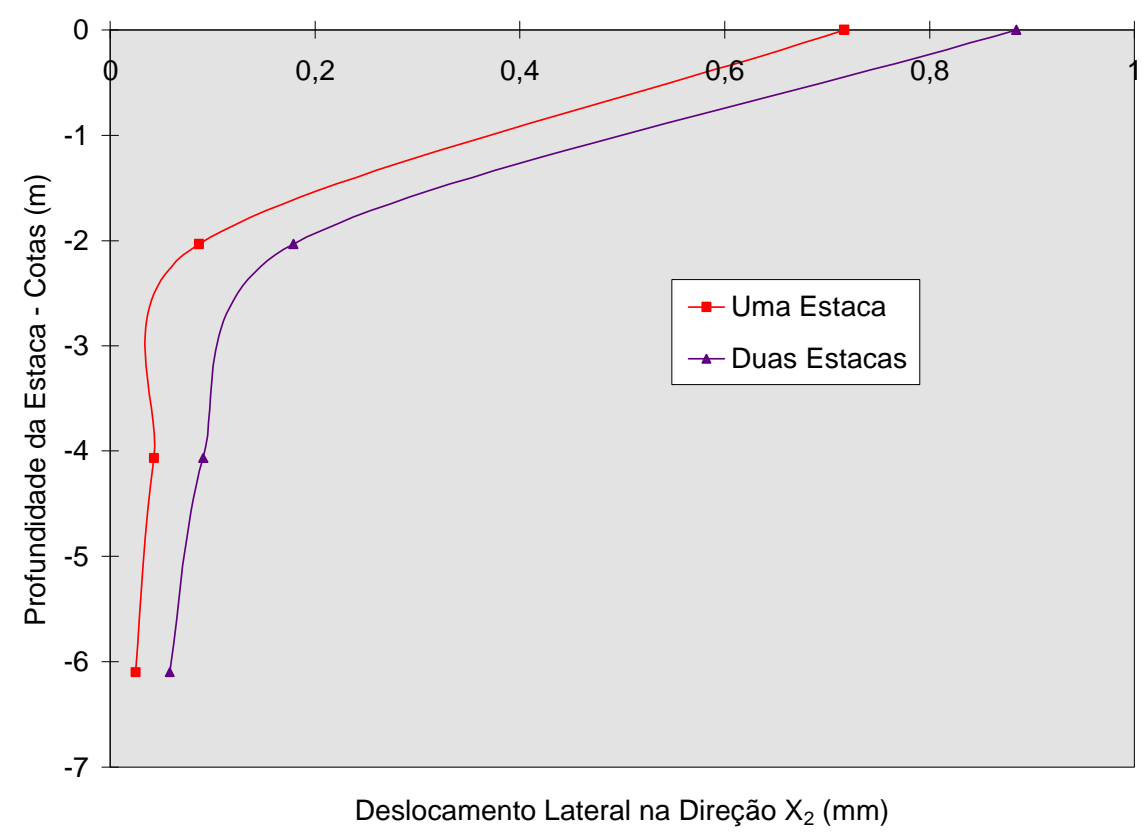

Fig. 4.4b) - Deslocamento Lateral de uma estaca isolada e de duas estacas idênticas na direção $X_{2}$. 


\section{b) Exemplo 2}

Agora são apresentadas quatro estacas espaçadas igualmente $(\mathrm{s}=1,0 \mathrm{~m}) \mathrm{e}$ apenas com cargas aplicadas horizontalmente nas duas direções, com intensidade de $181,60 \mathrm{kN}$ e sentidos variáveis de maneira que mantenham uma simetria entre as cargas, observando-se assim a obtenção de deslocamentos iguais em módulo (tabela 4.4).

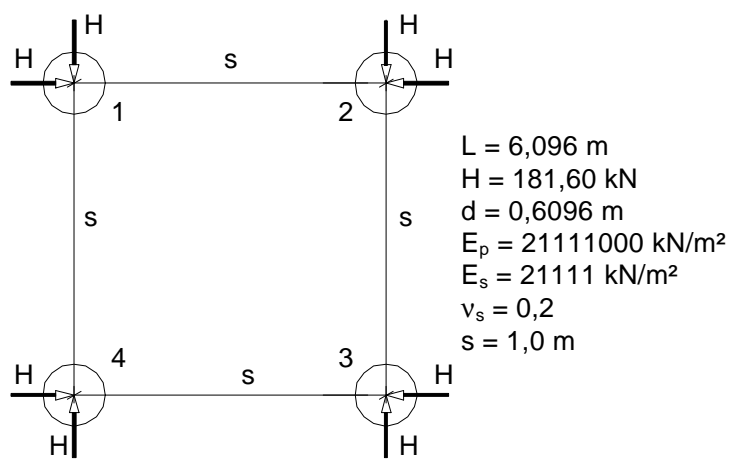

Fig. 4.5 - Grupo de 4 estacas sujeitas à cargas horizontais nas duas direções.

Tab. 4.4 - Deslocamentos laterais e rotações no topo do grupo de estacas.

\begin{tabular}{|l|c|c|c|c|}
\hline & Estaca 1 & Estaca 2 & Estaca 3 & Estaca 4 \\
\hline Carga (Dir. $\left.\mathrm{X}_{1}\right)$ & $181,60 \mathrm{kN}$ & $-181,60 \mathrm{kN}$ & $-181,60 \mathrm{kN}$ & $181,60 \mathrm{kN}$ \\
\hline Carga (Dir. $\left.\mathrm{X}_{2}\right)$ & $181,60 \mathrm{kN}$ & $181,60 \mathrm{kN}$ & $-181,60 \mathrm{kN}$ & $-181,60 \mathrm{kN}$ \\
\hline Desl. $\mathrm{X}_{1}(\mathrm{~mm})$ & 2,5611 & $-2,5611$ & $-2,5611$ & 2,5611 \\
\hline Rot. Em $\mathrm{X}_{2}$ (rad.) & $-0,1610.10^{-2}$ & $0,1610.10^{-2}$ & $0,1610.10^{-2}$ & $-0,1610.10^{-2}$ \\
\hline Desl. $\mathrm{X}_{2}(\mathrm{~mm})$ & 2,5611 & 2,5611 & $-2,5611$ & $-2,5611$ \\
\hline Rot. Em $\mathrm{X}_{1}$ (rad.) & $0,1610.10^{-2}$ & $0,1610.10^{-2}$ & $-0,1610.10^{-2}$ & $-0,1610.10^{-2}$ \\
\hline
\end{tabular}

\section{c) Exemplo 3}

Para um grupo quadrado de 9 estacas com comprimento de 15 m, diâmetro igual a 0,35 m e espaçamento "s" = 1,5 m, será aplicada uma carga de $20 \mathrm{kN}$ em cada uma delas na direção $X_{1}$. Da simetria de posicionamento divide-se as estacas em subgrupos como mostra a figura 4.7. 


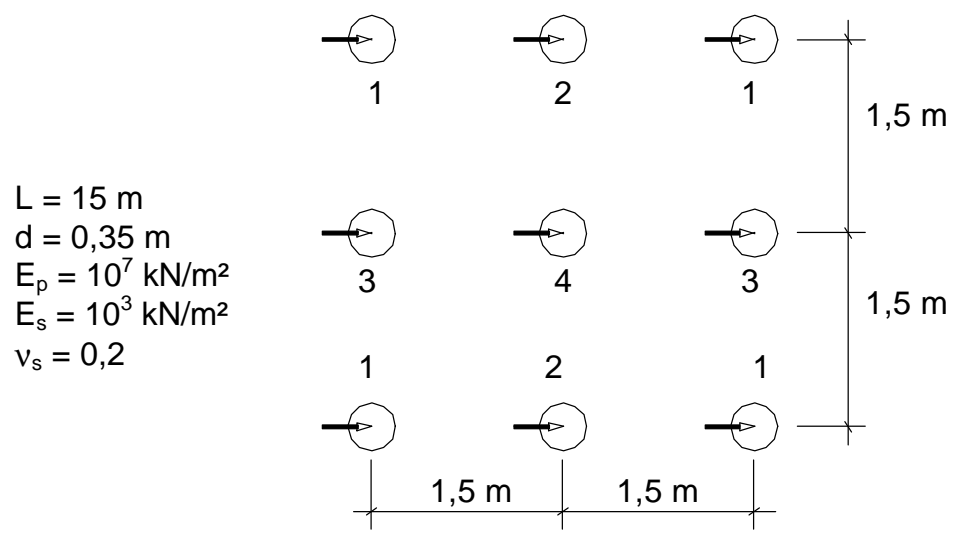

Fig. 4.7 - Divisão das Estacas em quatro subgrupos

Tab. 4.5 - Deslocamentos Laterais para os quatro subgrupos de estacas.

\begin{tabular}{|c|c|c|c|c|}
\hline \multirow{2}{*}{ Estacas } & Sub-Grupo 1 & Sub-Grupo 2 & Sub-Grupo 3 & Sub-Grupo 4 \\
\cline { 2 - 5 } & \multicolumn{3}{|c|}{ Deslocamento Horizontal na Direção $\mathbf{X}_{\mathbf{1}}$ (mm) } \\
\hline 0. & 32,9463 & 35,2837 & 35,8423 & 38,6322 \\
\hline $\mathrm{L} / 3$ & 8,3425 & 8,4658 & 8,7340 & 8,8908 \\
\hline $2 \mathrm{~L} / 3$ & 4,0663 & 4,0416 & 3,9527 & 3,8155 \\
\hline $\mathrm{L}$ & 2,4740 & 2,3857 & 2,5233 & 2,4177 \\
\hline
\end{tabular}

Podendo-se concluir que as estacas mais distantes do centro geométrico têm os menores deslocamentos no topo, enquanto que os maiores deslocamentos ficam por conta das mais próximas (figura 4.8).

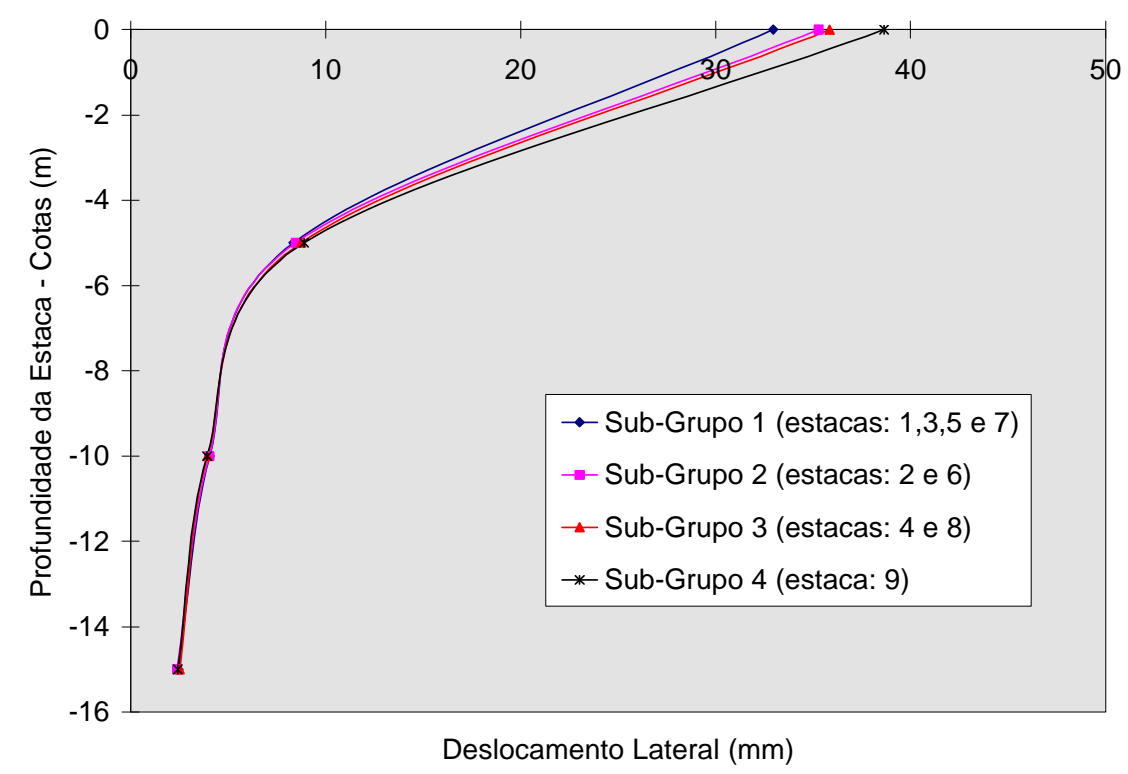

Fig. 4.8 - Deslocamentos laterais ao longo das estacas e seus respectivos subgrupos. 


\section{4) Blocos de Capeamento Rígido em Grupos de Estacas Sujeitas à Cargas Horizontais}

A utilização destes blocos permite a idealização de uma estrutura formada por um radier espesso e estaqueado num solo elástico-linear, homogêneo, isótropo e semi-infinito. Neste trabalho admite-se que não existe contato entre o bloco e o solo.

Para a análise numérica esta implementação é feita através da colocação de condições de contorno no topo das estacas, tal que a cabeça da estaca agora é engastada no bloco e todos os elementos do grupo deslocam-se igualmente.

Sabendo-se que a equação final do sistema (MEC/MEF) para o cálculo de deslocamentos é tal que:

$[\overline{\mathrm{K}}]\{\overline{\mathrm{U}}\}=\{\mathrm{F}\}$

e reiterando novamente que:

$[\overline{\mathrm{K}}]$ : Matriz de rigidez da fundação.

$\{\overline{\mathrm{U}}\}$ : Vetor de deslocamentos laterais e rotações na cabeça da estaca, e

$\{F\}$ : Vetor de carregamentos externos no topo da estaca.

Pode-se, a partir da colocação de uma matriz identidade multiplicando o vetor de forças e para a apresentação desta teoria, admitir somente a ocorrência de cargas e deslocamentos na direção $\mathrm{X}_{1}$, ou seja:

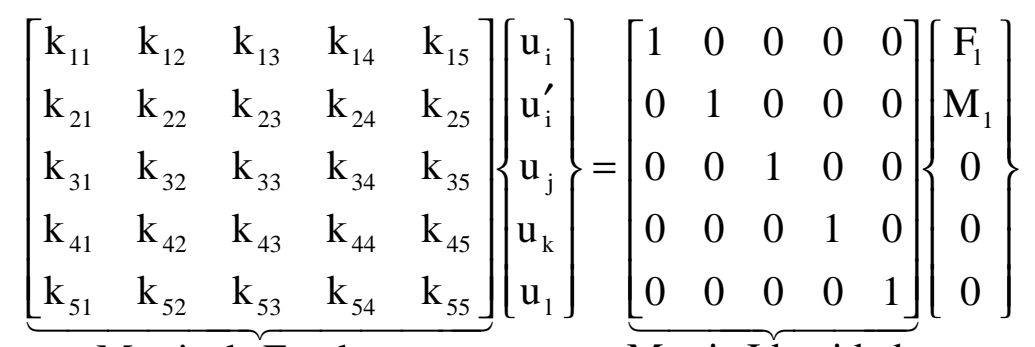

Matriz de Fundacao

Matriz Identidade

Supondo-se agora que foram prescritos o deslocamento e a rotação na cabeça da estaca $\left(u_{i}\right.$ e $\left.u_{i}^{\prime}\right)$, neste caso faz-se a troca de colunas de coeficientes de rigidez multiplicáveis pelos valores prescritos no primeiro termo por coeficientes da matriz identidade multiplicáveis pelas respectivas forças externas do segundo termo, trocando-se também os sinais.

Fazendo-se as substituições para o caso suposto, obtém-se que: 


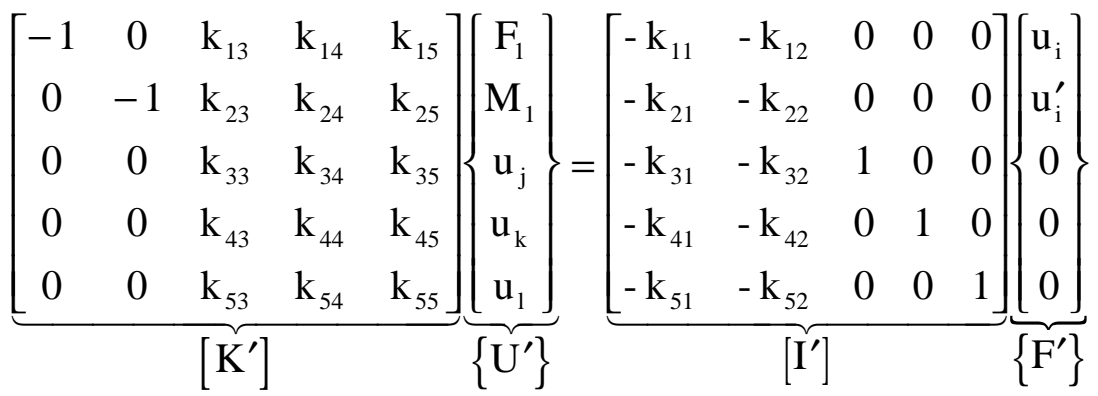

Onde todos os coeficientes do segundo termo da equação (4.33) são conhecidos, visto que:

- $\left[\mathrm{K}^{\prime}\right]$ e [I'] são matrizes que possuem coeficientes de rigidez e coeficientes oriundos a matriz identidade, respectivamente, sendo todos conhecidos.

- $\left\{\mathrm{U}^{\prime}\right\}$ é o vetor de forças e deslocamentos incógnitos.

- $\left\{F^{\prime}\right\}$ é o vetor de forças e deslocamentos prescritos.

Pode-se multiplicar a matriz $\left[\mathrm{I}^{\prime}\right]$ pelo vetor $\left\{\mathrm{F}^{\prime}\right\}$ chegando-se agora ao seguinte sistema:

$$
\left[\mathrm{K}^{\prime}\right]\left\{\mathrm{U}^{\prime}\right\}=\{\mathrm{W}\}
$$

onde:

$$
\{\mathrm{W}\}=\left[\mathrm{I}^{\prime}\right]\left\{\mathrm{F}^{\prime}\right\}
$$

Resolvendo-se o sistema (4.34) obtém-se os valores incógnitos tanto de forças quanto de deslocamentos.

Este processo é normalmente utilizado para, através da prescrição de um deslocamento qualquer para um grupo de estacas, descobrir a carga que nela deverá ser aplicada para que este grupo desloque igualmente no caso de estacas sob blocos de capeamento rígido.

\subsection{1) Avaliação do Método}

\section{a) Exemplo 1}

No problema mostrado na figura 4.9 (POULOS, 1980), pede-se para calcular o deslocamento lateral de um grupo de estacas, todas com diâmetro igual a 1 pé, sob um bloco de capeamento rígido, devido a uma carga de 100 kips $\left(\mathrm{H}_{\mathrm{G}}\right)$ na direção $X_{1}$. Adotou-se um coeficiente de Poisson igual a 0,5 e $K_{R}=10^{-3}$. 

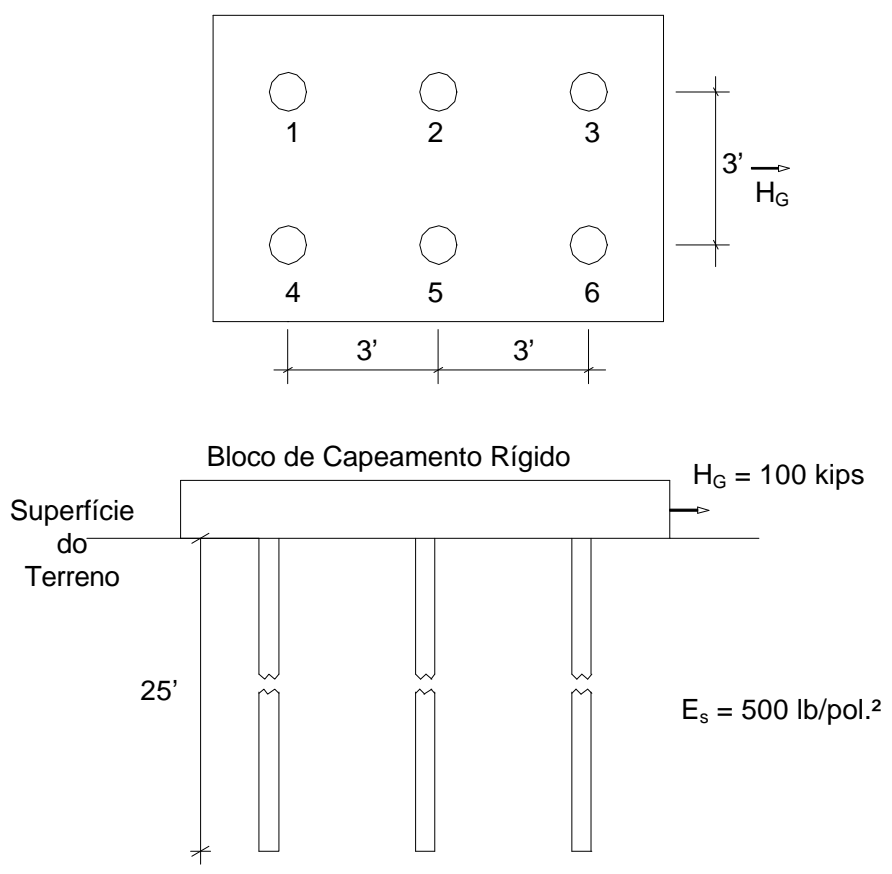

Fig. 4.9 - Figura adaptada de POULOS (1980).

Utilizando-se o método em questão pode-se assumir que todas as estacas deslocam igualmente e que sua rotação é restringida.

Prescrevendo-se agora deslocamento de 1" (deslocamento unitário), obtémse os esforços necessários para que este deslocamento ocorra.

Devido a simetria, existem apenas duas forças distintas aplicadas na estaca $\left(\mathrm{H}_{1}\right.$ e $\left.\mathrm{H}_{2}\right)$, que são mostradas na tabela 4.6.

Tab. 4.6 - Forças causadas pelos deslocamentos horizontais unitários nos respectivos subgrupos.

\begin{tabular}{|c|c|c|}
\hline Estacas & $\mathbf{K}_{1}$ & $\mathbf{K}_{\mathbf{2}}$ \\
\hline $1,3,4$ e 6 & 15,582 (kips/pol.) & - \\
\hline 2 e 5 & - & 10,351 (kips/pol.) \\
\hline
\end{tabular}

Da equação de equilíbrio tem-se que:

$4 \mathrm{H}_{1}+2 \mathrm{H}_{2}=100$

e como:

$\mathrm{K}_{1}=15,582 \mathrm{kips} / \mathrm{pol}$. (coeficiente de mola do sistema).

$\mathrm{K}_{2}=10,351 \mathrm{kips} / \mathrm{pol}$.

e

$H_{n}=K_{n} \cdot u_{n}$, onde pode-se dizer que $u_{1}=u_{2}$ (sendo valores unitários). 
então:

$\mathrm{H}_{1} \cong 1,505 \mathrm{H}_{2}$

Substituindo na equação de equilíbrio, obtém-se:

$\mathrm{H}_{2}=12,4667$ kips e portanto

$\mathrm{H}_{1}=18,7666$ kips.

Colocando estes valores nas suas respectivas estacas, ou seja:

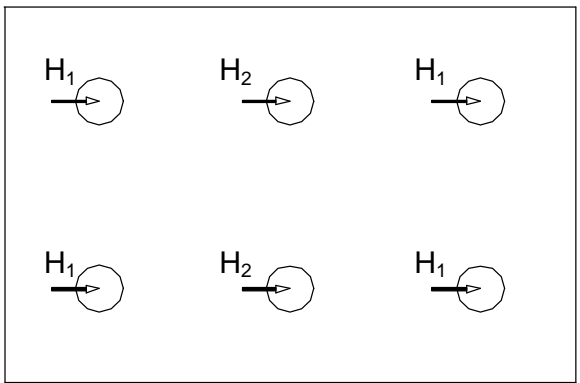

Fig. 4.10 - Distribuição das forças sobre a cabeça das estacas

Liberando-se os deslocamentos e executando novamente o modelo (prescrevendo-se agora as forças $\mathrm{H}_{1}$ e $\mathrm{H}_{2}$ ) chega-se assim ao mesmo deslocamento para todas as estacas, como é visto abaixo:

$\mathrm{u}=1,2044$ pol. (no topo das estacas)

Os valores obtido por Poulos foram:

UPOULOS $=1,53$ pol.

$\mathrm{H}_{1 \text { POULOS }}=20,1 \mathrm{kips}$

$\mathrm{H}_{\text {2POULOS }}=9,8$ kips.

Comparando-se os resultados percebe-se uma certa discrepância provavelmente decorrente do fato de que Poulos estendeu o uso do seu modelo desenvolvido para duas estacas, para a análise de grupos genéricos onde todos os espaçamentos deveriam ser idênticos. Como isso não ocorre no exemplo apresentado, vários coeficientes de interação foram obtidos através da superposição desses fatores, considerando as estacas duas a duas, divergindo assim do modelo descrito neste trabalho onde todos os efeitos da interação soloestrutura são obtidos através de uma combinação entre o MEC e o MEF mais refinada.

Observa-se novamente que as estacas mais distantes para ambos os casos são mais carregadas do que as mais próximas do centro geométrico, concluindo-se que para cargas idênticas as estacas internas (mais próximas) deslocarão mais. 


\section{b) Exemplo 2}

Um último exemplo a ser feito, apresenta a variação de espaçamentos entre as estacas. Este exemplo é utilizado para mostrar que quanto maior é a relação espaçamento-diâmetro (s/d), mais uniforme ficam as distribuições de carga para as estacas.

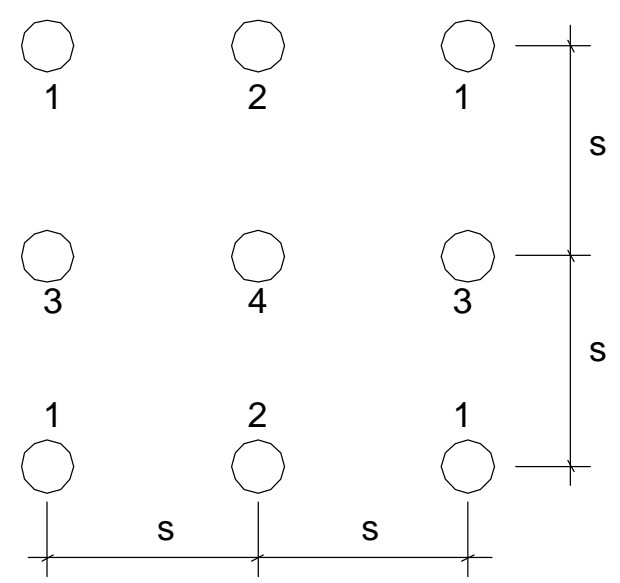

Fig. 4.11 - Divisão das Estacas em quatro subgrupos e espaçamento "s" variando.

A seguir apresenta-se um gráfico com os comportamentos dos quatro subgrupos de estacas e seus vários espaçamentos.

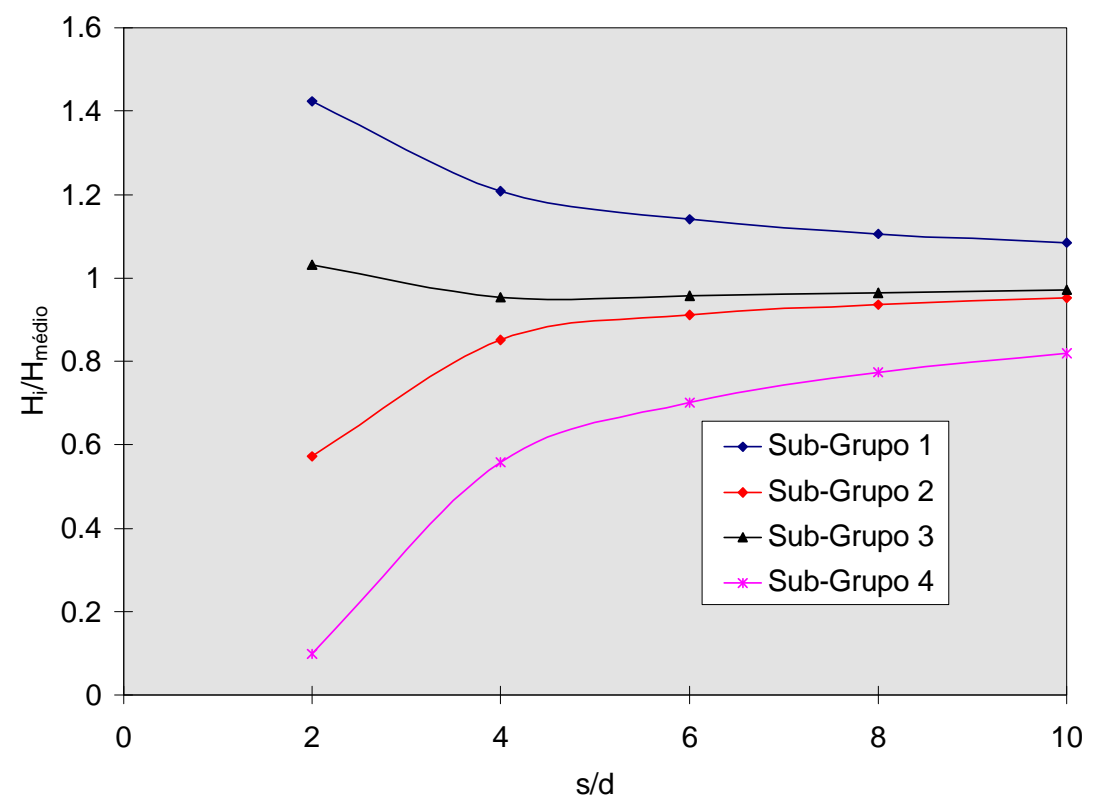

Fig. 4.12 - Comportamento dos subgrupos de estacas para diversos espaçamentos. 


\section{CAPÍTULO 5 \\ ESTACAS VERTICAIS ISOLADAS SUBMETIDAS \\ À CARREGAMENTOS VERTICAIS}

\section{1) Introdução}

No capítulo 2 foram apresentadas as equações integrais e a discretização das mesmas, pelo MEC, relacionando pontos fontes e campos situados em um meio semi-infinito, homogêneo, isótropo e elástico-linear.

Neste capítulo estas equações integrais serão utilizadas para a solução do problema de estacas verticais isoladas imersas em um maciço de solos e solicitadas por forças verticais.

As hipóteses básicas são as mesmas já adotadas no capítulo 3 (seção 3.2), salvo que agora as estacas estarão sujeitas somente a carregamentos verticais.

\section{2) Análise Elástica em Estacas Isoladas}

Este modelo é desenvolvido admitindo-se a estaca como sendo um único elemento linear com 4 pontos de colocação possuindo cada ponto um parâmetro nodal de deslocamento vertical como mostra a figura 5.1.

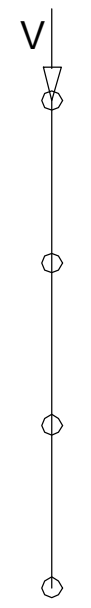

(a)

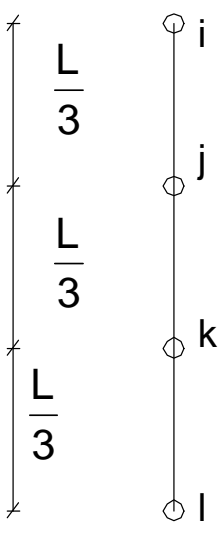

(b)

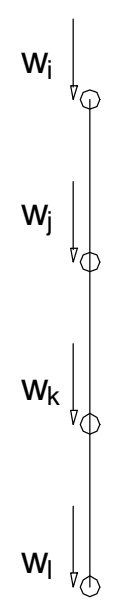

(c)

Fig. 5.1 - Discretização do Problema; a) Força vertical no topo da estaca; b) Pontos de colocação na estaca; c) Parâmetros nodais no elemento. 
As tensões de cisalhamento variam quadraticamente ao longo do fuste, sendo definidos 3 nós funcionais para representá-las, de forma que as funções interpoladoras podem ser escritas como:

$$
\left\{\begin{array}{l}
\varphi_{\mathrm{p} 1} \\
\varphi_{\mathrm{p} 2} \\
\varphi_{\mathrm{p} 3}
\end{array}\right\}=\left\{\begin{array}{c}
\frac{1}{2}\left(9 \xi^{2}-9 \xi+2\right) \\
-9 \xi^{2}+6 \xi \\
\frac{1}{2}\left(9 \xi^{2}-3 \xi\right)
\end{array}\right\}
$$

Onde:

$$
\xi=\frac{\mathrm{Z}}{\mathrm{L}}
$$

Sendo:

z: a cota de um ponto genérico pertencente à estaca;

L: o comprimento da estaca.

As tensões normais na base das estacas são admitidas com distribuição uniforme na área da mesma, sendo representadas por um quarto nó funcional.

A figura 5.2, mostra esta discretização:
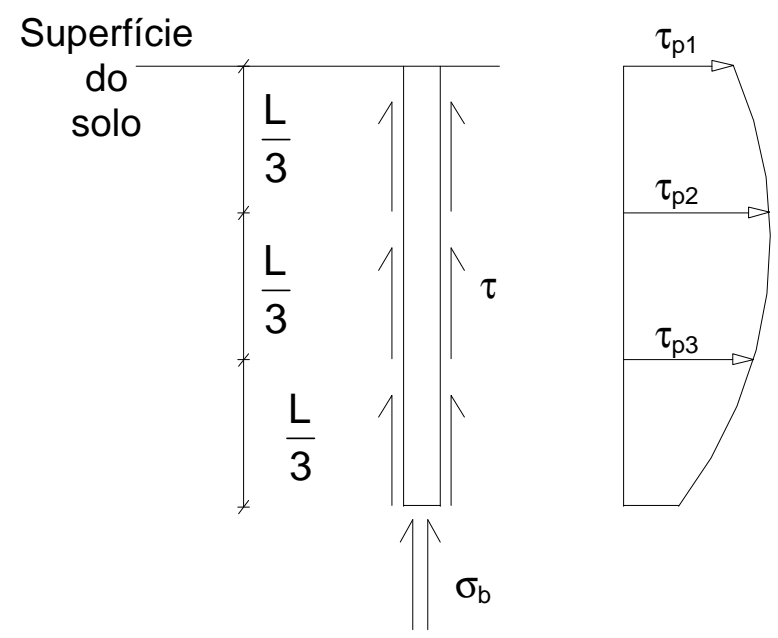

Fig. 5.2 - Representação das funções interpoladoras na estaca.

Como as tensões cisalhantes são quadráticas, estas podem ser escritas por um polinômio do segundo grau, ou seja:

$$
\mathrm{P}(\mathrm{z})=\mathrm{Az} \mathrm{z}^{2}+\mathrm{Bz}+\mathrm{C}
$$


Escrevendo este polinômio em função dos valores das forças da interface, obtém-se:

$$
\tau_{\mathrm{p}}(\mathrm{z})=\varphi_{\mathrm{p} 1} \tau_{\mathrm{p} 1}+\varphi_{\mathrm{p} 2} \tau_{\mathrm{p} 2}+\varphi_{\mathrm{p} 3} \tau_{\mathrm{p} 3}
$$

ou

$$
\tau(\mathrm{z})=\{\bar{\varphi}\}^{\mathrm{T}}\{\tau\}
$$

Como a estaca é considerada como um único elemento finito, pode-se adotar para este caso um polinômio cúbico como função aproximadora de deslocamento, isto é:

$$
\mathrm{w}_{\mathrm{ap}}(\mathrm{z})=\mathrm{Az}^{3}+\mathrm{Bz}^{2}+\mathrm{Cz}+\mathrm{D}
$$

e conseqüentemente:

$$
\mathrm{w}_{\text {ap }}^{\prime}(\mathrm{z})=3 \mathrm{Az}^{2}+2 \mathrm{Bz}+\mathrm{C}
$$

A energia potencial total da barra é escrita da seguinte forma:

$$
\Pi=U+\Omega^{\prime}=\frac{E_{p} A_{p}}{2} \int_{0}^{L} w_{a p}^{\prime}(z)^{2} d z-V_{i}+\int_{0}^{L} \tau_{p}(z) w_{a p}(z) d z+\int_{A_{p}} \sigma_{b} w_{1} d A_{p}
$$

onde:

$A_{p}$ : área da seção transversal da estaca;

V: força vertical externa aplicada no topo da estaca.

Por analogia aos procedimentos utilizados na seção 3.4 .2 determina-se a matriz de rigidez do problema, bem como as matrizes de transformação para o presente caso, chegando-se ao seguinte sistema:

$$
\left[\mathrm{K}_{\mathrm{c}}\right]\left\{\delta_{\mathrm{e}}\right\}=\{\mathrm{F}\}-[\mathrm{Q}]\{\mathrm{P}\}
$$

onde:

$$
\begin{aligned}
& {\left[\mathrm{K}_{\mathrm{c}}\right]=\frac{\mathrm{E}_{\mathrm{p}} \mathrm{A}_{\mathrm{p}}}{2}\left[\begin{array}{cccc}
148 & -189 & 54 & -13 \\
-189 & 432 & -297 & 54 \\
54 & -297 & 432 & -189 \\
-13 & 54 & -189 & 148
\end{array}\right]} \\
& {[\mathrm{Q}]=\frac{\mathrm{L}}{80}\left[\begin{array}{cccc}
7 & 2 & 1 & 0 \\
3 & 36 & -9 & 0 \\
3 & -18 & 45 & 0 \\
7 & -20 & 23 & \frac{80}{\mathrm{~L}}
\end{array}\right]}
\end{aligned}
$$


Sendo ainda todos os termos desta última matriz , [Q], multiplicados pela área lateral da estaca, com exceção do último termo, $\mathrm{q}_{4 \times 4}$, que será multiplicado pela área da base da mesma.

Os demais termos do sistema ficam da seguinte forma:

$$
\begin{aligned}
& \left\{\delta_{e}\right\}^{T}=\left\{\begin{array}{llll}
w_{i} & w_{j} & w_{k} & w_{1}
\end{array}\right\} \\
& \{F\}^{T}=\left\{\begin{array}{llll}
\mathrm{V} & 0 & 0 & 0
\end{array}\right\} \\
& \{P\}^{T}=\left\{\begin{array}{llll}
\tau_{p 1} & \tau_{p 2} & \tau_{p 3} & \sigma_{b}
\end{array}\right\}
\end{aligned}
$$

Como já visto anteriormente, a contribuição do solo para o sistema é feita através da integração das soluções fundamentais. Devido as idealizações feitas neste capítulo com relação a consideração das tensões cisalhantes e normais, algumas observações devem ser feitas:

- Os coeficientes da matriz [G], são obtidos através de uma integração dupla, sendo desenvolvida analiticamente de 0 a $2 \pi$, no sentido circunferencial e outra numericamente ao longo do eixo da estaca, quando o ponto fonte e o ponto campo não coincidirem. A integração numérica é resolvida através da Regra da Quadratura de Gauss, ou seja:

$$
\begin{aligned}
& \mathrm{x}_{\mathrm{i}}(\mathrm{s}) \neq \mathrm{x}_{\mathrm{i}}(\mathrm{p}) \quad(\mathrm{i}=1,2,3) \\
& \therefore \mathrm{g}_{\mathrm{ij}}=\int_{\Gamma} \mathrm{u}_{33}^{*} \varphi_{\mathrm{j}}^{\mathrm{T}} \mathrm{d} \Gamma
\end{aligned}
$$

onde:

$\Gamma=\frac{\mathrm{L}}{2} \xi$, e sendo assim:

$\mathrm{g}_{\mathrm{ij}}=\frac{\mathrm{L}}{2} \int_{\xi} \mathrm{u}_{33}^{*} \varphi_{\mathrm{j}}^{\mathrm{T}} \mathrm{d} \xi$

Pela Regra da Quadratura de Gauss:

$\mathrm{g}_{\mathrm{ij}}=\frac{\mathrm{L}}{2} \sum_{\mathrm{m}=1}^{\mathrm{Ng}} \mathrm{u}_{33}^{*} \varphi^{\mathrm{T}} \mathrm{w}_{\mathrm{m}}$

- Para o caso dos pontos (fonte e campo) serem iguais, situação que ocorre na obtenção do coeficiente de influência do solo, $g_{44}$ (referente a contribuição da tensão normal, $\sigma_{b}$, no ponto de colocação "l"), a integral deve ser resolvida analiticamente, no sentido circunferencial do comprimento do elemento, devido a ocorrência de singularidade. Este 
problema é solucionado integrando-se a solução fundamental $\left(\mathrm{u}_{33}^{*}\right)$ em função da área de ação desta tensão normal (área da base da estaca), isto é:

$$
\sigma_{\mathrm{b}} \int_{0}^{2 \pi} \int_{0}^{\mathrm{Ro}} \mathrm{u}_{33}^{*} \mathrm{rdrd} \theta=2 \pi \sigma_{\mathrm{b}} \int_{0}^{\mathrm{Ro}} \mathrm{u}_{33}^{*} \mathrm{rdr}
$$

que resulta em:

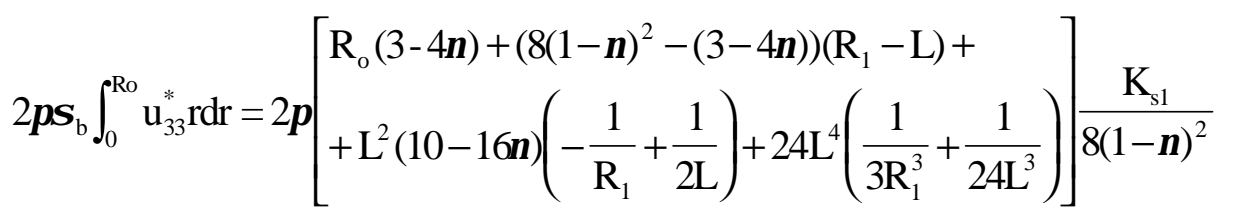

onde:

$$
\begin{aligned}
& \mathrm{K}_{\mathrm{s} 1}=\frac{1-\mathrm{v}^{2}}{\pi \mathrm{Es}} \\
& \mathrm{R}_{1}=\sqrt{4 \mathrm{~L}^{2}+\mathrm{R}_{\mathrm{o}}^{2}} \\
& \mathrm{R}_{\mathrm{o}}=\frac{\text { diametro }}{2}
\end{aligned}
$$

A interação MEC/MEF também pode ser descrita por analogia a seção 3.4.2, mas não havendo necessidade agora de expansão da matriz [G] coeficientes de influência do solo, visto que não ocorrem rotações em torno do sistema, não aumentando assim o vetor de parâmetros nodais.

Portanto o sistema final de equações fica da seguinte forma:

$$
[\overline{\mathrm{K}}]_{4 \times 4}\{\mathrm{U}\}_{4 \times 1}=\{\mathrm{F}\}_{4 \times 1}
$$

onde:

$[\overline{\mathrm{K}}]$ : matriz de rigidez final do sistema de interação (MEC/MEF);

$\{\mathrm{U}\}$ : vetor de deslocamentos considerados no problema;

$\{F\}$ : vetor de carregamento externo. 


\subsection{1) Avaliação do Modelo}

Nesta seção serão apresentados alguns exemplos com o intuito de expressar em números a formulação desenvolvida neste capítulo. Os resultados obtidos serão comparados com exemplos apresentados por BUTTERFIELD \& BANERJEE (1971) e WHITAKER \& COOKE (1966). Além de exemplos e comparações feitas com os modelos apresentados por FERRO (1993) e VALLABHAN \& SIVAKUMAR (1986).

\section{a) Exemplo 1}

A figura 5.3 apresenta um exemplo citado por FERRO (1993), onde uma estaca é solicitada por um carga vertical de $726.40 \mathrm{kN}$.

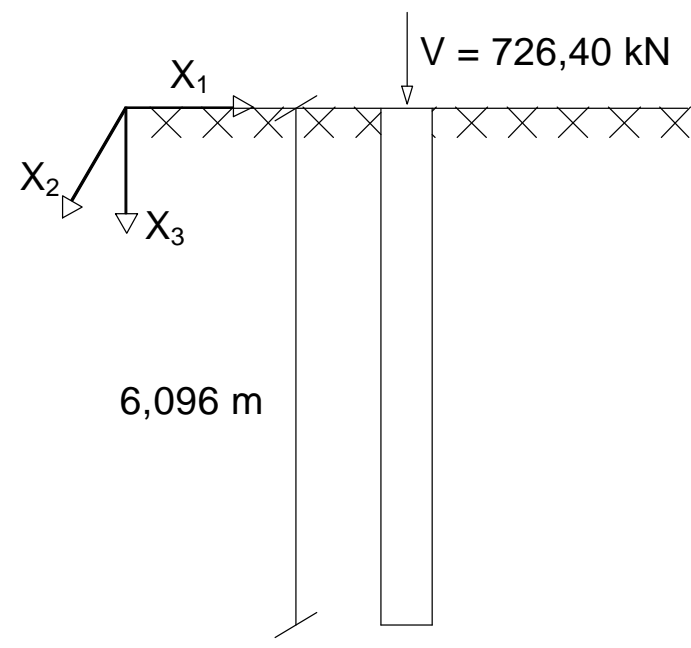

Fig. 5.3 - Figura adaptada de FERRO (1993) - Estaca em meio semi-infinito sujeita a uma carga vertical.

Os recalques ocorridos neste problema pela formulação em questão $\left(\right.$ MEF_4PAR_FÇ2 $\left.^{\circ}\right)$, são apresentados na figura 5.4 e demostram uma boa concordância, quando comparados com os modelos de FERRO (1993) e VALLABHAN \& SIVAKUMAR (1986). 


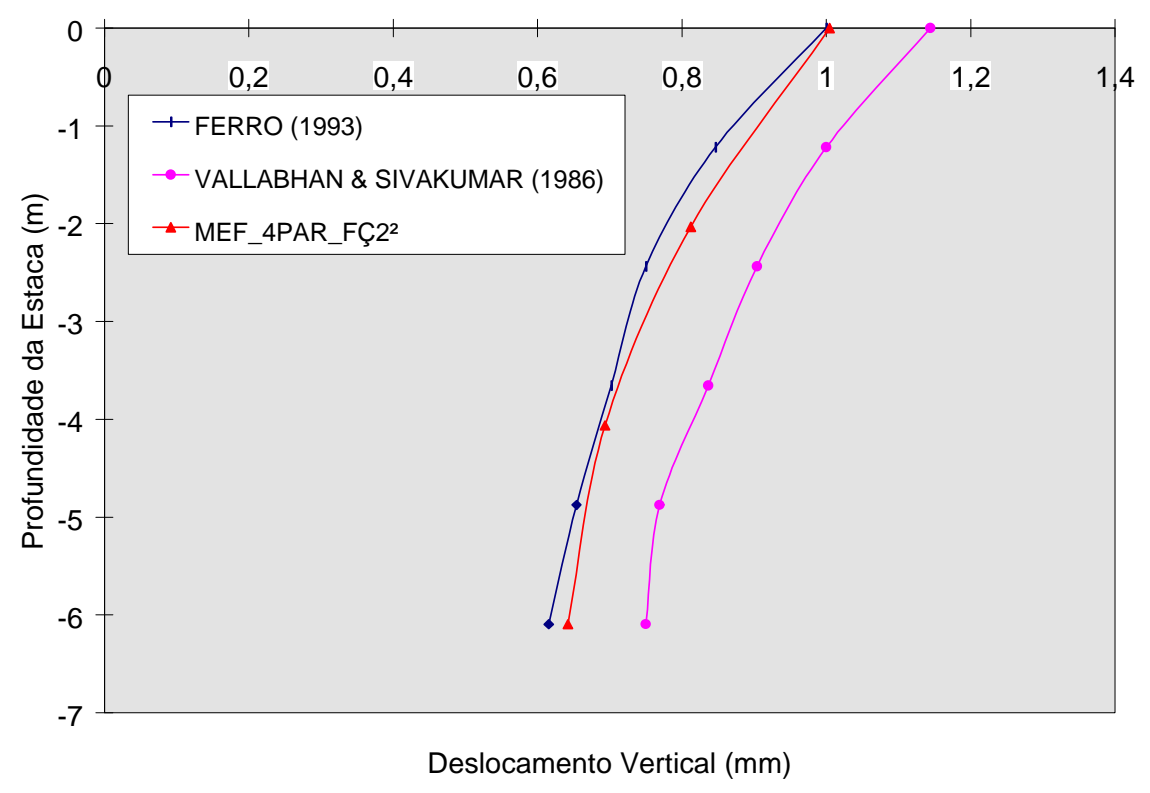

Fig. 5.4 - Comparação entre os modelos - deslocamentos verticais ao longo da estaca.

\section{b) Exemplo 2}

WHITAKER \& COOKE (1966), ensaiaram uma estaca com 12,2m de comprimento e diâmetro de $0,61 \mathrm{~m}$, solicitada por uma carga vertical de intensidade igual a $1100 \mathrm{kN}$. O módulo de elasticidade longitudinal da estaca é de $2,067.10^{7} \mathrm{kN} / \mathrm{m}^{2}$, o do solo é igual a $72400 \mathrm{kN} / \mathrm{m}^{2}$ e seu coeficiente de Poisson é 0,5 .

Neste ensaio, WHITAKER \& COOKE (1966), obtiveram um deslocamento vertical, medido na cabeça da estaca, de $0.284 \mathrm{~cm}$. O deslocamento no topo da estaca para o modelo proposto neste capítulo é de $0.2867 \mathrm{~cm}$, o que leva a erro percentual de apenas 0,952\%.

A figura 5.5 apresenta um gráfico comparativo dos recalques obtidos através do modelo proposto por FERRO (1993) e do modelo em questão (MEF_4PAR_FÇ2 ${ }^{\circ}$ ), onde se observa novamente uma boa convergência entre os modelos. 


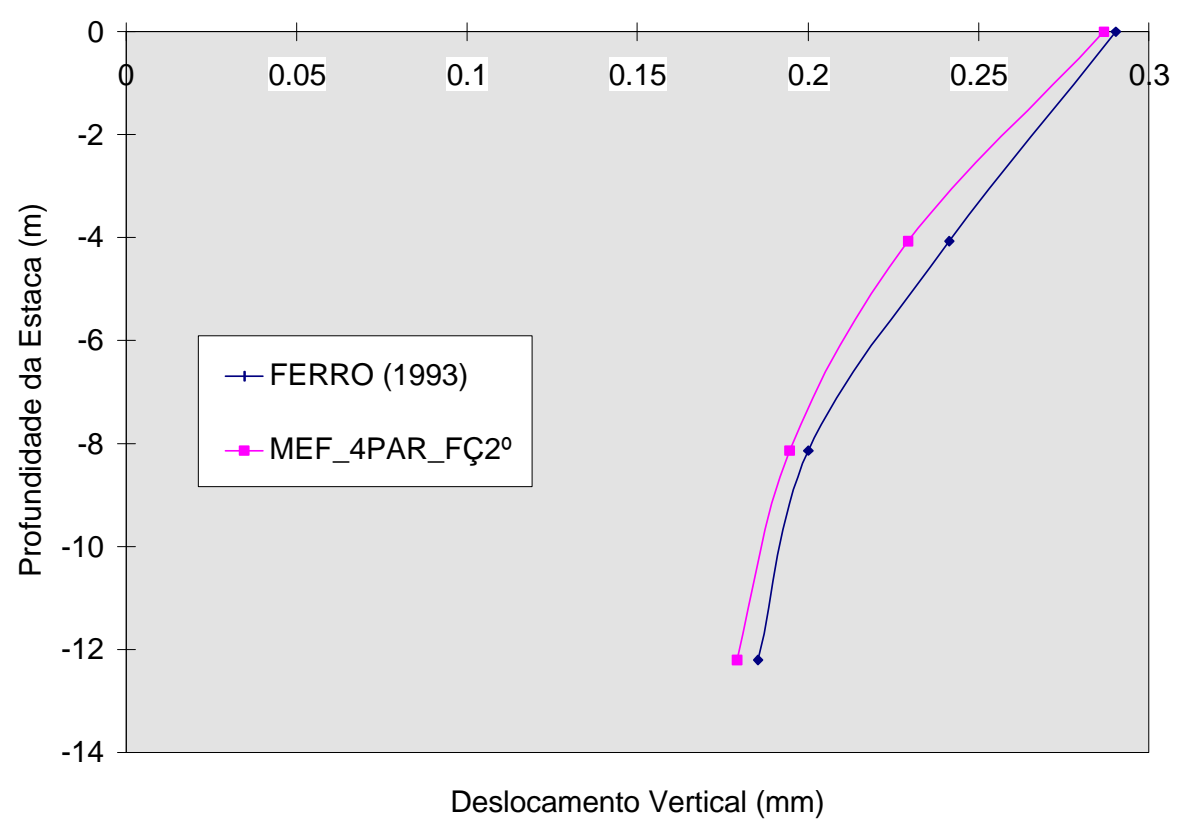

Fig. 5.5 - Comparação entre os modelos - deslocamentos verticais ao longo da estaca.

\section{c) Exemplo 3}

BUTTERFIELD \& BANERJEE (1971), apresentaram os resultados obtidos da relação carga-deslocamento para uma estaca sob carregamento vertical em função do seu comprimento (fig. 5.6).

Admitiu-se que o coeficiente de Poisson $\left(v_{s}\right)$ é igual a 0,5 e a relação entre 0 módulo de elasticidade longitudinal da estaca e o módulo de elasticidade transversal do solo $\left(\frac{E_{p}}{G_{s}}\right)$ foi assumido igual a 6000 .

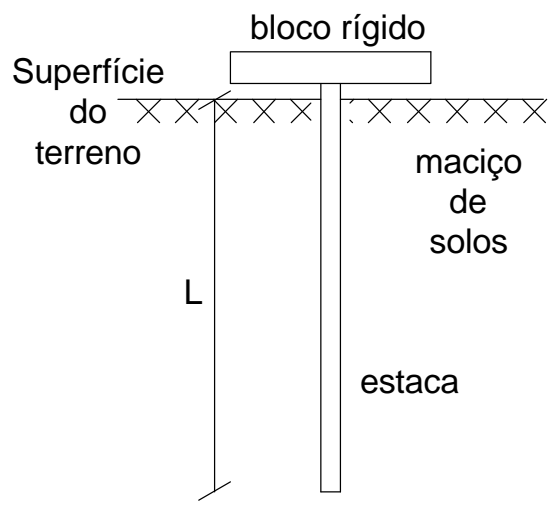

Fig. 5.6 - Estaca isolada em um semi-espaço e sob um bloco rígido. 
A figura 5.7 mostra as comparações feitas entre os modelos de forma gráfica e adimensional.

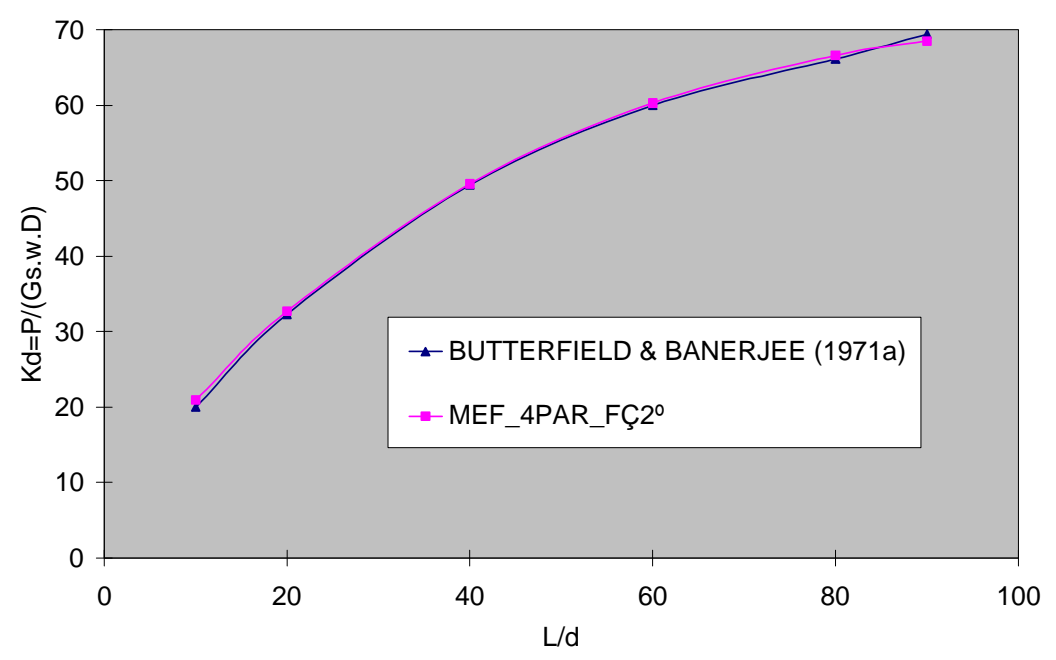

Fig. 5.7 - Comparações de modelos - curvas carga-deslocamento para uma estaca isolada sujeita a uma carga unitária horizontal.

Sendo:

$$
\mathrm{K}_{\mathrm{p}}=\frac{\mathrm{P}}{\mathrm{G}_{\mathrm{s}} \mathrm{wD}}
$$

onde:

P: é a carga aplicada sobre a estaca;

D: é o diâmetro da estaca;

L: é o comprimento da estaca;

$\mathrm{G}_{\mathrm{s}}$ : é o módulo de elasticidade transversal do solo.

Este exemplo foi apresentado com a finalidade de enfatizar mais ainda os bons resultados aqui descritos, quando comparados com os outros modelos e também mostrar que a rigidez da estaca $K_{p}$ aumenta conforme aumenta-se a relação comprimento-diâmetro $\left(\frac{\mathrm{L}}{\mathrm{D}}\right)$. 


\section{CAPÍTULO 6 \\ ESTACAS ISOLADAS E GRUPOS DE ESTACAS VERTICAIS E INCLINADAS SOLICITADAS POR CARREGAMENTOS VERTICAIS E HORIZONTAIS}

\section{1) Introdução}

Neste capítulo será apresentada uma formulação para a análise de estacas isoladas imersas em um meio contínuo, semi-infinito, homogêneo, isótropo e elástico-linear, sujeitas a cargas verticais e horizontais simultaneamente.

Posteriormente a solução se estenderá para grupos de estacas e estacas sob blocos de capeamento rígido.

As hipóteses básicas adotadas serão as mesmas que foram levadas em consideração anteriormente (capítulos 3, 4 e 5).

\section{2) Estacas Isoladas Sujeitas a Cargas Verticais e Horizontais}

Este modelo é desenvolvido admitindo-se a estaca como sendo um único elemento com 14 parâmetros nodais, onde 4 parâmetros são de deslocamentos laterais na direção $X_{1}, 4$ são de deslocamentos laterais na direção $X_{2}$ e 4 são de deslocamentos verticais na direção $X_{3}$. Existindo ainda mais uma rotação em torno do eixo $X_{1}$ e outra em torno de $X_{2}$.

As funções aproximadoras para deslocamentos são constituídas por polinômios do $4^{\circ}$ grau para as direções $X_{1}$ e $X_{2}$ e cúbicas para a direção $X_{3}$.

As funções aproximadoras para as forças de interação são cúbicas para as direções $X_{1}$ e $X_{2}$, quadráticas ao longo do fuste e uniformemente distribuídas na base da estaca para a direção $X_{3}$.

A figura 6.1 mostra claramente estas hipóteses adotadas para 0 desenvolvimento desta formulação. 


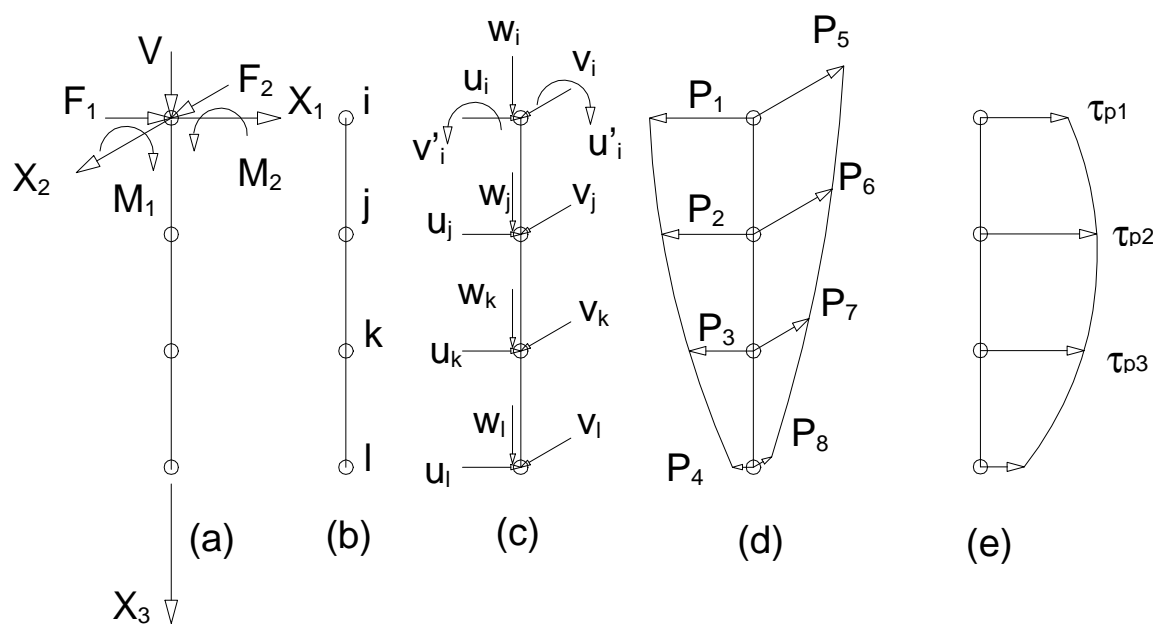

Fig. 6.1 - Discretização do problema; a) Forças no topo da estaca; b) Pontos de colocação na estaca; c) Parâmetros nodais de deslocamentos; d) Forças de interação variando cubicamente nas direções $X_{1} e$ $\mathrm{X}_{2}$; e) Forças de interação variando quadraticamente na direção $X_{3}$.

Portanto, para a direção $\mathrm{X}_{1}$ :

$\mathrm{u}_{\mathrm{ap}}(\mathrm{z})=\mathrm{A}_{1} \mathrm{z}^{4}+\mathrm{B}_{1} \mathrm{z}^{3}+\mathrm{C}_{1} \mathrm{z}^{2}+\mathrm{D}_{1} \mathrm{z}+\mathrm{E}_{1}$

$\mathrm{P}_{\mathrm{X}_{1}}(\mathrm{z})=\mathrm{A}_{2} \mathrm{z}^{3}+\mathrm{B}_{2} \mathrm{z}^{2}+\mathrm{C}_{2} \mathrm{z}+\mathrm{D}_{2}$

Para a direção $\mathrm{X}_{2}$ :

$\mathrm{v}_{\mathrm{ap}}(\mathrm{z})=\mathrm{A}_{3} \mathrm{z}^{4}+\mathrm{B}_{3} \mathrm{z}^{3}+\mathrm{C}_{3} \mathrm{z}^{2}+\mathrm{D}_{3} \mathrm{z}+\mathrm{E}_{3}$

e

$\mathrm{P}_{\mathrm{X}_{2}}(\mathrm{z})=\mathrm{A}_{4} \mathrm{z}^{3}+\mathrm{B}_{4} \mathrm{z}^{2}+\mathrm{C}_{4} \mathrm{z}+\mathrm{D}_{4}$

E para a direção $X_{3}$ :

$$
\begin{aligned}
& \mathrm{w}_{\text {ap }}(\mathrm{z})=\mathrm{A}_{5} \mathrm{z}^{3}+\mathrm{B}_{5} \mathrm{z}^{2}+\mathrm{C}_{5} \mathrm{z}+\mathrm{D}_{5}, \\
& \tau_{\mathrm{p}}(\mathrm{z})=\mathrm{A}_{6} \mathrm{z}^{2}+\mathrm{B}_{6} \mathrm{z}+\mathrm{C}_{6} \\
& \mathrm{e} \\
& \sigma_{\mathrm{b}}=1
\end{aligned}
$$

Sabendo-se que:

$\Pi=\mathrm{U}+\Omega^{\prime}$

Tem-se que: 


$$
\begin{aligned}
\Pi_{\mathrm{ap}}= & \frac{\mathrm{E}_{\mathrm{p}} \mathrm{I}_{\mathrm{p}}}{2} \int_{0}^{\mathrm{L}} \mathrm{u}_{\mathrm{ap}}^{\prime \prime}{ }^{2}(\mathrm{z}) \mathrm{dz}+\frac{\mathrm{E}_{\mathrm{p}} \mathrm{I}_{\mathrm{p}}}{2} \int_{0}^{\mathrm{L}} \mathrm{v}_{\mathrm{ap}}^{\prime \prime 2}(\mathrm{z}) \mathrm{dz}+\frac{\mathrm{E}_{\mathrm{p}} \mathrm{A}_{\mathrm{p}}}{2} \int_{0}^{\mathrm{L}} \mathrm{w}_{\mathrm{ap}}^{\prime}{ }^{2}(\mathrm{z}) \mathrm{dz}- \\
& -\mathrm{F}_{1} \mathrm{u}_{\mathrm{i}}-\mathrm{M}_{1} \mathrm{u}_{\mathrm{i}}^{\prime}-\mathrm{F}_{2} \mathrm{v}_{\mathrm{i}}-\mathrm{M}_{2} \mathrm{v}_{\mathrm{i}}^{\prime}-\mathrm{Vw}_{\mathrm{i}}+\int_{0}^{\mathrm{L}} \mathrm{P}_{\mathrm{x} 1}(\mathrm{z}) \mathrm{u}_{\mathrm{ap}}(\mathrm{z}) \mathrm{dz}+ \\
& +\int_{0}^{\mathrm{L}} \mathrm{P}_{\mathrm{x} 2}(\mathrm{z}) \mathrm{v}_{\mathrm{ap}}(\mathrm{z}) \mathrm{dz}+\int_{0}^{\mathrm{L}} \tau_{\mathrm{p}}(\mathrm{z}) \mathrm{w}_{\mathrm{ap}}(\mathrm{z}) \mathrm{dz}+\int_{\mathrm{A}_{\mathrm{p}}} \sigma_{\mathrm{b}} \mathrm{w}_{1} \mathrm{dA} \mathrm{A}_{\mathrm{p}}
\end{aligned}
$$

O processo utilizado para a determinação da matriz de rigidez, do vetor de deslocamentos e de forças de interação do elemento estrutural, estaca, é idêntico aos descritos nos capítulos 3,4 e 5, diferenciando ,agora, apenas na ordem da matriz $(14 \times 14)$ e dos vetores $(14 \times 1)$.

Sendo assim, tem-se:

$$
\left[\mathrm{K}_{\mathrm{c}}\right]\{\mathrm{U}\}=\{\mathrm{F}\}-[\mathrm{Q}]\{\mathrm{P}\}
$$

Estas matrizes e vetores já foram determinados anteriormente, bastando agora, somente serem mostrados suas corretas posições.

Para a matriz de rigidez deste elemento, seus coeficientes serão dados em função de " $a_{i j}$ ", " $b_{i j}$ ", para os termos relativos aos parâmetros nodais de deslocamentos laterais e de rotação (já descritos na eq. 4.5), e " $c_{i j}$ " para os de deslocamentos verticais (já descritos na eq. 5.9), portanto:

$$
\left[\mathrm{K}_{\mathrm{c}}\right]=\left[\begin{array}{cccccccccccccc}
\mathrm{a}_{11} & 0 & 0 & \mathrm{a}_{12} & 0 & \mathrm{a}_{13} & 0 & 0 & \mathrm{a}_{14} & 0 & 0 & \mathrm{a}_{15} & 0 & 0 \\
0 & \mathrm{~b}_{11} & 0 & 0 & \mathrm{~b}_{12} & 0 & \mathrm{~b}_{13} & 0 & 0 & \mathrm{~b}_{14} & 0 & 0 & \mathrm{~b}_{15} & 0 \\
0 & 0 & \mathrm{c}_{11} & 0 & 0 & 0 & 0 & \mathrm{c}_{12} & 0 & 0 & \mathrm{c}_{13} & 0 & 0 & \mathrm{c}_{14} \\
\mathrm{a}_{21} & 0 & 0 & \mathrm{a}_{22} & 0 & \mathrm{a}_{23} & 0 & 0 & \mathrm{a}_{24} & 0 & 0 & \mathrm{a}_{25} & 0 & 0 \\
0 & \mathrm{~b}_{21} & 0 & 0 & \mathrm{~b}_{22} & 0 & \mathrm{~b}_{23} & 0 & 0 & \mathrm{~b}_{24} & 0 & 0 & \mathrm{~b}_{25} & 0 \\
\mathrm{a}_{31} & 0 & 0 & \mathrm{a}_{32} & 0 & \mathrm{a}_{33} & 0 & 0 & \mathrm{a}_{34} & 0 & 0 & \mathrm{a}_{35} & 0 & 0 \\
0 & \mathrm{~b}_{31} & 0 & 0 & \mathrm{~b}_{32} & 0 & \mathrm{~b}_{33} & 0 & 0 & \mathrm{~b}_{34} & 0 & 0 & \mathrm{~b}_{35} & 0 \\
0 & 0 & \mathrm{c}_{21} & 0 & 0 & 0 & 0 & \mathrm{c}_{22} & 0 & 0 & \mathrm{c}_{23} & 0 & 0 & \mathrm{c}_{24} \\
\mathrm{a}_{41} & 0 & 0 & \mathrm{a}_{42} & 0 & \mathrm{a}_{43} & 0 & 0 & \mathrm{a}_{44} & 0 & 0 & \mathrm{a}_{45} & 0 & 0 \\
0 & \mathrm{~b}_{41} & 0 & 0 & \mathrm{~b}_{42} & 0 & \mathrm{~b}_{43} & 0 & 0 & \mathrm{~b}_{44} & 0 & 0 & \mathrm{~b}_{45} & 0 \\
0 & 0 & \mathrm{c}_{31} & 0 & 0 & 0 & 0 & \mathrm{c}_{32} & 0 & 0 & \mathrm{c}_{33} & 0 & 0 & \mathrm{c}_{34} \\
\mathrm{a}_{51} & 0 & 0 & \mathrm{a}_{52} & 0 & \mathrm{a}_{53} & 0 & 0 & \mathrm{a}_{54} & 0 & 0 & \mathrm{a}_{55} & 0 & 0 \\
0 & \mathrm{~b}_{51} & 0 & 0 & \mathrm{~b}_{52} & 0 & \mathrm{~b}_{53} & 0 & 0 & \mathrm{~b}_{54} & 0 & 0 & \mathrm{~b}_{55} & 0 \\
0 & 0 & \mathrm{c}_{41} & 0 & 0 & 0 & 0 & \mathrm{c}_{42} & 0 & 0 & \mathrm{c}_{43} & 0 & 0 & \mathrm{c}_{44}
\end{array}\right]
$$

Bastando agora apenas multiplicar os coeficientes " $a_{i j}$ " $e$ " $b_{i j}$ " pela constante $\frac{E_{p} I_{p}}{40 L^{3}}$ e os coeficientes $c_{i j}$ pela constante $\frac{E_{p} A_{p}}{2}$.

Para o caso da matriz de transformação [Q], o mesmo procedimento será utilizado, sendo aqui chamados de coeficientes relativos as forças de interação 
laterais, os termos " $d_{i j}$ " e " $e_{i j}$ ", e os relativos as forças de interação verticais, os termos " "fij".

$$
[Q]=\left[\begin{array}{cccccccccccc}
\mathrm{d}_{11} & 0 & 0 & \mathrm{~d}_{12} & 0 & 0 & \mathrm{~d}_{13} & 0 & 0 & \mathrm{~d}_{14} & 0 & 0 \\
0 & \mathrm{e}_{11} & 0 & 0 & \mathrm{e}_{12} & 0 & 0 & \mathrm{~d}_{13} & 0 & 0 & \mathrm{e}_{14} & 0 \\
0 & 0 & \mathrm{f}_{11} & 0 & 0 & \mathrm{f}_{12} & 0 & 0 & \mathrm{f}_{13} & 0 & 0 & \mathrm{f}_{14} \\
\mathrm{~d}_{21} & 0 & 0 & \mathrm{~d}_{22} & 0 & 0 & \mathrm{~d}_{23} & 0 & 0 & \mathrm{~d}_{24} & 0 & 0 \\
0 & \mathrm{e}_{21} & 0 & 0 & \mathrm{e}_{22} & 0 & 0 & \mathrm{e}_{23} & 0 & 0 & \mathrm{e}_{24} & 0 \\
\mathrm{~d}_{31} & 0 & 0 & \mathrm{~d}_{32} & 0 & 0 & \mathrm{~d}_{33} & 0 & 0 & \mathrm{~d}_{34} & 0 & 0 \\
0 & \mathrm{e}_{31} & 0 & 0 & \mathrm{e}_{32} & 0 & 0 & \mathrm{e}_{33} & 0 & 0 & \mathrm{e}_{34} & 0 \\
0 & 0 & \mathrm{f}_{21} & 0 & 0 & \mathrm{f}_{22} & 0 & 0 & \mathrm{f}_{23} & 0 & 0 & \mathrm{f}_{24} \\
\mathrm{~d}_{41} & 0 & 0 & \mathrm{~d}_{42} & 0 & 0 & \mathrm{~d}_{43} & 0 & 0 & \mathrm{~d}_{44} & 0 & 0 \\
0 & \mathrm{e}_{41} & 0 & 0 & \mathrm{e}_{42} & 0 & 0 & \mathrm{e}_{43} & 0 & 0 & \mathrm{e}_{44} & 0 \\
0 & 0 & \mathrm{f}_{31} & 0 & 0 & \mathrm{f}_{32} & 0 & 0 & \mathrm{f}_{33} & 0 & 0 & \mathrm{f}_{34} \\
\mathrm{~d}_{51} & 0 & 0 & \mathrm{~d}_{52} & 0 & 0 & \mathrm{~d}_{53} & 0 & 0 & \mathrm{~d}_{54} & 0 & 0 \\
0 & \mathrm{e}_{51} & 0 & 0 & \mathrm{e}_{52} & 0 & 0 & \mathrm{e}_{53} & 0 & 0 & \mathrm{e}_{54} & 0 \\
0 & 0 & \mathrm{f}_{41} & 0 & 0 & \mathrm{f}_{42} & 0 & 0 & \mathrm{f}_{43} & 0 & 0 & \mathrm{f}_{44}
\end{array}\right]
$$

Tendo ainda os coeficientes " $\mathrm{d}_{\mathrm{ij}}$ " e " $\mathrm{e}_{\mathrm{ij}}$ " que devem ser multiplicados pela constante $\frac{\mathrm{L}}{6720}$ e os coeficientes " $\mathrm{f}_{\mathrm{ij}}$ " multiplicados por $\frac{\mathrm{L}}{80}$.

E os vetores são dados da seguinte forma:

$$
\begin{aligned}
& \{F\}^{T}=\left\{\begin{array}{llllllllllllll}
\mathrm{F}_{1} & \mathrm{~F}_{2} & \mathrm{~F}_{3} & \mathrm{M}_{1} & \mathrm{M}_{2} & 0 & 0 & 0 & 0 & 0 & 0 & 0 & 0 & 0
\end{array}\right\} \\
& \left\{\mathrm{u}_{\mathrm{p}}\right\}^{\mathrm{T}}=\left\{\begin{array}{llllllllllllll}
\mathrm{u}_{\mathrm{i}} & \mathrm{v}_{\mathrm{i}} & \mathrm{w}_{\mathrm{i}} & \mathrm{u}_{\mathrm{i}}^{\prime} & \mathrm{v}_{\mathrm{i}}^{\prime} & \mathrm{u}_{\mathrm{j}} & \mathrm{v}_{\mathrm{j}} & \mathrm{w}_{\mathrm{j}} & \mathrm{u}_{\mathrm{k}} & \mathrm{v}_{\mathrm{k}} & \mathrm{w}_{\mathrm{k}} & \mathrm{u}_{1} & \mathrm{v}_{1} & \mathrm{w}_{1}
\end{array}\right\} \\
& \left\{\mathrm{P}_{\mathrm{p}}\right\}=\left\{\begin{array}{llllllllllll}
\mathrm{P}_{1} & \mathrm{P}_{5} & \mathrm{P}_{9} & \mathrm{P}_{2} & \mathrm{P}_{6} & \mathrm{P}_{10} & \mathrm{P}_{3} & \mathrm{P}_{7} & \mathrm{P}_{11} & \mathrm{P}_{4} & \mathrm{P}_{8} & \mathrm{P}_{12}
\end{array}\right\}
\end{aligned}
$$

Na discretização do solo, como já visto anteriormente, tem-se que:

$$
\left\{\mathrm{u}_{\mathrm{s}}\right\}=[\mathrm{G}]\left\{\mathrm{P}_{\mathrm{s}}\right\}
$$

onde:

$\left\{\mathrm{u}_{\mathrm{s}}\right\}^{\mathrm{T}}=\left\{\begin{array}{llllllllllll}\mathrm{u}_{\mathrm{i}} & \mathrm{v}_{\mathrm{i}} & \mathrm{w}_{\mathrm{i}} & \mathrm{u}_{\mathrm{j}} & \mathrm{v}_{\mathrm{j}} & \mathrm{w}_{\mathrm{j}} & \mathrm{u}_{\mathrm{k}} & \mathrm{v}_{\mathrm{k}} & \mathrm{w}_{\mathrm{k}} & \mathrm{u}_{\mathrm{l}} & \mathrm{v}_{\mathrm{l}} & \mathrm{w}_{\mathrm{l}}\end{array}\right\}$

$$
\left\{\mathrm{P}_{\mathrm{s}}\right\}=\left\{\mathrm{P}_{\mathrm{p}}\right\}=\left\{\begin{array}{llllllllllll}
\mathrm{P}_{1} & \mathrm{P}_{5} & \mathrm{P}_{9} & \mathrm{P}_{2} & \mathrm{P}_{6} & \mathrm{P}_{10} & \mathrm{P}_{3} & \mathrm{P}_{7} & \mathrm{P}_{11} & \mathrm{P}_{4} & \mathrm{P}_{8} & \mathrm{P}_{12}
\end{array}\right\}
$$

$\mathrm{E}$ o tensor de deslocamentos fundamentais é dado da seguinte maneira:

$$
u_{i j}^{*}(s, p)=\left[\begin{array}{ccc}
u_{11}^{*} & u_{12}^{*} & u_{13}^{*} \\
u_{21}^{*} & u_{22}^{*} & u_{23}^{*} \\
u_{31}^{*} & u_{32}^{*} & u_{33}^{*}
\end{array}\right]
$$

Faltando ainda multiplicar estes termos pelo coeficiente de ponderação $\left(\mathbf{w}_{\mathrm{m}}\right)$, visto que as integrais são resolvidas numericamente, salvo a integral referente ao 
termo $\mathrm{u}_{33}^{*}$ no ponto nodal "4" que é singular e portanto resolvida analiticamente (Cap. 5).

Fazendo-se agora a interação MEC/MEF, onde, o presente caso de idealização do maciço de solos, apresenta matrizes e vetores de ordem (12x12) e (12x1) respectivamente, isto é:

$$
\left\{\mathrm{u}_{\mathrm{s}}\right\}_{12 \times 1}=[\mathrm{G}]_{12 \times 12}\left\{\mathrm{P}_{\mathrm{s}}\right\}_{12 \times 1}
$$

E como já visto, a equação proveniente o MEF para a discretização da estaca, é dada da seguinte forma:

$$
\left[\mathrm{K}_{\mathrm{c}}\right]_{14 \times 14}\left\{\mathrm{u}_{\mathrm{p}}\right\}_{14 \times 1}=\{\mathrm{F}\}_{14 \times 1}-[\mathrm{Q}]_{14 \times 12}\left\{\mathrm{P}_{\mathrm{p}}\right\}_{12 \times 1}
$$

Colocando a equação do solo em função das forças de interação, têm-se:

$$
\left\{\mathrm{P}_{\mathrm{s}}\right\}_{12 \times 1}=[\mathrm{G}]_{12 \times 12}^{-1}\left\{\mathrm{P}_{\mathrm{s}}\right\}_{12 \times 1}
$$

Substituindo a eq. (6.22) na equação da estaca, obtém-se:

$$
\left[\mathrm{K}_{\mathrm{c}}\right]_{14 \times 14}\left\{\mathrm{u}_{\mathrm{p}}\right\}_{14 \times 1}=\{\mathrm{F}\}_{14 \times 1}-[\mathrm{Q}]_{14 \times 12}[\mathrm{G}]_{12 \times 12}^{-1}\left\{\mathrm{u}_{\mathrm{s}}\right\}_{12 \times 1}
$$

onde:

$$
[\mathrm{M}]_{14 \times 12}=[\mathrm{Q}]_{14 \times 12}[\mathrm{G}]_{12 \times 12}^{-1}
$$

Expande-se agora a matriz [M] com a finalidade de se obter-se a mesma ordem desta matriz para com as demais através da compatibilidade deslocamentos existente entre a estaca e o solo. Para o caso em questão, colocadas duas colunas de zeros, a partir da terceira coluna, referentes as rotações em torno dos dois eixos, ou seja:

$$
[\overline{\mathrm{M}}]_{14 \times 14}=\left[\begin{array}{ccccccccc}
\mathrm{m}_{11} & \mathrm{~m}_{12} & \mathrm{~m}_{13} & 0 & 0 & \ldots \ldots . & \ldots \ldots & \mathrm{m}_{113} & \mathrm{~m}_{114} \\
\mathrm{~m}_{21} & \mathrm{~m}_{22} & \mathrm{~m}_{23} & 0 & 0 & \ldots \ldots & \ldots \ldots & \mathrm{m}_{213} & \mathrm{~m}_{214} \\
\mathrm{~m}_{31} & \mathrm{~m}_{23} & \mathrm{~m}_{33} & 0 & 0 & \ldots \ldots & \ldots \ldots & \mathrm{m}_{313} & \mathrm{~m}_{314} \\
\ldots \ldots & \ldots \ldots & \ldots \ldots & 0 & 0 & \ldots \ldots & \ldots \ldots & \ldots \ldots & \ldots \ldots \\
\ldots \ldots & \ldots \ldots & \ldots \ldots & 0 & 0 & \ldots \ldots & \ldots \ldots & \ldots \ldots & \ldots \ldots \\
\ldots \ldots & \ldots \ldots & \ldots \ldots & 0 & 0 & \ldots \ldots & \ldots \ldots & \ldots \ldots & \ldots \ldots \\
\ldots \ldots & \ldots \ldots . & \ldots \ldots & 0 & 0 & \ldots \ldots & \ldots \ldots & \ldots \ldots & \ldots \ldots \\
\mathrm{m}_{131} & \mathrm{~m}_{132} & \mathrm{~m}_{133} & 0 & 0 & \ldots \ldots & \ldots \ldots & \mathrm{m}_{1313} & \mathrm{~m}_{1314} \\
\mathrm{~m}_{141} & \mathrm{~m}_{142} & \mathrm{~m}_{143} & 0 & 0 & \ldots \ldots & \ldots \ldots . & \mathrm{m}_{1413} & \mathrm{~m}_{1414}
\end{array}\right]_{14 \times 14}
$$

Como:

$$
\left\{\mathrm{u}_{\mathrm{s}}\right\}=\left\{\mathrm{u}_{\mathrm{p}}\right\}=\{\overline{\mathrm{U}}\}
$$

Portanto:

$$
\left[\left[\mathrm{K}_{\mathrm{c}}\right]_{14 \times 14}+\left[\overline{\mathrm{M}}_{14 \times 14}\right]\{\overline{\mathrm{U}}\}_{14 \times 1}=\{\mathrm{F}\}_{14 \times 1}\right.
$$


E finalmente:

$$
[\overline{\mathrm{K}}]_{14 \times 14}\{\overline{\mathrm{U}}\}_{14 \times 1}=\{\mathrm{F}\}_{14 \times 1}
$$

\subsection{1) Avaliação do Modelo}

\section{a) Exemplo 1}

Para este exemplo serão admitidas as mesmas características dos exemplos citados nos itens 4.2.1a e 5.2.1a, verificando-se assim que o modelo em questão é exeqüível, ou seja a resolução do sistema sob ação simultânea de cargas horizontais e verticais é consistente com a formulação descrita neste capítulo. As tabelas, 6.1 e 6.2, apresentam resultados destes três exemplos avaliados.

Tab. 6.1 - Deslocamentos laterais, verticais e rotações em uma estaca solicitada por cargas verticais e horizontais separadamente.

\begin{tabular}{|c|c|c|c|c|c|}
\hline \multirow{2}{*}{ Exemplos } & \multicolumn{4}{|c|}{ Ex. 4.2.1a) } & Ex. 5.2.1a) \\
\hline & $X_{1}(\mathrm{~mm})$ & $\mathrm{X}_{2}(\mathrm{~mm})$ & $\theta_{2}$ (rad.) & $\theta_{1}$ (rad.) & $\mathrm{X}_{3}(\mathrm{~mm})$ \\
\hline 0 & 0,7166 & 0,7166 & $-0,6336 \cdot 10^{-3}$ & $0,6336.10^{-3}$ & 1,0047 \\
\hline $\mathrm{L} / 3$ & 0,0866 & 0,0866 & & & 0,8121 \\
\hline $2 \mathrm{~L} / 3$ & 0,0426 & 0,0426 & & & 0,6934 \\
\hline L & 0,0249 & 0,0249 & & & 0,6418 \\
\hline
\end{tabular}

Tab. 6.2 - Deslocamentos laterais, verticais e rotações em uma estaca solicitada por cargas verticais e horizontais simultaneamente.

\begin{tabular}{|c|c|c|c|c|c|}
\hline \multirow{2}{*}{ Cotas } & \multicolumn{5}{|c|}{ Ex. 6.2.1a) } \\
\cline { 2 - 6 } & $\mathbf{X}_{\mathbf{1}}(\mathbf{m m})$ & $\mathbf{X}_{\mathbf{2}}$ (mm) & $\theta_{\mathbf{2}}$ (rad.) & $\theta_{\mathbf{1}}$ (rad.) & $\mathbf{X}_{\mathbf{3}}$ (mm) \\
\hline 0 & 0,7166 & 0,7166 & $-0,6336.10^{-3}$ & $0,6336.10^{-3}$ & 1,0047 \\
\hline $\mathrm{L} / 3$ & 0,0866 & 0,0866 & & & 0,8121 \\
\hline $2 \mathrm{~L} / 3$ & 0,0426 & 0,0426 & & & 0,6934 \\
\hline $\mathrm{L}$ & 0,0249 & 0,0249 & & & 0,6418 \\
\hline
\end{tabular}




\section{3) Grupos de Estacas Sujeitas a Carregamentos Horizontais e Verticais}

A análise de grupos de estacas sujeitas a cargas horizontais já foi assunto abordado neste trabalho (seção 4.3). Nesta seção será descrito o acoplamento das parcelas referentes ao tratamento de cargas verticais no processo de expansão do modelo apresentado na seção 6.2.

Sabendo-se que "Ne" é o número de estacas de um grupo, basta simplesmente multiplicá-lo pela atual ordem das matrizes e vetores do sistema para se ter as suas respectivas ordem finais.

Novamente admite-se que se está trabalhando com duas estacas $(\mathrm{Ne}=2)$, apenas para efeito de simplificação.

Sendo assim, a matriz de coeficientes de influência proveniente do maciço de solos, obtida através do MEC, será:

$$
[\mathrm{G}]_{24 \times 24}=\left[\begin{array}{ll}
{\left[\mathrm{MEC}_{11}\right]_{12 \times 12}} & {\left[\mathrm{MEC}_{12}\right]_{12 \times 12}} \\
{\left[\mathrm{MEC}_{21}\right]_{12 \times 12}} & {\left[\mathrm{MEC}_{22}\right]_{12 \times 12}}
\end{array}\right]_{24 \times 24}
$$

onde:

$\mathrm{MEC}_{11}, \mathrm{MEC}_{12}, \mathrm{MEC}_{21}$ e $\mathrm{MEC}_{22}$ já foram descritos anteriormente (eq. 4.27).

No tratamento da estaca via MEF, sabe-se que suas matrizes e vetores tem a seguinte ordem:

$\mathrm{K}_{\mathrm{c}}(14 \mathrm{Ne} \times 14 \mathrm{Ne}), \mathrm{Q}(14 \mathrm{Ne} \times 12 \mathrm{Ne}), \mathrm{P}_{\mathrm{p}}(12 \mathrm{Ne}), \mathrm{U}_{\mathrm{p}}(14 \mathrm{Ne})$ e $\mathrm{F}(14 \mathrm{Ne})$.

$E$ também sabe-se que não existe influência entre uma estaca e outra, portanto para o caso de se ter 2 estacas, tem-se:

$$
\left[\mathrm{K}_{\mathrm{c}}\right]_{28 \times 28}=\left[\begin{array}{cc}
{\left[\mathrm{MEF}_{11}\right]_{14 \mathrm{X} 14}} & {[0]_{14 \times 14}} \\
{[0]_{14 \times 14}} & {\left[\mathrm{MEF}_{22}\right]_{14 \times 14}}
\end{array}\right]_{28 \times 28}
$$

onde:

$M E F_{11}, M E F_{12}, M E F_{21}, M E F_{22}$ já foram descritos (eq. 4.28).

Da mesma maneira, a matriz de transformação de forças pode ser apresentada como:

$$
[\mathrm{Q}]_{28 \times 24}=\left[\begin{array}{cc}
{\left[\mathrm{Q}_{11}\right]_{14 \times 12}} & {[0]_{14 \times 12}} \\
{[0]_{14 \times 12}} & {\left[\mathrm{Q}_{22}\right]_{14 \times 12}}
\end{array}\right]_{28 \times 24}
$$

sendo:

$Q_{11}, Q_{12}, Q_{21}$ e $Q_{22}$ também já descritos anteriormente (eq. 4.29).

$\mathrm{E}$ utilizando-se o processo de superposição de efeitos, pode-se chegar a seguinte matriz de rigidez do sistema: 


$$
[\mathrm{T}]_{28 \times 28}=\left[\begin{array}{cc}
{\left[\mathrm{MEC}_{11}+\mathrm{MEF}_{11}\right]_{14 \times 14}} & {\left[\mathrm{MEC}_{12}\right]_{14 \times 14}} \\
{\left[\mathrm{MEC}_{21}\right]_{14 \times 14}} & {\left[\mathrm{MEC}_{22}+\mathrm{MEF}_{22}\right]_{14 \times 14}}
\end{array}\right]_{28 \times 28}
$$

\subsection{1) Avaliação do Modelo}

\section{a) Exemplo 1}

A figura 6.2 mostra um exemplo, apresentado por BUTTERFIELD \& BANERJEE (1971), onde um grupo de 4 estacas é solicitado por um carregamento vertical idêntico aplicado sob o topo das mesmas.

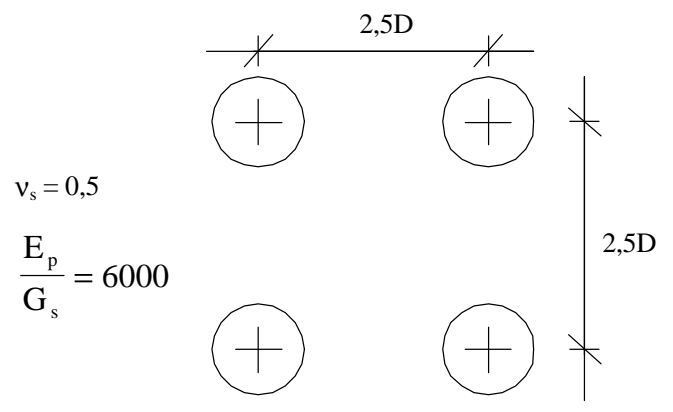

Fig. 6.2 - Grupo com 4 estacas igualmente solicitadas por uma carga vertical.

Os resultados obtidos pelo modelo proposto neste trabalho (MODELO_14PAR) são apresentados graficamente na figura 6.3 e mostram um aumento da rigidez do sistema $\left(\frac{\mathrm{P}}{\mathrm{G}_{\mathrm{s}} \mathrm{wD}}\right)$ de acordo com o aumento da relação comprimento-diâmetro (L/d). 


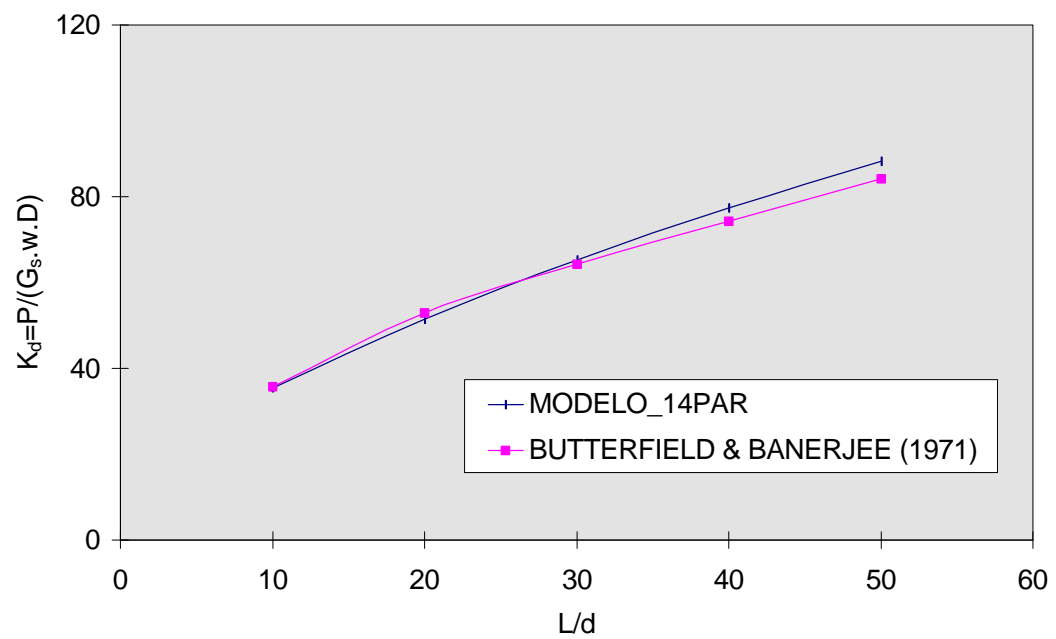

Fig. 6.3 - Comparações de modelos - curvas carga-deslocamento para uma estaca isolada sujeita a uma carga unitária horizontal.

\section{b) Exemplo 2}

Neste exemplo são apresentadas 4 estacas submetidas à carregamentos horizontais e verticais simétricos, como mostra a fig. 6.4.

$$
\begin{aligned}
& E_{p}=2,1 \cdot 10^{7} \mathrm{kN} / \mathrm{m}^{2} \\
& v_{s}=0,5 \\
& E_{s}=21000 \mathrm{kN} / \mathrm{m}^{2} \\
& D=0,40 \mathrm{~m} \\
& H=150 \mathrm{kN} \\
& V=200 \mathrm{kN} \\
& L_{p}=15 \mathrm{~m} \\
& \mathrm{~s}=1,0 \mathrm{~m}
\end{aligned}
$$

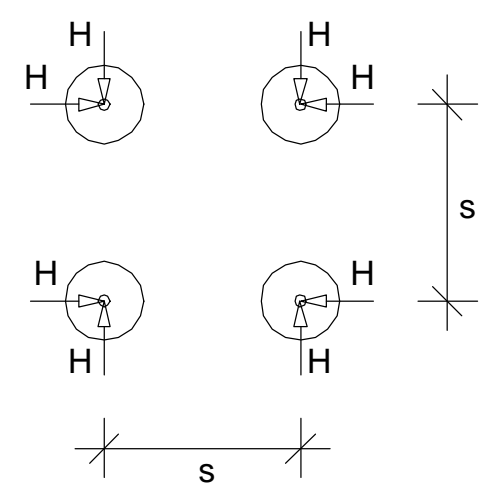

Fig. 6.4 - Grupo de estacas submetidas à cargas horizontais e verticais simultaneamente.

Dada a simetria de carregamentos, conseqüentemente os deslocamentos também serão simétricos, sendo esses apresentados na tabela 6.3. 
Tab. 6.3 - Deslocamentos laterais, verticais e rotações no topo do grupo de estacas.

\begin{tabular}{|l|c|c|c|c|}
\hline & Estaca 1 & Estaca 2 & Estaca 3 & Estaca 4 \\
\hline Carga (Dir. $\mathbf{X}_{\mathbf{1}}$ ) & $150 \mathrm{kN}$ & $-150 \mathrm{kN}$ & $-150 \mathrm{kN}$ & $150 \mathrm{kN}$ \\
\hline Carga (Dir. $\mathbf{X}_{\mathbf{2}}$ ) & $150 \mathrm{kN}$ & $150 \mathrm{kN}$ & $-150 \mathrm{kN}$ & $-150 \mathrm{kN}$ \\
\hline Carga (Dir. $\mathbf{X}_{\mathbf{3}}$ ) & $200 \mathrm{kN}$ & $200 \mathrm{kN}$ & $200 \mathrm{kN}$ & $200 \mathrm{kN}$ \\
\hline Desl. $\mathbf{X}_{\mathbf{1}}$ (mm) & 2,3975 & $-2,3975$ & $-2,3975$ & 2,3975 \\
\hline Rot. em $\mathbf{X}_{\mathbf{2}}$ (rad.) & $-0,5045.10^{-2}$ & $0,5045.10^{-2}$ & $0,5045.10^{-2}$ & $-0,5045.10^{-2}$ \\
\hline Desl. $\mathbf{X}_{\mathbf{2}}$ (mm) & 2,3975 & 2,3975 & $-2,3975$ & $-2,3975$ \\
\hline Rot. em $\mathbf{X}_{\mathbf{1}}$ (rad.) & $0,5045.10^{-2}$ & $0,5045.10^{-2}$ & $-0,5045.10^{-2}$ & $-0,5045.10^{-2}$ \\
\hline Desl. $\mathbf{X}_{\mathbf{3}}$ (mm) & 3,4394 & 3,4394 & 3,4394 & 3,4394 \\
\hline
\end{tabular}

Obs.: Os deslocamentos descritos acima, são referentes ao topo das suas respectivas estacas.

\section{4) Blocos de Capeamento Rígido}

Para a utilização de blocos de capeamento rígido, lembrando que as demais matrizes e vetores do modelo aqui proposto já foram ampliadas, basta apenas expandir a ordem da matriz identidade $\mathrm{I}(10 \mathrm{Ne} \times 10 \mathrm{Ne})$, descrita na seção 4.4 , para uma matriz agora de ordem $14 \mathrm{Ne} \times 14 \mathrm{Ne}$, englobando assim as parcelas referentes as forças e/ou deslocamentos verticais.

\subsection{1) Avaliação do Modelo}

A figura 6.5 apresenta um bloco de capeamento rígido sobre um grupo de 6 estacas com comprimentos e diâmetros idênticos 25pés e 1pé, respectivamente, solicitadas por uma carga vertical de 300 kips. O coeficiente de comprexibilidade entre a estaca e o solo $\left(K=\frac{E_{p}}{E_{s}}\right)$ é igual a 2000. Será admitido um módulo de elasticidade do solo de 80 kips/pés² (POULOS, 1980).

A resolução deste problema implica na obtenção dos recalques (idênticos) que ocorrem no topo de cada estaca. Os resultados são comparados com os apresentados por POULOS (1980). 

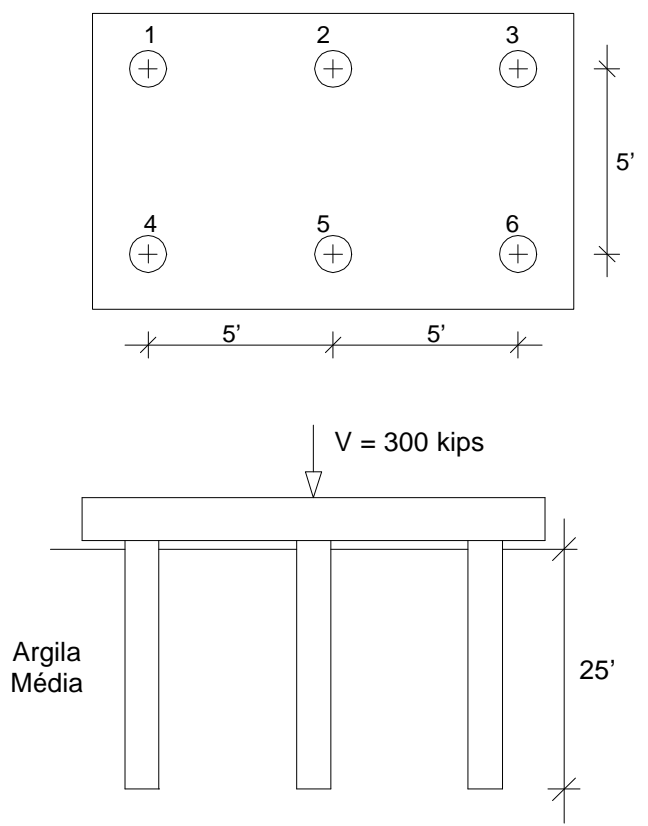

Fig. 6.5 - Figura adaptada de POULOS (1980).

Começando-se este problema, prescreve-se um valor unitário (1"), para todas as estacas, referente a ocorrência de um deslocamento vertical no topo destas. Obtém-se assim os esforços necessários para que estes deslocamentos idênticos ocorram.

Devido a simetria geométrica do sistema, pode-se notar que existem dois sub-grupos de estacas, sendo o primeiro formado pelas estacas 1 , 3, 4 e $6\left(V_{1}\right)$ e o segundo formado pelas estacas 2 e $5\left(V_{2}\right)$.

Os resultados destes esforços (coeficientes de mola $\mathrm{K}_{1}$ e $\mathrm{K}_{2}$ ) necessários para a ocorrência do deslocamento unitário, são apresentados na tabela 6.4.

Tab. 6.4 - Forças causadas pelos deslocamentos verticais unitários nos respectivos subgrupos.

\begin{tabular}{|c|c|c|}
\hline Coef. de Mola & $\mathbf{K}_{1}$ & $\mathbf{K}_{\mathbf{2}}$ \\
\hline Estacas & 34,784 (kips/pol.) & - \\
\hline $1,3,4$ e 6 & - & 23,186 (kips/pol.) \\
\hline 2 e 5 &
\end{tabular}

Da equação de equilíbrio, tem-se:

$4 \mathrm{~V}_{1}+2 \mathrm{~V}_{2}=300 \mathrm{kips}$

E como:

$\mathrm{K}_{1}=34,784$ (kips/pol.)

$\mathrm{K}_{2}=23,186(\mathrm{kips} / \mathrm{pol}$.)

e 
$\mathrm{V}_{\mathrm{n}}=\mathrm{K}_{\mathrm{n}} \cdot \mathrm{w}_{\mathrm{n}}$, onde pode-se dizer que $\mathrm{w}_{1}=\mathrm{w}_{2}$ (valores de deslocamentos unitários).

Então:

$\mathrm{V}_{1}=1,5002 \mathrm{~V}_{2}$

Substituindo na equação de equilíbrio, obtém-se:

$\mathrm{V}_{2}=56,252 \mathrm{kips}$ e conseqüentemente,

$\mathrm{V}_{1}=37,496$ kips

Recalculando novamente o sistema agora com as forças, $V_{1}$ e $V_{2}$ prescritas, chega-se a um recalque comum para todas as estacas, sendo este:

$\mathrm{w}=1,6172$ pol.

Os valores obtidos por Poulos foram os seguintes:

$\mathrm{V}_{1}=57,4 \mathrm{kips}$

$\mathrm{V}_{2}=35,2$ kips

$\mathrm{e}$

$\mathrm{W}_{\text {POULOS }}=1,66$ pol.

As diferenças ocorridas com relação aos deslocamentos e forças aconteceram provavelmente devido ao um melhor refinamento utilizado pelo modelo proposto para discretizar o maciço de solos (MEC) e também devido ao modelo de Poulos ter sido desenvolvido para duas estacas e estendido posteriormente para grupos genéricos de espaçamentos idênticos, o que não ocorre no exemplo em questão.

\section{5) Estacas inclinadas}

Para o tratamento de estacas inclinadas serão adotadas todas as hipóteses básicas e a formulação considerada para as estacas verticais (isoladas e em grupos) constituídas por um único elemento contendo 14 parâmetros nodais (MODELO_14PAR) e solicitadas por cargas horizontais e verticais, bastando agora multiplicar corretamente as matriz de rigidez do sistema pela sua correspondente matriz de rotação e por sua transposta, sendo esta matriz também utilizada para a determinação dos pontos "campo" e "fonte" necessários para o desenvolvimento do MEC.

FERRO (1999), apresenta uma formulação, onde a determinação dos pontos "campo" é feita admitindo-se uma posição qualquer para a estaca imersa em um meio contínuo. O seu eixo central, em relação a um sistema de coordenadas 
globais, forma os ângulos $\alpha, \beta$ e $\gamma$, respectivamente em relação aos eixos $X_{1}, X_{2}$ e $X_{3}$.

De uma forma semelhante, as coordenadas de um ponto "p" (ponto campo) na superfície lateral da estaca serão escritas em função das coordenadas de um ponto "s" (ponto fonte) no centro da seção para o presente caso (fig. 6.6).

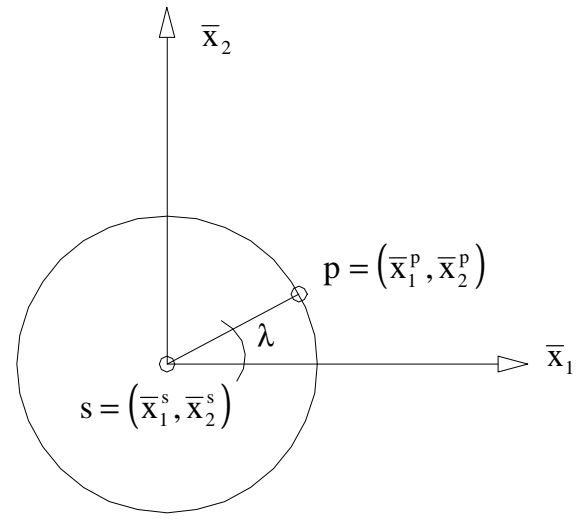

Fig. 6.6 - Sistema de coordenadas locais para uma seção da estaca.

Pela qual fica definido um sistema de coordenadas locais da seguinte maneira:

$$
\begin{aligned}
& \overline{\mathrm{x}}_{1}^{\mathrm{p}}=\overline{\mathrm{x}}_{1}^{\mathrm{s}}+\mathrm{r}_{\mathrm{f}} \cos \lambda \\
& \overline{\mathrm{x}}_{2}^{\mathrm{p}}=\overline{\mathrm{x}}_{2}^{\mathrm{s}}+\mathrm{r}_{\mathrm{f}} \operatorname{sen} \lambda \\
& \overline{\mathrm{x}}_{3}^{\mathrm{p}}=\overline{\mathrm{x}}_{3}^{\mathrm{s}}
\end{aligned}
$$

Colocando estas equações na forma matricial, tem-se:

$$
\left\{\overline{\mathrm{X}}^{\mathrm{p}}\right\}=\left\{\overline{\mathrm{x}}^{\mathrm{s}}\right\}+\{\mathrm{M}\} \mathrm{r}_{\mathrm{f}}
$$

Onde o vetor $\{\mathrm{M}\}$ é dado por:

$$
\{M\}=\left\{\begin{array}{c}
\cos \lambda \\
\operatorname{sen} \lambda \\
0
\end{array}\right\}
$$

As coordenadas do ponto "p" no sistema global podem ser expressas, como:

$$
\left\{\mathrm{x}^{\mathrm{p}}\right\}=[\mathrm{R}]^{\mathrm{T}}\left\{\overline{\mathrm{x}}^{\mathrm{p}}\right\}
$$

onde:

$\left\{\mathrm{x}^{\mathrm{p}}\right\}$ : coordenadas no ponto "p" no sistema global;

$[R]^{T}$ : matriz de rotação transposta que relaciona os sistemas de coordenadas local e global.

Esta matriz transposta é dada da seguinte maneira: 


$$
[\mathrm{R}]^{\mathrm{T}}=\left[\begin{array}{ccc}
\sqrt{\mathrm{CY}^{2}+\mathrm{CZ}^{2}} & \frac{-\mathrm{CXCY}}{\sqrt{\mathrm{CY}^{2}+\mathrm{CZ}^{2}}} & \frac{-\mathrm{CXCZ}}{\sqrt{\mathrm{CY}^{2}+\mathrm{CZ}^{2}}} \\
0 & \frac{\mathrm{CZ}}{\sqrt{\mathrm{CY}^{2}+\mathrm{CZ}^{2}}} & \frac{-\mathrm{CY}}{\sqrt{\mathrm{CY}^{2}+\mathrm{CZ}^{2}}} \\
\mathrm{CX} & \mathrm{CY} & \mathrm{CZ}
\end{array}\right]
$$

Sendo:

$$
\mathrm{CX}=\frac{\mathrm{x}_{\mathrm{k}}-\mathrm{x}_{\mathrm{j}}}{\mathrm{L}_{\mathrm{p}}} ; \mathrm{CY}=\frac{\mathrm{y}_{\mathrm{k}}-\mathrm{y}_{\mathrm{j}}}{\mathrm{L}_{\mathrm{p}}} ; \mathrm{CZ}=\frac{\mathrm{z}_{\mathrm{k}}-\mathrm{z}_{\mathrm{j}}}{\mathrm{L}_{\mathrm{p}}}
$$

e os índices "k" e "j", das coordenadas $x, y, z$, referentes aos nós final e inicial dos elementos, respectivamente.

Substituindo o vetor de coordenadas locais do ponto "p" (eq. 6.34) na equação 6.36 , tem-se que:

$$
\left\{\mathrm{X}^{\mathrm{p}}\right\}=[\mathrm{R}]^{\mathrm{T}}\left(\left\{\overline{\mathrm{x}}^{\mathrm{s}}\right\}+[\mathrm{M}] \mathrm{r}_{\mathrm{f}}\right)
$$

As coordenadas do ponto "s", escritas no sistema global, ficam da seguinte maneira:

$$
\left\{x_{p}\right\}=[R]^{T}\left([R]\left\{x_{s}\right\}+\{M\} r_{f}\right)
$$

e finalizando:

$$
\left\{\mathrm{x}^{\mathrm{p}}\right\}=\left(\left\{\mathrm{x}^{\mathrm{s}}\right\}+\{\mathrm{N}\} \mathrm{r}_{\mathrm{f}}\right)
$$

onde:

$$
\{\mathrm{N}\}=\left\{\begin{array}{c}
\frac{\mathrm{CY}^{2} \cos \lambda+\mathrm{CZ}^{2} \cos \lambda-\mathrm{CXCY} \operatorname{sen} \lambda}{\sqrt{\mathrm{CY}^{2}+\mathrm{CZ}^{2}}} \\
\frac{\mathrm{CZ}}{\sqrt{\mathrm{CY}^{2}+\mathrm{CZ}^{2}}} \operatorname{sen} \lambda \\
\mathrm{CX} \cos \lambda+\mathrm{CY} \operatorname{sen} \lambda
\end{array}\right\}
$$

Desta maneira qualquer ponto "campo" na superfície lateral de lateral de uma esta cilíndrica, tem sua posição definida em relação a um ponto "fonte" no eixo da estaca.

Para o caso do MEF, o tratamento das estacas inclinadas será feito de tal forma que a matriz de rigidez da cada uma delas será obtida inicialmente em relação ao sistema de coordenadas local e posteriormente as variáveis locais serão transformadas em variáveis globais através da matriz de rotação entre os sitemas de coordenadas, ou seja:

$$
\left[\mathrm{K}_{\mathrm{c}}^{\mathrm{g}}\right]=[\mathrm{R}]\left[\mathrm{K}_{\mathrm{c}}\right][\mathrm{R}]^{\mathrm{T}}
$$

A matriz do MEC é obtida no sistema global, ou seja: 


$$
\left\{\mathrm{u}_{\mathrm{s}}\right\}=[\mathrm{G}]\left\{\mathrm{P}_{\mathrm{s}}\right\}
$$

Desta forma o sistema final para estacas inclinadas será:

$$
\left[[\mathrm{R}]\left[\mathrm{K}_{\mathrm{c}}\right][\mathrm{R}]^{\mathrm{T}}+[\overline{\mathrm{M}}]\right]\{\overline{\mathrm{U}}\}=\{\mathrm{F}\}
$$

\subsection{1) Avaliação do Modelo}

\section{a) Exemplo 1}

No exemplo a seguir apresenta-se uma estaca inclinada sujeita a cargas horizontais $\left(\mathrm{H}_{1}=\mathrm{H}_{2}=100 \mathrm{kN}\right)$ e a uma vertical $(\mathrm{V}=300 \mathrm{kN})$.

A figura 6.7 apresenta dos demais dados do problema, incluindo o ângulo de inclinação existente entre o eixo longitudinal da estaca e o eixo $X_{3}(\gamma)$ e o ângulo que a projeção da estaca em planta (plano $X Y$ ) faz com o eixo $X 1(\lambda)$.

$$
\begin{aligned}
& E_{p}=2,1 \cdot 10^{7} \mathrm{kN} / \mathrm{m}^{2} \\
& E_{s}=10500 \mathrm{kN} / \mathrm{m}^{2} \\
& v_{s}=0,5 \\
& L p=15 \mathrm{~m} \\
& D=0,35 \mathrm{~m}
\end{aligned}
$$
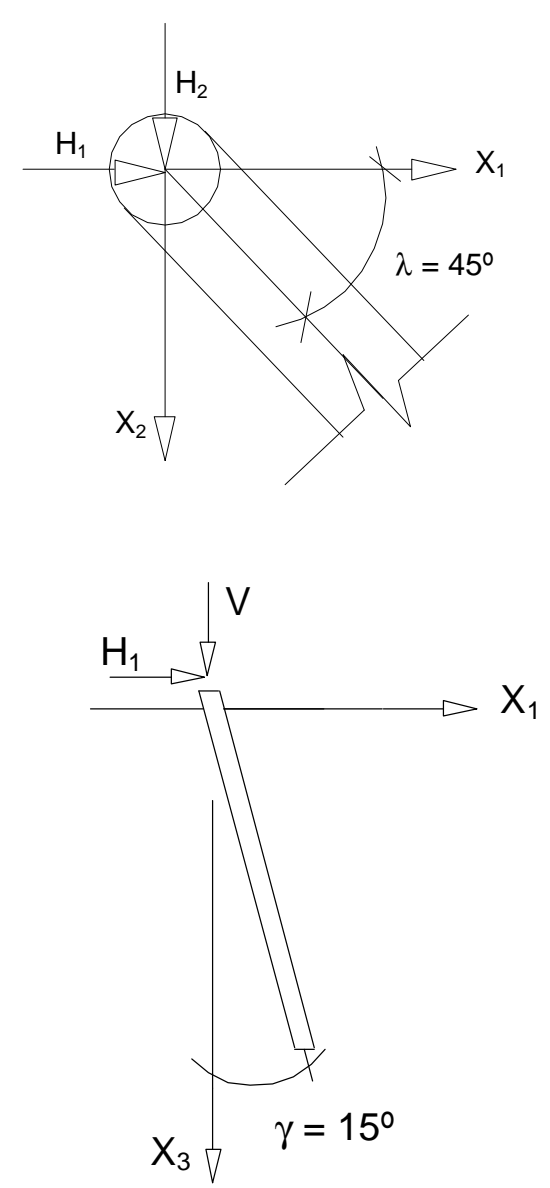

Fig. 6.7 - Estaca inclinada solicitada por cargas verticais e horizontais.

$\mathrm{Na}$ tabela 6.5 são mostrados os resultados obtidos neste problema, demonstrando uma semelhança de valores de deslocamentos horizontais e 
rotações em torno de seus respectivos eixos. Isto ocorre devido a simetria de cargas horizontais e também pelo ângulo de projeção em planta $(\lambda)$ ser igual a $45^{\circ}$.

Tab. 6.5 - Deslocamentos laterais, verticais e rotações em uma estaca inclinada sujeita a cargas horizontais e verticais.

\begin{tabular}{|c|c|c|c|c|c|}
\hline \multirow{2}{*}{ Direções } & \multicolumn{2}{|c|}{$\mathrm{X}_{\mathbf{1}}$} & \multicolumn{2}{c|}{$\mathrm{X}_{\mathbf{2}}$} & $\mathrm{X}_{\mathbf{3}}$ \\
\cline { 2 - 6 } & Desl. (mm) & Rot. (rad.) & Desl. (mm) & Rot. (rad.) & Desl. (mm) \\
\hline 0 & 6,8336 & $-0,7067.10^{-2}$ & 6,8336 & $0,7067.10^{-2}$ & 4,4974 \\
\hline $\mathrm{L} / 3$ & $-0,2100$ & & $-0,2100$ & & 3,8974 \\
\hline $2 \mathrm{~L} / 3$ & 0,8515 & & & & 3,5229 \\
\hline $\mathrm{L}$ & $-0,2234$ & & 0,8515 & & 3,3704 \\
\hline
\end{tabular}

\section{b) Exemplo 2}

A figura 6.8 apresenta duas estacas inclinadas submetidas a cargas horizontais opostas na direção $X_{1}$, mas com intensidade em módulo igual a $200 \mathrm{kN}$ e ainda uma carga vertical aplicada no topo de cada estaca igual a $150 \mathrm{kN}$.
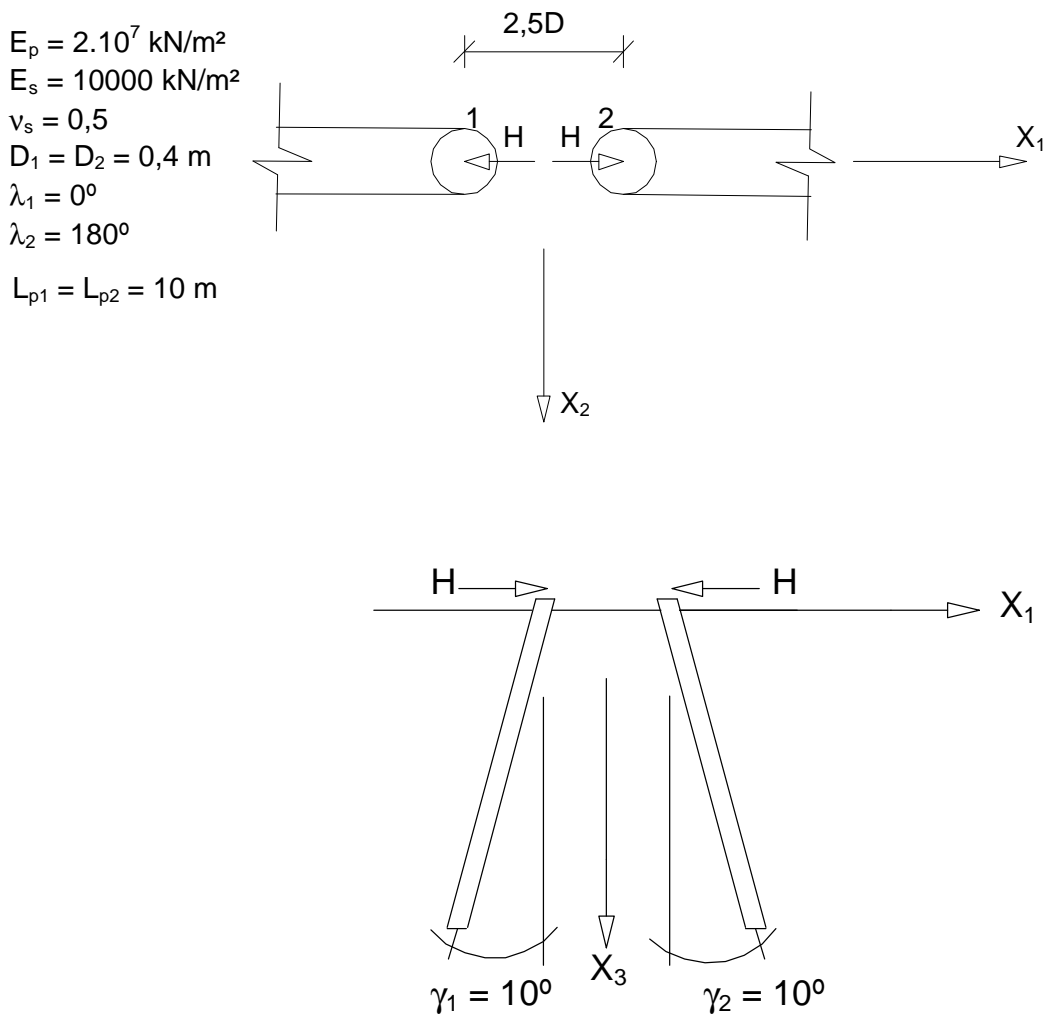

Fig. 6.8 - Estacas inclinadas solicitadas por cargas horizontais. 
A tabela 6.6 apresenta os resultados obtidos neste problema, podendo-se observar nesta, uma concordância entre os deslocamentos (em módulo) nas duas estacas. Isto ocorre devido a simetria de cargas horizontais e também pelo posicionamento das estacas.

Tab. 6.6 - Deslocamentos laterais, verticais e rotações em duas estacas inclinadas solicitadas por cargas horizontais.

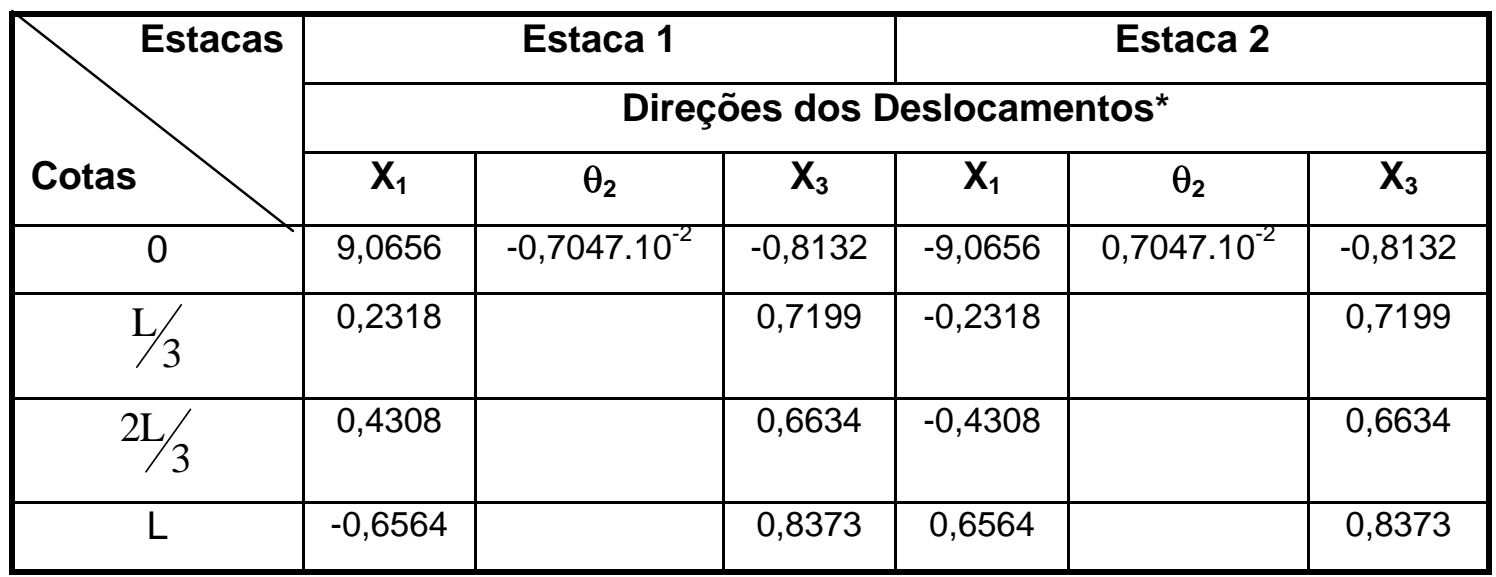

* Os deslocamentos lineares são dados em milímetros e as rotações em torno do eixo $\mathrm{X}_{2}$ são dadas em radianos.

\section{c) Exemplo 3}

Finalizando este capítulo, é apresentado na figura 6.9 um grupo composto por 4 estacas inclinadas solicitadas por carregamentos horizontais e verticais colocados de forma a se obter deslocamentos iguais em módulo em todas as estacas grupo. 

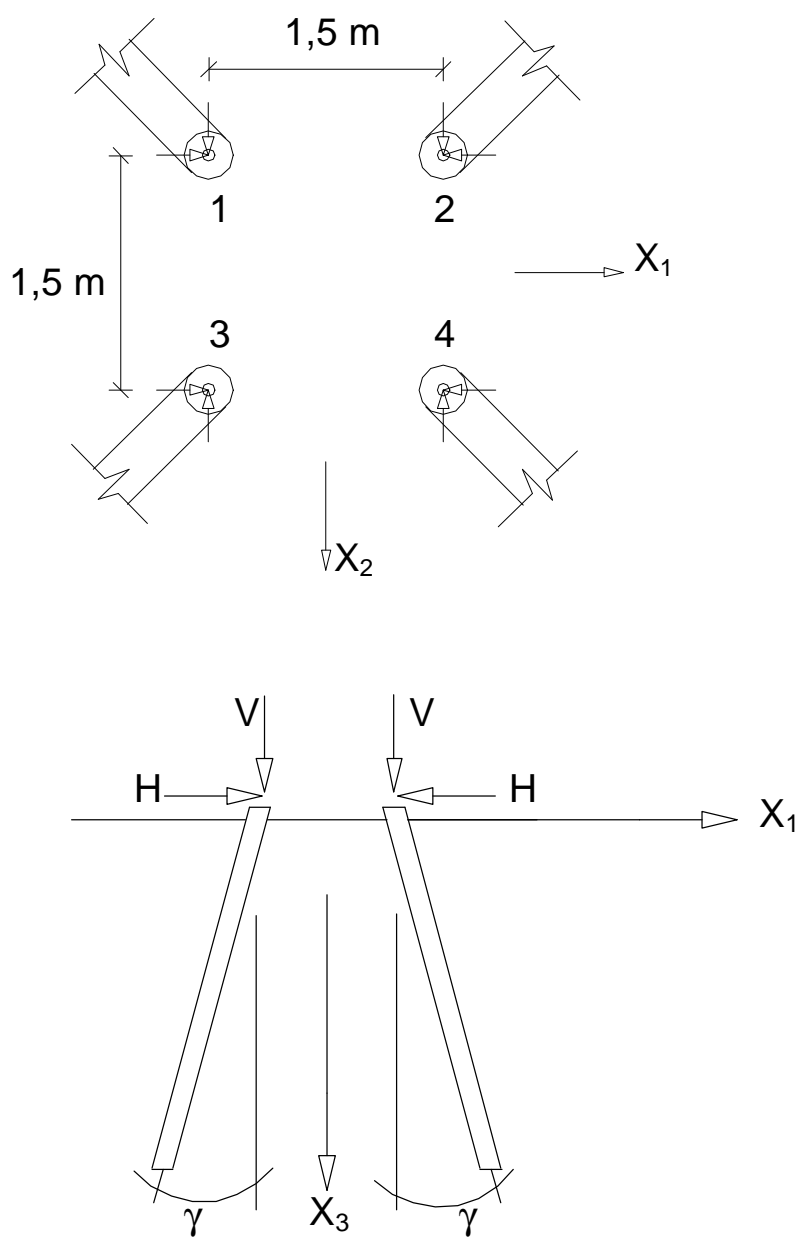

Fig. 6.9 - Grupos com 4 estacas inclinadas solicitadas por cargas horizontais e verticais.

Os demais dados do problema são citados abaixo:

$$
\begin{array}{lll}
\mathrm{E}_{\mathrm{s}}=10500 \mathrm{kN} / \mathrm{m}^{2} & \gamma_{1}=\gamma_{2}=\gamma_{3}=\gamma_{4}=12^{\circ} \\
\mathrm{E}_{\mathrm{p}}=2,1.107 \mathrm{kN} / \mathrm{m}^{2} & \lambda_{1}=225^{\circ} & \lambda_{2}=315^{\circ} \\
\mathrm{Lp} p_{1}=\mathrm{Lp}_{2}=\mathrm{Lp} \mathrm{p}_{3}=\mathrm{Lp}_{4}=25 \mathrm{~m} & \lambda_{3}=45^{\circ} & \lambda_{4}=135^{\circ} \\
\mathrm{D}_{1}=\mathrm{D}_{2}=\mathrm{D}_{3}=\mathrm{D}_{4}=0,40 \mathrm{~m} & \mathrm{H}=250 \mathrm{kN} & \mathrm{V}=400 \mathrm{kN}
\end{array}
$$

$\mathrm{Na}$ tabela 6.7 são mostrados estes deslocamentos lineares, bem como as rotações no topo das estacas. 
Tab. 6.7 - Deslocamentos laterais, verticais e rotações no topo do grupo de estacas inclinadas.

\begin{tabular}{|c|c|c|c|c|}
\hline & Estaca 1 & Estaca 2 & Estaca 3 & Estaca 4 \\
\hline Carga (Dir. $\mathrm{X}_{1}$ ) & $250 \mathrm{kN}$ & $-250 \mathrm{kN}$ & $-250 \mathrm{kN}$ & $250 \mathrm{kN}$ \\
\hline Carga (Dir. $X_{2}$ ) & $250 \mathrm{kN}$ & $250 \mathrm{kN}$ & $-250 \mathrm{kN}$ & $-250 \mathrm{kN}$ \\
\hline Carga (Dir. $\mathrm{X}_{3}$ ) & $400 \mathrm{kN}$ & $400 \mathrm{kN}$ & $400 \mathrm{kN}$ & $400 \mathrm{kN}$ \\
\hline Desl. $X_{1}(\mathrm{~mm})$ & 3,5782 & $-3,5782$ & $-3,5782$ & 3,5782 \\
\hline Rot. Em X $\mathbf{X}_{2}$ (rad.) & $-0,1944.10^{-1}$ & $0,1944 \cdot 10^{-1}$ & $0,1944 \cdot 10^{-1}$ & $-0,1944.10^{-1}$ \\
\hline Desl. $X_{2}(\mathrm{~mm})$ & 3,5782 & 3,5782 & $-3,5782$ & $-3,5782$ \\
\hline Rot. Em X (rad.) & $0,1944 \cdot 10^{-1}$ & $0,1944.10^{-1}$ & $-0,1944.10^{-1}$ & $-0,1944.10^{-1}$ \\
\hline Desl. $X_{3}(\mathrm{~mm})$ & 6,5093 & 6,5093 & 6,5093 & 6,5093 \\
\hline
\end{tabular}

A igualdade (em módulo) ocorrida para os deslocamentos, foi ocasionada devido a simetria de cargas nas estacas e da geometria do sistema. 


\section{CAPÍTULO 7 CONCLUSÃO}

Neste trabalho foram apresentadas diversas formulações utilizando o MEC em conjunto com o MEF e até mesmo com MDF para analisar o problema de estacas imersas em um meio contínuo.

Comprovou-se que o MEC é um método numérico adequado para se empregar na análise de sólidos tridimensionais de domínio semi-infinito. Conseqüentemente as soluções fundamentais de MINDLIN (1936), tornaram-se convenientes, pois através delas, elimina-se a necessidade de discretização da superfície livre, reduzindo assim as dimensões das matrizes utilizadas na resolução do problema, além de se adequarem perfeitamente ao modelo idealizado proposto para o maciço de solos, que foi tratado como um meio contínuo, semi-infinito, elástico-linear, homogêneo e isótropo.

As estacas, por sua vez, foram tratadas como elementos de barra. A dedução de várias formulações ocorreu com a finalidade de se obter um polinômio com poucos pontos de colocação e que satisfizesse aos objetivos deste trabalho. $O$ modelo final idealizado para a interação estaca-solo com ou sem blocos de capeamento rígido, é composto de 14 parâmetros nodais, sendo 4 parâmetros para deslocamentos lineares em cada direção $\left(X_{1}, X_{2}\right.$ e $\left.X_{3}\right)$ e mais 2 parâmetros relativos as rotações em torno dos eixos $X_{1}$ e $X_{2}$ no topo das estacas.

Comprovou-se através da boa concordância de resultados obtidos, quando da comparação deste modelo com outros modelos teóricos (FERRO, 1993; VALLABHAN \& SIVAKUMAR, 1986; BUTTERFIELD \& BANERJEE, 1971; POULOS, 1980) e até mesmo com ensaios experimentais (KÉRISEL \& ADAM, 1967; WHITAKER \& COOKE, 1966), que o modelo em questão se adequa ao tratamento proposto neste trabalho. E mesmo quando comparou-se os demais modelos aqui desenvolvidos e apresentados com os de outros autores, chegou-se a resultados satisfatórios.

Pode-se concluir com este trabalho que os deslocamentos (verticais e horizontais) nas estacas são diretamente influenciados seu comprimento, pela rigidez do sistema e pelo espaçamento entre elas. Ainda podendo-se afirmar que para o caso de haverem blocos de capeamento rígido, ou seja, quando os deslocamentos do topo dos elementos são idênticos, as estacas mais distantes do centro geométrico do sistema são as que absorvem mais cargas e as mais 
próximas do centro são as que absorvem menos. As distribuições de carga tornamse mais uniformes conforme aumentam os espaçamentos. Também observou-se que em solos moles, ocorre uma rápida redução de deslocamentos laterais na parte superficial da estaca e para comprimentos mais profundos, as reduções são pequenas ou quase não existem. Para solos mais rígidos as reduções de deslocamentos são mais moderadas na parte superficial da este e em determinadas profundidades maiores praticamente não há variação de deslocamentos.

Os exemplos apresentados para estacas sujeitas a cargas verticais serviram para comprovar a eficiência do modelo e validar também as características que influenciam o sistema estaca-solo quanto à deslocamentos verticais, citadas anteriormente para os deslocamentos horizontais.

As matrizes de rotação adotados para a resolução do problema de estacas inclinadas satisfizeram aos propósitos aqui requeridos, visto que através delas, pode-se chegar, utilizando valores de cargas e geometrias simétricas, a deslocamentos coerentes.

Alguns aprimoramentos podem ser implementados ao modelo proposto, tais como a estratificação do solo, a determinação da posição da camada indeslocável do maciço de solos, assim como a colocação de uma placa flexível e posteriormente acoplar o sistema placa-estaca-solo a uma superestrutura. 


\section{REFERÊNCIAS BIBLIOGRÁFICAS}

Obs: As referências bibliográficas que foram colocadas em negrito, são as que foram lidas para o desenvolvimento deste trabalho.

ALIZADEH, M. \& DAVISSON, M. T. (1970). Lateral load tests on piles-Arkansas River Project. J.S.M.F.D., ASCE, vol. 96, SM5, p. 1583-1604.

ALIZADEH, M. (1969). Lateral load testes on instrumented timber piles. ASTM, STP 444, p. 379-394.

ANAGNOSTOPOULOS, C. \& GEORGIADIS, M. (1993). Interaction of axial and lateral piles responses. Journal of Geotechnical Engineering, vol. 119, p. 793-798.

BADIE, S. S. \& SALMON, D. C. (1996). A quadratic order elastic foundation finite element. Computers \& Structures, vol. 58, n. 3.

BANERJEE, P. K. \& BUTTERFIELD, R. (1977). Finite element method in geomechanics. J. Wiley \& Sons, p. 529-570.

BANERJEE, P. K. \& DAVIS, T. G. (1977). Analysis of pile groups embedded in Gibson soil. Proc. $9^{\text {th }}$ Int. Conf. Soil Mech., Fdn Engng, Tokyo.

BANERJEE, P. K. \& DAVIS, T. G. (1978). The behavior of axially and laterally loaded single piles embedded in non-homogeneous soils. Geot, vol. 28, n. 3, p. 309-326.

BANERJEE, P. K. (1976). Integral equation methods for analysis of piece-wise nonhomogeneous, three-dimensional elastic solids of arbitrary shape. Int. J. Mech. Sci. 18, p. 293-303.

BOLTON, R. (1972). Stresses in circular plates on elastic foundations. Journal Engineering Mechanics Division, June. 
BOUSSINESQ, J. (1885). Applications des potenciels à L'etude de L'equilibre et du moviment des solides elastique. Gualtier-Villars, Paris.

BRANSBY, M. F. \& S. M. SPRINGMAN (1996). 3-D finite element modeling of pile groups adjacent to surcharge loads. Computers and Geotechnics, vol. 19, n. 4, p. 301-324.

BREBBIA, C. A. \& DOMINGUEZ, J. (1984). Boundary elements: an introductory course. Southampton: CML Publ..

BRINCH HANSEN, J. (1961). The ultimate resistance of rigid piles against transversal forces. Danish Geotechnical Institute, Bulletin 12.

BROMS, B. B. (1964a). Lateral resistance of piles in cohesive soils. Journal of Soil Mechanics and Foundations Division. ASCE, vol. 90, no SM2, MAR, p. 27-63.

BROMS, B. B. (1965). Design of lateral loaded piles. Journal of Soil Mechanics and Foundations Division. ASCE, vol. 91, no SM3, MAI, p. 79-99.

BROWN, P. T. \& WEISNER T. J. (1975). The behavior of uniformly loaded piles strip footings. Soil and Fndns., vol. 15, n. 4, p. 13-21.

BUTTERFIELD, R. \& BANERJEE P. K. (1971). The elastic analysis of compressible piles and piles groups. Geotechnique, vol. 21, n.1.

CALDERÓN, E. T. \& VENTURINI, W. S. (1997). Interação de placas com o meio contínuo através do método dos elementos de contorno. In: XXVIII Jornadas Sul-Americanas de Engenharia Estrutural. São Carlos.

CALDERÓN, E. T. (1991). Uma formulação alternativa para o estudo de placas sobre fundação elástica pelo método dos elementos de contorno. São Carlos. Dissertação (mestrado) - Escola de Engenharia de São Carlos, Universidade de São Paulo.

CERRUTI, V. (1882). Mem. Fis. Mat.. Acc. Lincei, Roma. 
CHAKRAVORTY, A. K. \& GHOSH, A. (1975). Finite difference solution for circular plates on elastic foundations. International Journal for Numerical Methods in Engineering, vol. 9.

CHARI, T. R. \& MEYERHOF, G. G. (1983). Ultimate capacity of rigid single piles under inclined loads in sand. Canadian Geotechnical Journal, vol. 20, p. 849854.

CHEN, L. \& POULOS, H. G. (1993). Analysis of pile-soil interaction under lateral loading using infinite and finite elements. Computers and Geotechnics, vol. 15, p. 189-220.

CHEUNG, Y. K. \& NAG, D. K. (1968). Plates and beams on elastic foundationslinear and non-linear behavior. Géotechnique, vol. 18.

CHILTON, D. S. \& WEKEZER, J. W. (1990). Plates on elastic foundation. Journal of Structural Engineering, vol. 16, n. 11.

CINTRA, J. C. A. (1983). Carregamento Lateral em Estacas. São Carlos. Publicação 058/94. Escola de Engenharia de São Carlos, Universidade de São Paulo.

DAMJANIC, F. \& OWEN, D.R.J. (1984). Mapped infinite elements in transient thermal analysis. Computers and Structures, vol. 19, p. 673-687.

DAVIS, E. H. \& POULOS, H. G. (1972). The analysis of pile-raft systems. Aust. Geomechs. Jnl., vol. G2, n. 1, p. 21-27.

DAVISSON, M. T. \& ROBINSON, K. E. (1965). Bending and Buckling of partially embedded piles. Proc. Sixth Int. Conf. on Soil Mech. and Found. Eng.. Montreal, vol. 2, p. 243-246.

DAVISSON, M. T. \& SALLEY, J. R. (1970). Model study of laterally loaded piles. J. Am. Soc. Civ. Engrs, SM5, p. 1605-1627. 
DOUGLAS, D. J. \& DAVIS, E. H. (1964). The movement of buried footings due to moment and horizontal load and the movement of anchor plates. Geot., vol. 14, p. $115-132$.

FATEMI-ARDAKANI, B. (1987). A contribution to the analysis of pile-supported raft foundations. Southampton. Tese (doutorado). Universidade de Southampton.

FEAGIN, L. B. (1937). Lateral pile loading tests. Transactions, ASCE, vol. 102, Paper n. 1959, p. 236-254.

FERRO, N. C. P. (1993). Uma Combinação do método dos elementos de contorno com o método dos elementos finitos para análise de fundações enrijecidas por estacas. São Carlos. Dissertação (mestrado). Escola de Engenharia de São Carlos, Universidade de São Paulo. Departamento de Estruturas.

FRANCIS, A. J. (1964). Analysis of pile groups with flexural resistance. J.S.M.F.D., ASCE, vol. 90, SM3, p. 1-32.

FREUDENTHAL, A. M. \& GEIRINGER, H. (1958). The mathematical theories of the inelastic continuum. Handbuch der Physik, vol. 6, Springer-Verlage, Berlin.

GIBSON, R. E. \& LUMB, P. (1983). Numerical solution of some problems in the consolidation of clay. Proc. Inst. Civ. Engrs., London.

GILL, H. L. \& DEMARS, K. R. (1970). Displacements of laterally loaded structures in nonlinearly responsive soil. Technical report R670. Port Hueneme, California: Naval Civil Engineering Laboratory.

GLESER, S. M. (1953). Lateral load testes on vertical fixed-head and free-head piles. ASTM, STP 154, p. 75-93.

GORBUNOV-POSSADOV, M. \& SEREBRJANYI, R. V. (1961). Design of structures on elastic foundations. Proceedings of the $5^{\text {th }}$ International Conference on Soil Mechanics and Foundations Engineering. 
HAIN, S. J. \& LEE, I. K. (1978). The analysis of flexible pile-raft systems. Geotechnique, vol. 28, n. 1, p. 65-83.

HEMSLEY, J. A. (1990a,b). Elastic solutions for large matrix problems in foundation interaction analysis. In: Proc. Inst. Civ. Engrs.

HRENNIKOFF, A. (1950). Analysis of pile foundations with batter piles. Trans. ASCE, vol. 115, p. 351.

JONES, R. \& XENOPHONTOS, J. (1977). The Vlasov foundation model. Int. J. of Mech. Sci., vol. 19, p. 317-323.

KÉRISEL, J. \& ADAM, M. (1967). Calcul des forces horizontales applicables aux fondations profondes dans les argiles el limons. Annales L.T.B.T.P., n. 239, p. 1653.

KUHLEMEYER, ROGER (1979). Static and dynamic laterally loaded floating piles. Journal of the Geotechnical Engineering Division, vol. 105, n. GT2, p. 289-304.

KUKRETI, A. R.; ZAMAN M. M. \& ISSA, A. (1993). Analysis of fluids storage tanks including foundation-superstructure interaction. Applied Math. Modeling, vol. 17, dec.

LOVE, A. E. H. (1944). A treatise on the mathematical theory of elasticity. New York. Dover.

MANZOLI, O. L. (1992). Formulação do método dos elementos de contorno para placas sobre fundação elástica. São Carlos. Dissertação (mestrado) - Escola de Engenharia de São Carlos, Universidade de São Paulo.

MATLOCK, H. \& REESE, L. C. (1961). Foundation analysis of offshore pile supported structures. Proc. Fifth Int. Conf. on Soil Mech. and Found. Eng.. Paris, vol. 2, p. 91-97. 
MCCLELLAND, B. \& FOCHT, J. A. (1956). Soil modulus for laterally loaded piles. J. Am. Soc. Civ. Engrs, SM4.

MENDONÇA, A.V. (1997). Análise da interação placa-estaca-solo via um combinação do método dos elementos finitos com o método dos elementos de contorno. São Carlos. Dissertação (mestrado). Escola de Engenharia de São Carlos, Universidade de São Paulo.

MESSAFER, T. \& COATES, L. E. (1990), An application of FEM/BEM coupling to foundation analysis. Advances in Boundary Methods, vol. 3.

MEYERHOF, G. G. \& SASTRY, V. V. R. N. (1985). Bearing capacity of rigid piles under eccentric and inclined loads. Canadian Geotechnical Journal, vol. 22, p. 267-276.

MEYERHOF, G. G. \& SASTRY, V. V. R. N. (1987). Full-displacement pressuremeter method for rigid piles under lateral loads and moments.. Canadian Geotechnical Journal, vol. 24, p. 471-478.

MEYERHOF, G. G., MATHUR, S. K. \& VALSANGKAR, A. J. (1981). Lateral resistance and deflection of rigid walls and piles in layered soils. Canadian Geotechnical Journal, vol. 18, p. 159-170.

MEYERHOF, G. G., SASTRY, V. V. R. N. \& YALCIN, A. S. (1988). Lateral resistance and deflection of flexible piles.. Canadian Geotechnical Journal, vol. 25, p. 511-522.

MINDLIN, R. D. (1936). Force at a point in the interior of a semi-infinite solid. Physics 7, p. $195-202$.

MON-MA, M. L. (1996). Integração quasi-singular através da subdivisão automática de elementos. Simpósio de Iniciação Científica da Universidade de São Paulo, vol. 2 , p. 26. 
NAKAGUMA, R. K. (1979). Three dimensional elastostatics using the boundary element method. Southampton. Thesis of Doctor of Philosophy. University of Southampton.

NATH, B. (1989). A mapping finite element method for the analysis of laterally loaded single piles. Computers and Geotechnics, vol. 7, p. 255-266.

NOVAK, M. (1974). Dynamic stiffness and damping of piles. Can. Geot. Jnl., vol. 11, n. 4, p. 574-598.

PAIVA, J. B. \& BUTTERFIELD, R. (1994). Numerical analysis of plate-soil interaction. Advances in Computational Mechanics, p. 275-281.

PAIVA, J. B. (1993). Formulação do método dos elementos de contorno para análise de interação solo-estrutura. São Carlos. Tese (livre docência). Escola de Engenharia de São Carlos, Universidade de São Paulo.

PALMER, L. A. \& THOMPSON, J. B. (1948). The earth pressure and deflection along the embedded lengths of piles subjected to lateral thrusts. Proc. $2^{\text {nd }}$ Int. Conf. S.M. and F.M., Rotterdam, vol. 5, p. 156-161.

POULOS, H. G. \& CHEN, L. T. (1995). Pile response to unsupported excavation-induce lateral soil movement. Can. Geotech. J., vol. 33, p. 670677.

POULOS, H. G. \& DAVIS, E. H. (1980). Pile foundation analysis and design. John Wiley \& Sons, New York, N.Y.

POULOS, H. G. (1971a). Behavior of laterally loaded piles: I-Single Piles. J.S.M.F.D., ASCE, vol. 97, n. SM5, p. 733-751.

POULOS, H. G. (1971b). Behavior of laterally loaded piles: II-Piles Groups. J.S.M.F.D., ASCE, vol. 97, n. SM5, p. 733-751. 
POULOS, H. G. (1973). Load deflection prediction for laterally loaded piles. Aust. Geomechs. Jnl, vol. G3, n. 1, p. 1-8.

POULOS, H. G. (1994). An approximate numerical analysis of plate-raft interaction. International Journal for Numerical and Analytical Methods in Geomechanics, vol. 18, p. 73-92.

PRAKASH, S. \& SARAN, D. (1967). Behavior of laterally loaded piles in cohesive soils. Proc. $3^{\text {rd }}$ Asian Conf., S.M., p. 235-238.

PRIDDLE, R. A. (1963). Load distribution in piled bents. Trans., Inst. Engrs. Aust., vol. CE5, n. 2, 43-54.

RANDOLPH, M. F. (1981). The response of flexible piles to lateral loading. Géotechnique, vol. 31, n. 2, p. 247-259.

REESE, L. C. \& MATLOCK, H. (1956). Non-dimensional solutions for laterally loaded piles with soil modulus assumed proportional to depth. Proc. Eighth Texas Conference o Soil Mechanics and Foundation Engineering. Austin. University of Texas.

SASTRY, V. V. R. N. \& MEYERHOF, G. G. (1986). Lateral soil pressures and displacements of rigid piles in homogeneous soils under eccentric and inclined loads. Canadian Geotechnical Journal, vol. 23, p. 281-286.

SASTRY, V. V. R. N. \& MEYERHOF, G. G. (1987. Rigid piles under inclined and eccentric loads. Canadian Geotechnical Journal, vol. 17, p. 209-232.

SASTRY, V.V.R.N. \& MEYERHOF, G.G. (1994). Behavior of flexible piles in layered sands under eccentric and inclined loads. Can. Geotech J., vol. 31, p. 513-520.

SAUL, W. E. (1968). Static and dynamic analysis of pile foundations. J. Strust. Div., ASCE, vol. 94, ST5, p. 1077-1100. 
SCOTT, R. F. (1981). Foundation Analysis. Prentice-Hall, Inc. Englewood Cliffs, NJ 0763.

SELVADURAI, A. P. S. (1979). Elastic analysis of soil-foundation interaction. Amsterdam. Elsevier Scientific Publishing Company.

SNEDDON, I. N. \& BERRY, D. S. (1958). The classical theory of elasticity. Handuch der Physik, vol. 6, Elasticity and Plasticity. Spring-Verlag, Berlin.

SPILLERS, W. R. \& STOLL, R. D. (1964). Lateral response of piles. J.S.M.F.D., ASCE, vol. 90, SM6, p. 1-9.

SUN, KEMING (1994). A numerical method for laterally loaded piles. Computers and Geotechnics, vol. 16, p. 263-289

TELLES, J. F. \& SÁ, A. C. O. (1986). Análise de problemas de elasticidade linear tridimensional pelo método dos elementos de contorno utilizando as soluções fundamentais de Kelvin e Mindlin. In: VII Congresso Latino-Americano sobre Métodos Computacionais para Engenharia. São Carlos.

TIMOSHENKO, S. P. \& GOODIER, J. N. (1970). Theory of elasticity. New York. McGraw-Hill.

VALLABHAN, C. V. G. \& SIVAKUMAR, J. (1986). Coupling of BEM and FEM for $3 D$ problems in geotechnical engineering. In: BREBBIA, C. A. \& CONNOR, J. J., eds. BETECH 86. Southampton: CML Publ., p. 675-686.

VENTURINI, W. S. (1988). Um estudo sobre o método dos elementos de contorno e suas aplicações em problemas de engenharia. São Carlos. Tese (livre docência) - Escola de Engenharia de São Carlos, Universidade de São Paulo.

VERRUIJT, A. \& KOOIJMAN, A. P. (1989). Laterally loaded piles in a layered elastic medium. Geotechnique, vol. 39, , no 1, p. 39-46. 
VLASOV, V. Z. \& LEONTIEV, N. N. (1966). Beams, plates e shells on elastic medium. Geotechnique, vol. 39, p. 39-46.

WERNER, H. (1970). Biogemont elastich eigespannter phähle. Beton und Stahlbetonbau. Alemanha, no 2, p. 90-108.

WHITAKER, T. \& COOKE, R. W. (1966). An investigation of the shaft and base resistance of large bored piles in London clay. Proc. Symp. On Large Bored Piles, p. 7 - 49.

WINKLER, E. (1867). Die lehre von der Elastizistat und Festigkeit. Domicius. Prage.

YALCIN, A. S. \& MEYERHOF, G. G. (1991). Bearing capacity of flexible piles under eccentric loads and inclined loads in layered soil. Canadian Geotechnical Journal, vol. 28, p. 909-917.

YANG, Z. W. \& LU, W. D. (1992). Static soil-structure interaction analysis by FE-BE coupling method. Applied Math. Modeling, vol. 16, July.

YEGIAN, M. \& WRIGHT, S. G. (1973). Lateral soil resistance - displacement relationships for pile foundations in soft clays. $5^{\text {th }}$ Annual Offshore Tech. Conf. Houston, vol. 2, p. 663-676.

YUAN, R. L. \& WANG, L. S. (1991). Generalized variational principle of plates on elastic foundation. Journal of Applied Mechanics, vol. 58, dec. 